Final Report

FHWA/IN/JTRP- 2009/28

\title{
DESIGN AND APPLICATIONS OF DRILLED DISPLACEMENT (SCREW) PILES
}

\author{
Prasenjit Basu \\ Monica Prezzi \\ Geotechnical Engineering \\ School of Civil Engineering \\ Purdue University \\ Joint Transportation Research Program \\ Project No: C-36-45U \\ File No: 6-18-19 \\ SPR 3006 \\ Prepared in Cooperation with the \\ Indiana Department of Transportation and \\ The U.S. Department of Transportation \\ Federal Highway Administration
}

The contents of this report reflect the views of the authors who are responsible for the facts and the accuracy of the data presented herein. The contents do not necessarily reflect the official views or policies of the Federal Highway Administration and the Indiana Department of Transportation. This report does not constitute a standard, specification or regulation.

Purdue University

West Lafayette, Indiana

September 4, 2009 


\title{
INDOT Research Project Implementation Plan
}

\author{
Date: September 4, 2009
}

Research Project Number: $\underline{\text { SPR-3006 }}$

Project Title: Design and Applications of Drilled Displacement (Screw) Piles

Principal Investigator (PI): Prof. Monica Prezzi Project Administrator (PA):

Note: If more than one implement or recommended, please fill in the information on each implementor's implementation items:

Name of Implementor: _ Mir Zaheer/Nayyar Zia _

Items (Research Results) to be implemented:

- Validate conclusions of the report concerning the limit shaft capacity of DD piles by model pile and full-scale pile tests

- Incorporate the equations for $K / K_{0}$ into the portion of the geotechnical design manual dealing with the design of DD piles

in sand

- Refine the methods proposed in this report for better pile design based on additional analyses and data

Help or resources needed for implementation (e.g., help from PI, funding, equipment, etc.):

- Additional funding, collaboration from implementers, access to well planned pile load testing data. In order to facilitate implementation of the design equations proposed, we recommend that an implementation project be funded to allow not only performance of additional laboratory and field load test to further validate the method proposed, but also to allow development of simple user-friendly DD pile design programs or spreadsheets that could be used in routine practice by INDOT engineers. This implementation project would also allow for training of INDOT engineers in up-to-date design methods for these piles, which are becoming increasingly common in practice. Another training component for this implementation project could be targeted to train INDOT pile inspectors and to produce a check-list for easy inspection and quality control.

Name of Implementor:

Items (Research Results) to be implemented:

Help or resources needed for implementation (e.g., help from PI, funding, equipment, etc.):

Name of Implementor:

Items (Research Results) to be implemented:

Help or resources needed for implementation (e.g., help from PI, funding, equipment, etc.):

Signatures of SAC members:

Please send a copy of this form to the INDOT Research Division and FHWA with the final report. 


\section{TECHNICAL SUMMARY}

\section{DESIGN AND APPLICATIONS OF DRILLED DISPLACEMENT (SCREW) PILES}

\section{INTRODUCTION}

Pile foundations have been used in construction for thousands of years as an economical means of transmitting the loads from superstructures to the underlying soil or rock strata. In pile design, piles must be able to sustain axial loads from the superstructure without failing in bearing capacity or settling so much that structural damage occurs or serviceability of the superstructure is jeopardized.

A wide variety of pile types are currently available for use in geotechnical engineering practice. The response of these piles to loading varies greatly depending on the installation or construction methods employed. On one end of the pile-behavior spectrum are the nondisplacement piles (e.g., bored piles or drilled shafts) and on the other end are the full-displacement piles (e.g., closed-ended pipe piles or precast reinforced concrete piles). There are other types of piles (e.g., open-ended pipe piles) that show behavior intermediate between nondisplacement and full-displacement piles. These piles are often called partialdisplacement piles. Many auger piles, which are installed by drilling a continuous-, segmented- or partial-flight auger into the ground, fall under the category of partialdisplacement piles. A variety of auger piling equipment is available in the market; consequently, the terminologies used for describing different types of auger piles vary across the world.

A special class of auger piles was created as a result of advances in auger piling technology; these are commonly known as "screw piles" in Europe, and "drilled displacement" or "augered displacement" piles in the USA. Drilled displacement (DD) piles are rotary displacement piles installed by inserting a specially designed helical auger segment into the ground with both a vertical force and a torque. The soil is displaced laterally within the ground (with minimal spoil generated), and the void created is filled with grout or concrete. DD piling technology is distinctively different from the helical piling technology in which a single- or multiple-helix steel auger is screwed into the ground to form the piles (similar to helical ground anchors). The installation of DD piles produces greater soil displacement than that produced by 
continuous-flight-auger (CFA) or auger castin-place (ACIP) piles (CFA and ACIP piles are generally associated with small soil displacement). In the case of DD piles, the radial displacement of soil during installation contributes to the high capacity obtained for these piles.

From a design point of view, fulldisplacement piles are preferable because they are capable of carrying larger loads than partial- or nondisplacement piles of similar geometry. However, pile driving may cause excessive vibration to neighboring structures or create excessive noise that may be unacceptable under certain conditions. Additionally, in some soil profiles (e.g., quick clays), the use of driven piles may not be advisable. DD piles often offer a viable alternative in cases where the installation of driven full-displacement is not advisable. The advantages of DD piles are (i) the ease of construction with minimal vibration or noise, and minimal spoil (important for contaminated sites), (ii) the high load carrying capacity due to partial- or fulldisplacement of the soil surrounding the pile, and (iii) the associated savings that result when they are installed in the right soil conditions.

A number of empirical relationships have been proposed in the literature to predict the load carrying capacity of DD piles. Over the last several decades researchers have correlated the capacity of DD piles with the results of different in situ tests. The currently available design methods for DD piles rely almost exclusively on empirical relations developed based on results of field pile load tests performed on particular types of DD piles, but there has been no theoretical research done on studying the effect of installation on the capacity of DD piles. This means that currently available methods are purely site specific.

This report outlines a very promising approach to model shaft resistance of DD piles in sand. We perform one-dimensional (1-D) finite element analysis (FEA) to model the installation and subsequent loading of a DD pile installed in sand. These analyses are valid for DD piles installed using drilling tools that have enlarged (large-diameter) displacement bodies. The report provides values of the lateral earth pressure coefficients to be used in the calculation of limit shaft resistance of DD piles in sand.

\section{FINDINGS}

This research took advantage of advanced computational techniques and a realistic constitutive model for sand to model installation of DD piles and their subsequent loading at the end of installation. The report provides a set of equations to calculate the coefficient of lateral earth pressure acting on the pile shaft at limit conditions. These equations can be used in determining the limit unit shaft resistance of DD piles in sand. 
Specifically, the present report shows that:

1) The changes in the soil caused by installation of DD piles are very complex and cannot be modeled with any reliability in a simplistic way.

2) The pile installation process is not simply a cavity expansion process, as many have believed. Shearing has a large impact in that it reduces approximately $50 \%$ of the very large normal stress on the pile shaft that would be predicted by cavity expansion alone.

3) With results of analyses such as presented in this report, it is possible to create effective design methods and quality assurance programs for DD piles.

4) Soil within a small zone (of radius up to $4 B$ ) surrounding the pile shaft dilates due to DD pile installation. A contractive zone is observed beyond this dilative zone. No significant volumetric change is observed in the zone beyond a radius of approximately equal to $12 B$ from the pile axis.

5) The lateral earth pressure coefficient $K$ acting on the pile shaft at the limit condition increases with increasing relative density and decreasing initial confinement. The value of $K / K_{0}$ for an initially anisotropic sand fabric is always smaller than that for an initially isotropic sand fabric.
6) The results of the FEA performed for DD piles in sand shows that the limit unit shaft resistance of DD piles is larger than that calculated for drilled shafts but smaller than that of piles jacked monotonically into the ground.

\section{IMPLEMENTATION}

Engineers can incorporate the results of this research in their work by using the DD pile design equations proposed in this report to calculate the limit unit shaft resistance of these piles in sand. INDOT engineers will have increasingly more confidence in the design methodology proposed as they start comparing their pile capacity predictions with pile load test measurements.

In order to facilitate implementation of the design equations proposed, we recommend that an implementation project be funded to allow not only performance of additional laboratory and field load test to further validate the method proposed, but also to allow development of simple user-friendly DD pile design programs or spreadsheets that could be used in routine practice by INDOT engineers. This implementation project would also allow for training of INDOT engineers in up-to-date design methods for these piles, which are becoming increasingly common in practice as a result of the many advantages they offer compared to other piles. Another training component for this implementation project could be targeted to train INDOT pile inspectors and 
to produce a check-list for easy inspection and quality control. We also propose to perform a cost-comparison analysis for various types of piles that could potentially be used in typical INDOT projects. This would highlight potential cost benefits of using DD piles that INDOT could take advantage of in future projects. 


\begin{abstract}
Key Words: Piles; drilled displacement; screw; sand; shaft resistance; design.

Drilled displacement (DD) piles (commonly known as 'screw piles' in Europe) are being increasingly used as foundation elements for structures, particularly in projects requiring accelerated construction or involving the rehabilitation of foundations of existing, overstressed structures. Different types of DD piles are available in practice; each type is classified according to the design of the drilling tool and associated installation method. Installation of DD piles causes substantial changes in the state of the soil surrounding the pile. These changes result from the complex loading imposed on the soil by expansion of a cylindrical cavity to make room for the specially designed drilling tool, by torsional and vertical shearing as the drilling tool gradually moves down into the ground, and by the reversed vertical shearing caused by extraction of the drilling tool from the ground. This report consolidates the information available on DD piling technology, reviews and compares the empirical design methods typically used for these piles, and presents a numerical approach to model the shaft resistance of DD piles in sand.

The installation of DD piles produces greater radial displacement of soil than that produced by nondisplacement piles (e.g., drilled shafts), particularly in the case of sandy soils which gain additional strength through densification. This radial displacement of soil around the pile shaft contributes to the high capacity obtained for DD piles. Accordingly, our focus has been on analyzing the shaft resistance of DD piles in sand and proposing a design procedure based on the results of the analyses. The analyses were done using the finite element (FE) method and an advanced constitutive model for sand. The constitutive model captures all the key features required for these analyses, and the FE analyses are 1D analyses of shaft resistance that can handle the large deformations and displacements involved in pile installation. Design equations that can be used to calculate the lateral earth pressure coefficient acting on the pile shaft are proposed.
\end{abstract}


TABLE OF CONTENTS

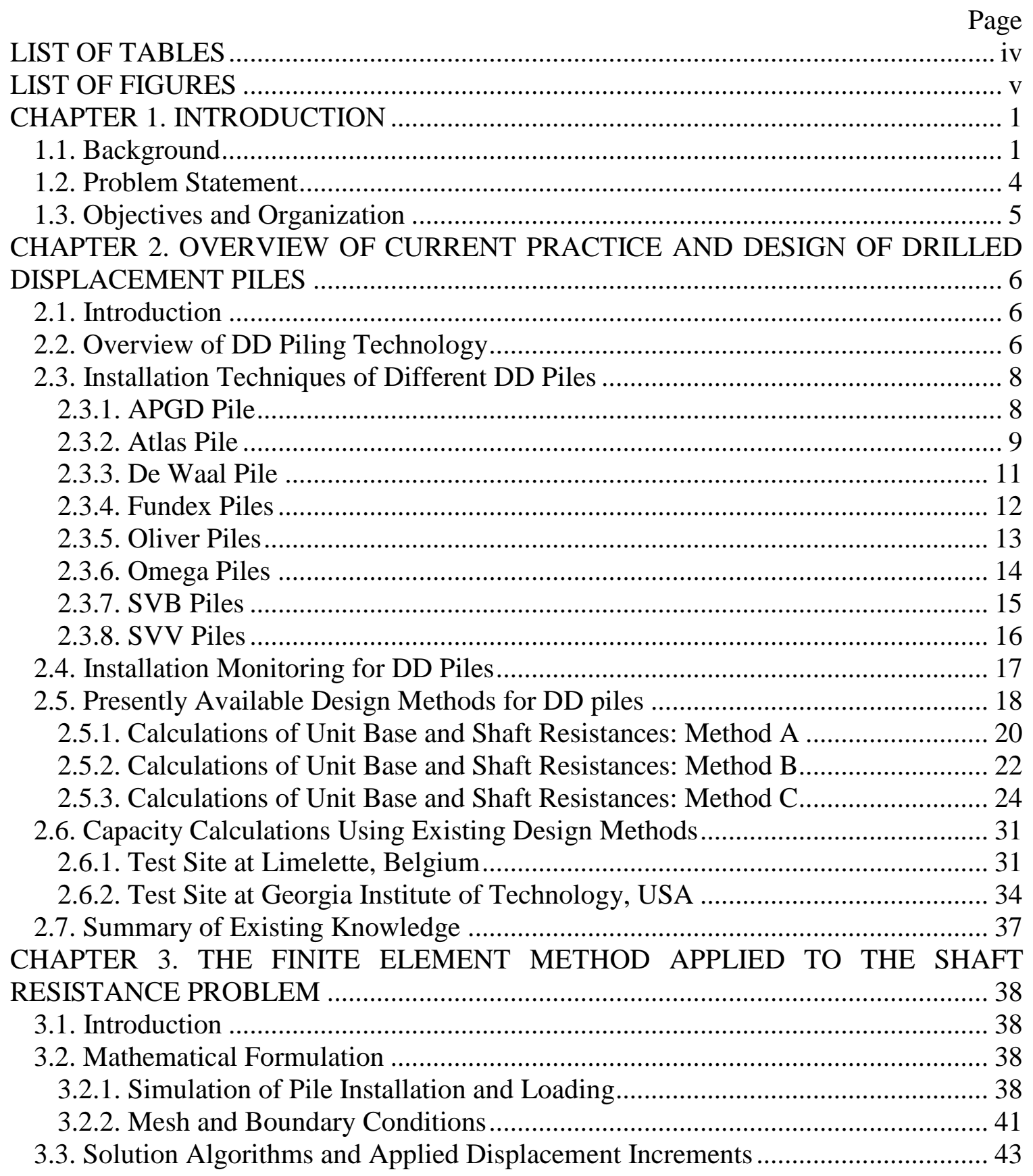


3.4. Constitutive Model Used in the Finite Element Analysis ...................................... 47

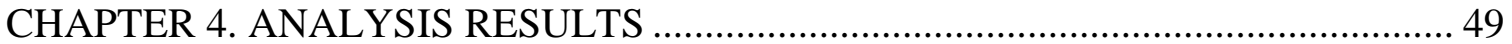

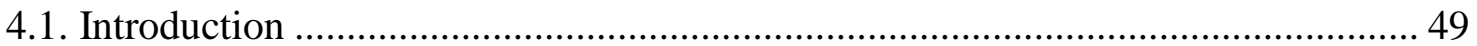

4.2. Soil Property-Based Method for Calculating Shaft Capacity of DD Piles............. 49

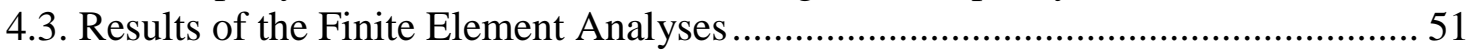

4.3.1. Evolution of Normal and Shear Stresses.................................................... 52

4.4. Summary of Analysis Results.......................................................................... 71

CHAPTER 5. USE OF RESULTS IN DESIGN OF DRILLED DISPLACEMENT PILES

5.1. Introduction

5.2. Proposed Equations for the Lateral Earth Pressure Coefficient ............................. 72

5.3. Effects of $K_{0}$ and Pile Diameter $B$ on the Earth Pressure Coefficient $K$................ 76

5.4. Comparison of Results from Coupled and Uncoupled Analysis ............................ 79

5.5. Comparison of Shaft Resistances for Different Pile Types .................................... 80

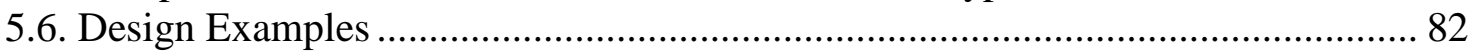

5.6.1. DD Pile in Homogeneous Sand Deposit: Example 1 .................................... 83

5.6.2. DD Pile in a Multilayered Sand Deposit: Example 2...................................... 86

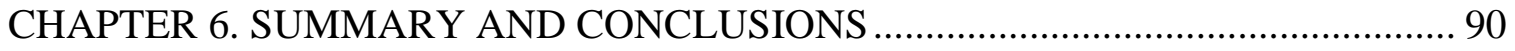

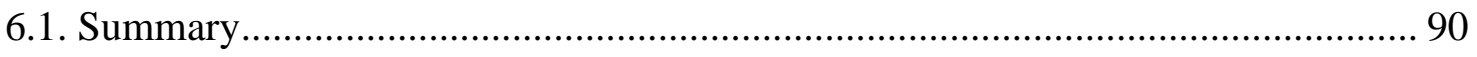

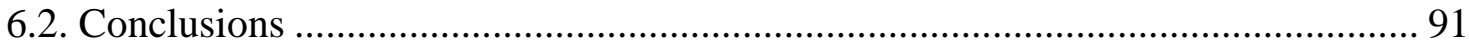

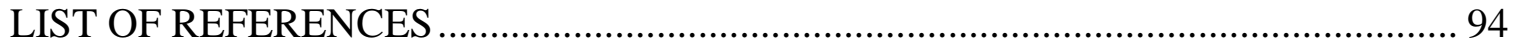




\section{LIST OF TABLES}

Table

Table 2.1 Values of $K$ for different soil types (Bustamante and Gianeselli 1998) ........... 21

Table 2.2 Values of $\alpha$ and $a$ for different in situ tests (Bustamante and Gianeselli 1998) 21

Table 2.3 Guidelines for selection of a design curve to estimate $q_{\mathrm{s}}$ from Figure 2.11 (Bustamante and Gianeselli 1998) ....................................................................... 21

Table 2.4 Values of $\alpha_{\mathrm{b}}$ and $\alpha_{\mathrm{si}}$ for use in Equations (2.12) and (2.14) (from Application

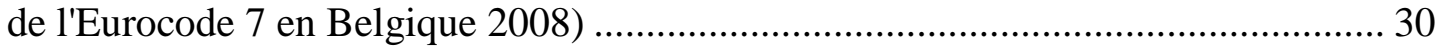

Table 2.5 Values of $\eta_{\mathrm{p}}{ }^{*}$ for use in Equation (2.14) (from Application de l'Eurocode 7 en

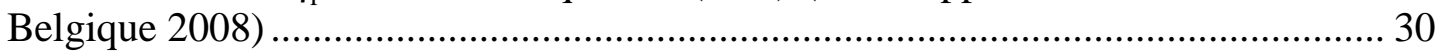

Table 2.6 Reduction factor $\omega$ (from Application de l'Eurocode 7 en Belgique 2008) ..... 30

Table 2.7 Pile geometries (Huybrechts and Whenham 2003) ...................................... 32

Table 2.8 Ultimate capacities of different DD piles at the Limelette test site, Belgium .. 34

Table 2.9 Calculated capacities for a DD pile, a full-displacement pile, and a nondisplacement pile (soil profile of the Georgia Institute of Technology test site). 36

Table 5.1 Calculation of limit shaft resistance (for Example 1) using different design

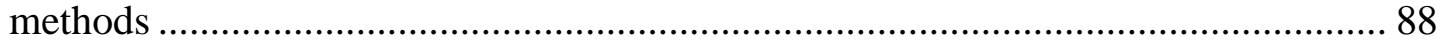

Table 5.2 Calculation of limit shaft resistance (for Example 2) using different design

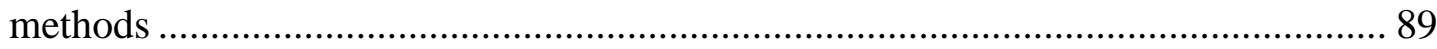




\section{LIST OF FIGURES}

Figure

Page

Figure 1.1 Categorization of piles based on the soil displacement produced during

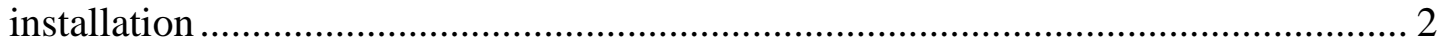

Figure 1.2 Nomenclature used for auger piles in Europe and in the USA....................... 2

Figure 2.1 Drilling tools for installation of different drilled displacement piles ............... 7

Figure 2.2 Installation stages for APGD piles .................................................... 9

Figure 2.3 Installation stages for Atlas piles.......................................................... 11

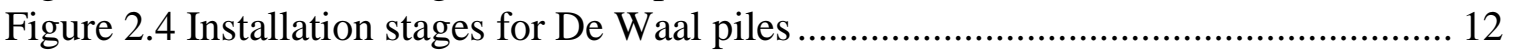

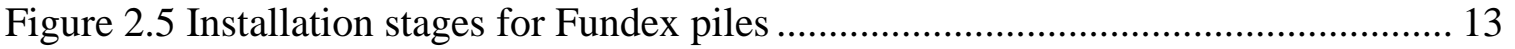

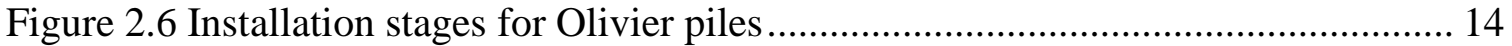

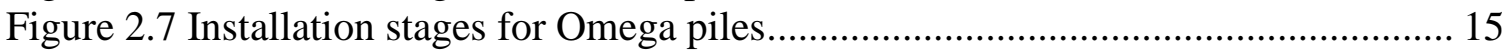

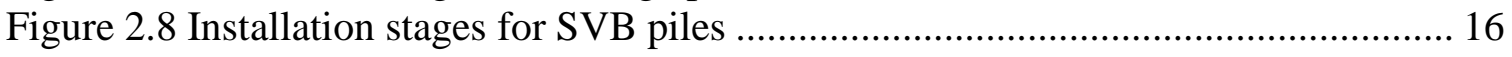

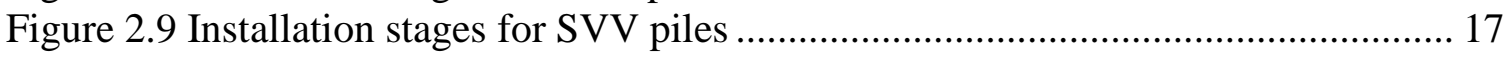

Figure 2.10 Design dimensions for some DD piles .................................................... 19

Figure 2.11 Values of unit shaft resistance $q_{\mathrm{sL}}$ as a function of $p_{1}, q_{\mathrm{c}}$, or $N$ (Bustamante and Gianeselli 1993, 1998) ............................................................................. 22

Figure 2.12 Values of $\beta$ for cone $\left(\beta_{\mathrm{c}}\right)$ and pile $\left(\beta_{\mathrm{p}}\right)$ based on $\phi_{\mathrm{CPT}}$ and penetration depth to diameter ratio (after Van Impe 1986; Van Impe et al. 1988).................................... 27

Figure 2.13 Average and modified cone resistance profiles at the Limelette test site...... 33

Figure 2.14 Average and modified cone resistance profiles at the Georgia Institute of

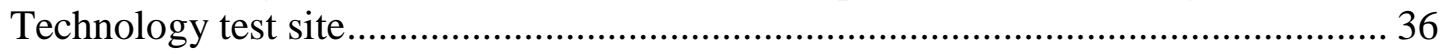

Figure 3.1 Idealization of the installation and loading of a DD pile .............................. 39

Figure 3.2 One-dimensional domain considered in the analysis: (a) finite element mesh

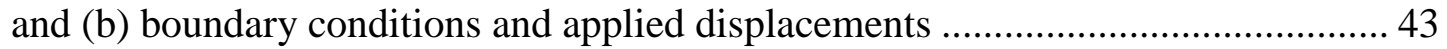

Figure 3.3 Different displacement increments: (a) cavity expansion, (b) shearing (vertical and torsional) associated with drilling, (c) upward (negative) vertical shearing during the extraction of the drilling tool, (d) downward vertical shearing during loading of the pile, (e) simultaneous application of radial, vertical and torsional displacements during the cavity expansion phase for a coupled analysis ..................................... 47

Figure 4.1 Schematic representation of the installation parameter $\eta$.......................... 52

Figure 4.2 Variation of normal stress on cavity wall during expansion of the cavity; limit cavity pressure is reached at the end of the cavity expansion ................................53

Figure 4.3 Evolution of normal (radial) effective stress, torsional shear stress and vertical shear stress (for anisotropic analysis) during installation and loading of a DD pile: (a) $\sigma^{\prime} \quad{ }_{\mathrm{v} 0}=50 \mathrm{kPa}, D_{\mathrm{R}}=45 \%, \eta=10^{\circ}$; (b) $\sigma^{\prime} \quad$ v0 $=50 \mathrm{kPa}, D_{\mathrm{R}}=45 \%, \eta=20^{\circ}$; (c) $\sigma^{\prime}$ v0 $=200 \mathrm{kPa}, D_{\mathrm{R}}=45 \%, \eta=10^{\circ}$; (d) $\sigma^{\prime} \quad$ v0 $=200 \mathrm{kPa}, D_{\mathrm{R}}=45 \%, \eta=20^{\circ}$; (e) $\sigma^{\prime}{ }_{\mathrm{v} 0}=$ 
$50 \mathrm{kPa}, D_{\mathrm{R}}=75 \%, \eta=10^{\circ}$; (f) $\sigma^{\prime}{ }_{\mathrm{v} 0}=50 \mathrm{kPa}, D_{\mathrm{R}}=75 \%, \eta=20^{\circ}$; (g) $\sigma^{\prime}{ }_{\mathrm{v} 0}=$ $200 \mathrm{kPa}, D_{\mathrm{R}}=75 \%, \eta=10^{\circ}$; and (h) $\sigma^{\prime} \quad$ v0 $=200 \mathrm{kPa}, D_{\mathrm{R}}=75 \%, \eta=20^{\circ}$

Figure 4.4 Evolution of normal (radial) effective stress, torsional shear stress and vertical shear stress (for isotropic analysis) during installation and loading of a DD pile: (a) $\sigma^{\prime} \quad{ }_{\mathrm{v} 0}=50 \mathrm{kPa}, D_{\mathrm{R}}=45 \%, \eta=10^{\circ}$; (b) $\sigma^{\prime} \quad$ v0 $=50 \mathrm{kPa}, D_{\mathrm{R}}=45 \%, \eta=20^{\circ}$; (c) $\sigma^{\prime}$ v0 $=200 \mathrm{kPa}, D_{\mathrm{R}}=45 \%, \eta=10^{\circ}$; (d) $\sigma^{\prime} \quad \mathrm{v} 0=200 \mathrm{kPa}, D_{\mathrm{R}}=45 \%, \eta=20^{\circ}$; (e) $\sigma^{\prime}{ }_{\mathrm{v} 0}=$ $50 \mathrm{kPa}, D_{\mathrm{R}}=75 \%, \eta=10^{\circ}$; (f) $\sigma^{\prime}$ v0 $=50 \mathrm{kPa}, D_{\mathrm{R}}=75 \%, \eta=20^{\circ}$; (g) $\sigma^{\prime}{ }_{\mathrm{v} 0}=$ $200 \mathrm{kPa}, D_{\mathrm{R}}=75 \%, \eta=10^{\circ}$; and (h) $\sigma^{\prime} \quad \mathrm{v} 0=200 \mathrm{kPa}, D_{\mathrm{R}}=75 \%, \eta=20^{\circ}$.

Figure 4.5 Stress paths in $e-p^{\prime} \quad$ space: (a) for different values of $\eta$, and (b) at different distances from the pile axis for $\eta=20^{\circ}$

Figure 4.6 Stress path (in $q-p^{\prime} \quad$ space) for the leftmost quadrature point in the first element of the mesh during installation and loading of a DD pile (for $\eta=20^{\circ}$ ) ......6 64

Figure 4.7 Effect of DD pile installation $\left(\eta=20^{\circ}\right.$ ) on the normal (radial) effective stress acting in the surrounding soil: (a) anisotropic analysis, and (b) isotropic analysis ... 65

Figure 4.8 Effect of DD pile installation $\left(\eta=20^{\circ}\right)$ on the mean effective stress in the surrounding soil: (a) anisotropic analysis, and (b) isotropic analysis

Figure 4.9 Effect of DD pile installation $\left(\eta=20^{\circ}\right)$ on the void ratio of the surrounding soil: (a) anisotropic analysis, and (b) isotropic analysis 68

Figure 4.10 Effect of the angle $\eta$ on the stress state of the soil surrounding the pile just after the installation of a DD pile: (a) normal (radial) effective stress, (b) mean effective stress, and (c) void ratio .... 70

Figure 5.1 K/K $K_{0}$ predictions for DD piles (anisotropic analysis): (a) $\eta=10^{\circ}$, and (b) $\eta=$ $20^{\circ}$.

Figure $5.2 \mathrm{~K} / \mathrm{K}_{0}$ predictions for DD piles (isotropic analysis): (a) $\eta=10^{\circ}$, and (b) $\eta=20^{\circ}$ 75

Figure 5.3 Variation of $K / K_{0}$ with different values of $\eta$ (anisotropic analysis with $\sigma^{\prime}$ v0 $=$ $100 \mathrm{kPa}$ and $D_{\mathrm{R}}=60 \%$ ) 76

Figure 5.4 Effect of $K_{0}$ on the earth pressure coefficient $K$ at limit state conditions (anisotropic analysis with $\sigma^{\prime}$ v0 $=100 \mathrm{kPa}$ ): (a) $\eta=10^{\circ}$, and (b) $\eta=20^{\circ}$ 77

Figure 5.5 Effect of pile diameter $B$ on the ratio $K / K_{0}$ at limit state conditions (anisotropic

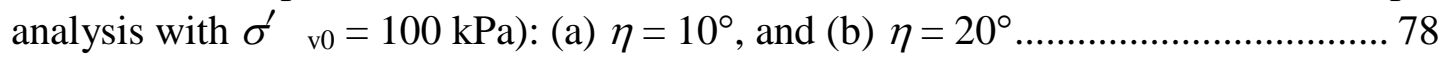

Figure 5.6 Comparison of $K / K_{0}$ obtained from coupled and uncoupled analysis: (a) $\eta=$ $10^{\circ}$, and (b) $\eta=20^{\circ}$

Figure 5.7 Comparison of $K / K_{0}$ for DD piles with those calculated for (a) a drilled shaft, and (b) a monotonically jacked pile..... 81

Figure 5.8 Pile and soil profile for the design examples: (a) the homogeneous sand deposit used in Example 1, and (b) the multilayered sand deposit used in Example 2

Figure 5.9 Cone resistance $q_{\mathrm{c}}$ profile for Example 1 86

Figure 5.10 Cone resistance $q_{\mathrm{c}}$ profile for Example 2 87 


\section{CHAPTER 1. INTRODUCTION}

\subsection{Background}

A wide variety of pile types are currently available for use in geotechnical engineering practice. The response of these piles to loading varies greatly depending on the installation or construction methods employed. On one end of the pile-behavior spectrum are the nondisplacement piles (e.g., bored piles or drilled shafts) and on the other end are the full-displacement piles (e.g., closed-ended pipe piles or precast reinforced concrete piles). Nondisplacement piles are constructed by removing a cylinder of soil from the ground and replacing the void created with concrete and reinforcement. Fulldisplacement piles, on the other hand, are driven or jacked into the ground. During the installation of the full-displacement piles, significant changes in the void ratio and stress state of the in situ soil take place because the soil surrounding the pile shaft is displaced mainly in the lateral direction and the soil below the base of the pile is preloaded. These changes produce a stiffer load-displacement response for the displacement piles compared with the nondisplacement piles, particularly in the case of sandy soils which gain additional strength through densification. There are other types of piles (e.g., openended pipe piles) that show behavior intermediate between nondisplacement and fulldisplacement piles. These piles are often called partial-displacement piles. Figure 1.1 shows the classification of different piles based on the soil displacement achieved during their installation. 


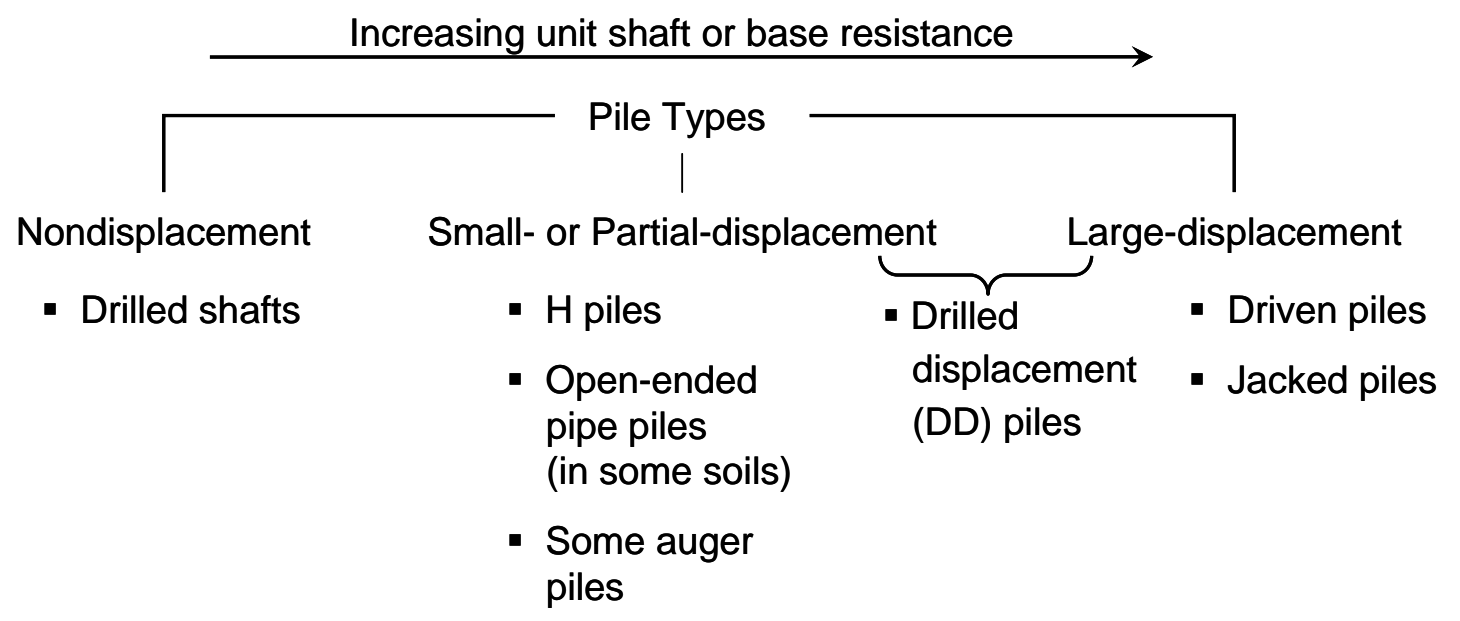

Figure 1.1 Categorization of piles based on the soil displacement produced during installation

Many auger piles, which are installed by drilling a continuous-, segmented- or partial-flight auger into the ground, fall under the category of partial-displacement piles. A variety of auger piling equipment is available in the market; consequently, the terminologies used for describing different types of auger piles vary across the world. Different auger piling equipments also produce different degrees of soil displacement during pile installation. The commonly used terminologies used for auger piles in North America and Europe are presented in Figure 1.2.

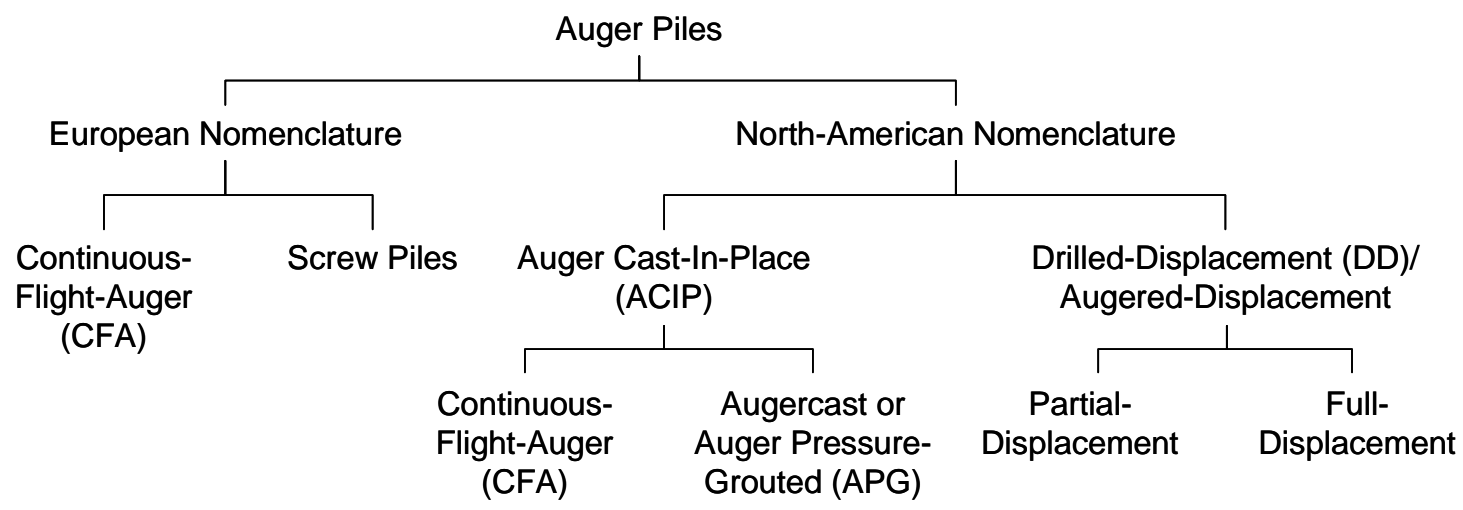

Figure 1.2 Nomenclature used for auger piles in Europe and in the USA 
A special class of auger piles was created as a result of advances in auger piling technology; these are commonly known as "screw piles" in Europe, and "drilled displacement" or "augered displacement" piles in the USA (Brown and Drew 2000; Brown 2005; Prezzi and Basu 2005). Drilled displacement (DD) piles are rotary displacement piles installed by inserting a specially designed helical auger segment into the ground with both a vertical force and a torque. The soil is displaced laterally within the ground (with minimal spoil generated), and the void created is filled with grout or concrete. A distinction should be made between concrete/grout cast DD piles described in this report and those where a single- or multiple-helix steel auger is screwed into the ground to form a pile. These piles (commonly known as 'helical piles' or 'helical piers') are similar to helical ground anchors but installed vertically to function as piles. Their design and installation differ greatly from those of the DD piles covered in this paper. The installation of DD piles produces greater soil displacement than that produced by continuous-flight-auger (CFA) or auger cast-in-place (ACIP) piles (CFA and ACIP piles are generally associated with small to no soil displacement). The radial displacement of soil, in the case of DD piles, contributes to the high capacity obtained for these piles.

From a design point of view, full-displacement piles are preferable because they are capable of carrying larger loads than partial- or nondisplacement piles of similar geometry. However, pile driving may cause excessive vibration to neighboring structures or create excessive noise that may be unacceptable under certain conditions. Additionally, in some soil profiles (e.g., quick clays), the use of driven piles may not be advisable. DD piles often offer a viable alternative in cases where the installation of driven full-displacement is not advisable. The advantages of DD piles are (i) the ease of construction with minimal vibration or noise, and minimal spoil (important for contaminated sites), (ii) the high load carrying capacity due to partial or full displacement of the soil surrounding the pile, and (iii) the associated savings that result when they are installed in the right soil conditions. 


\subsection{Problem Statement}

Despite the widespread use of different types of DD piles, the literature contains limited and scattered information on their design and installation. In this report we present a review of the current DD pile practice and design. The currently available design methods for DD piles rely almost exclusively on empirical relations developed based on results of field pile load tests performed on particular types of drilled displacement (DD) piles. However, the capacity of these piles depends to a great extent on the installation method and the changes that it causes to the state of the soil in the vicinity of the pile. Therefore, it is important to relate the capacity of piles to soil properties that reflect the state of the soil surrounding the pile after installation. The soil displacement produced during the installation of DD piles can vary from that of a partial- to a full-displacement pile depending on the design of the drilling tools and piling rig technology. Thus, proper analysis is necessary in the development of more precise design methods specific for each DD pile type by carefully assessing the impact of installation on their capacity.

This report outlines a very promising approach to model shaft resistance of DD piles in sand. We perform one-dimensional (1-D) finite element analysis (FEA) to model the installation and subsequent loading of a DD pile installed in sand. These analyses are valid for DD piles installed using drilling tools that have enlarged (large-diameter) displacement bodies. The FEA uses a two-surface plasticity-based constitutive model for sand and involves three distinct stages: (i) pile installation, (ii) removal of drilling tool from the ground, and (iii) loading of the pile. In this study we quantify the limit shaft resistance of DD piles through an integrated analysis framework that uses a suitable soil constitutive model and captures all features of pile installation and loading. The report provides a set of equations to calculate the coefficient of lateral earth pressure acting on the pile shaft. These equations can be used in determining the limit unit shaft resistance of DD piles in sand. 


\subsection{Objectives and Organization}

In Chapter 2, we describe the installation methods, general quality control procedures, and three widely practiced design methods for DD piles. The ultimate capacities of five different types of DD piles are calculated using these design methods and compared with those obtained from pile load test results reported in the literature. Additionally, in a separate design example, the capacities of a DD pile, a full-displacement pile and a nondisplacement pile in a residual soil profile are compared.

In Chapter 3, we describe different aspects of the 1-D FE model that we use to model installation and loading of a DD pile in sand. We consider the installation in sand to be a fully drained process. To assess the effect of inherent (fabric) anisotropy, which is due to the preferred orientation of the sand particles, on the pile-soil load-transfer behavior, we perform two sets of analyses: i) considering fabric anisotropy and ii) ignoring fabric anisotropy by switching off the constitutive model components pertaining to fabric anisotropy (i.e., by enforcing an isotropic fabric tensor).

In Chapter 4, we present and discuss the FEA results obtained at different stages of installation and loading of the pile. We also discuss the changes in the stress state of the soil during and after the installation of a DD pile.

In Chapter 5, based on the FE simulation results, we propose a set of equations for the estimation of unit limit shaft resistance of a DD pile. These equations demonstrate the effects of relative density and confinement on the unit limit shaft resistance of DD piles. In this chapter we also study the impact of an installation parameter on the shaft capacity of DD piles. We summarize the key findings of this research and present the conclusions drawn from this study in Chapter 6. 


\section{CHAPTER 2. OVERVIEW OF CURRENT PRACTICE AND DESIGN OF DRILLED DISPLACEMENT PILES}

\subsection{Introduction}

The development of DD piling technology evolved from the continuous-flight auger (CFA) piling technology. The remarkable progress in piling rig capabilities over the past few decades and the improvement of the auger pile drilling tools and installation techniques helped speed up the pile installation process and resulted in larger lateral soil displacement during installation. The piles that ensued because of these developments were called DD piles. However, DD piles are not just limited to those that are variations of the CFA or ACIP piles. A variety of other piles that have significantly different installation (drilling) tools are also included in this broad pile classification. Auger Pressure-Grouted Displacement (APGD), Atlas, De Waal, Fundex, Olivier, Omega, SVB, and SVV piles are few examples of DD piles that are installed using distinctive drilling tools. In this chapter we describe the installation methods, general quality control procedures, and three widely practiced design methods for DD piles.

\subsection{Overview of DD Piling Technology}

In general, the drilling tool of a DD pile contains one or more of the following components: a) a soil displacement body (an enlarged-diameter section which facilitates lateral soil movement), b) a helical, partial-flight auger segment (the only exception occurs in the case of SVB piles which are installed using a large-stem auger), and c) a specially designed sacrificial tip, which is attached to the bottom of the drilling tool. The shape of the displacement body varies from one pile type to another; broadly, it consists of a cylindrical body that, in some cases, also contains single or multiple helices (Figure 
2.1). A casing (mandrel) of diameter smaller than or equal to the diameter of the pile is connected to the drilling tool.

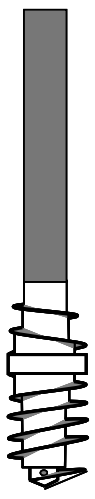

APGD

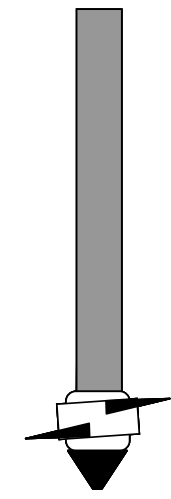

Atlas

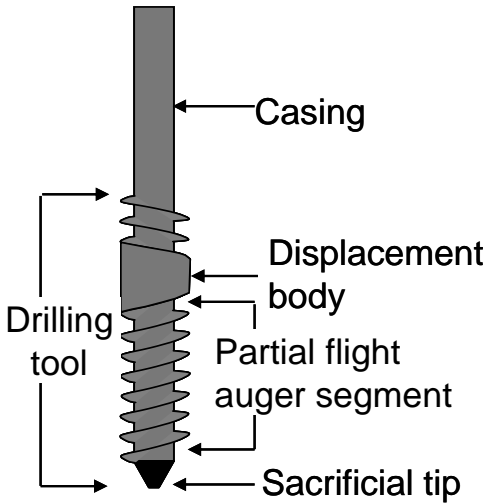

De Waal

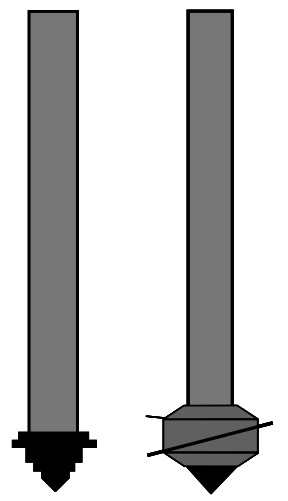

Fundex
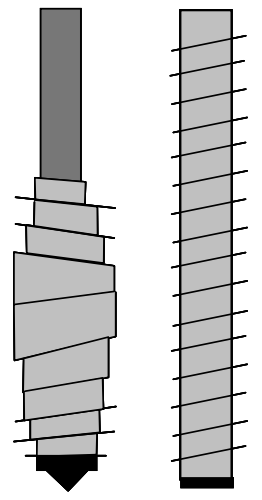

SVB

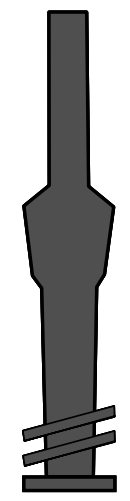

SVV

Figure 2.1 Drilling tools for installation of different drilled displacement piles

The degree of soil displacement produced during the installation of DD piles can vary from that of a partial- to that of a full-displacement pile depending on the design of the drilling tool and piling rig technology. DD piling rigs that have high torque capacities (150 kN-m to $500 \mathrm{kN}-\mathrm{m}$ or more) and provide vertical thrust during the drilling process are often used in practice [drilling proceeds as a result of both the rotation of the drilling tool and the crowd (axial) force typically applied by hydraulic rams]. Once the drilling tool reaches the desired depth, the sacrificial tip (if used) is released from the casing or displacement body. Concrete or grout is then placed through the casing as the drilling tool and the casing are extracted from the ground. The reinforcement is inserted either before or after concrete placement. The drilling tool and casing can be withdrawn from the ground with or without rotation (the rotation may be clockwise or counter-clockwise). A nearly smooth pile shaft is obtained if the casing is withdrawn with alternating $180^{\circ}$ clockwise and counter-clockwise rotations (as in the case of the Fundex pile). A nearly smooth shaft also results if the drilling tool is rotated clockwise as it is withdrawn from the ground (e.g., APGD, De Waal, and Omega piles). However, if the displacement body is rotated counter-clockwise (e.g., Atlas and Olivier piles) during withdrawal, then a screw-shaped shaft is obtained. 
Proper knowledge of the subsurface profile is needed for selecting the most efficient pile type for a given site. Although DD piles have been successfully used in various soil conditions, it is not recommended for certain conditions. In the case of very loose sandy soils or very soft clayey soils (characterized by SPT blow count $N<5$ or CPT cone resistance $q_{\mathrm{c}}<1 \mathrm{MPa}$ ), the performance of DD piles may be compromised because of possible difficulties encountered during installation (Bustamante and Gianeselli 1998). In the case of very dense sandy soils or thick alluvium layers, a drastic drop in the penetration rate may be observed and premature wear of the screw head (drilling tool) may result (Bustamante and Gianeselli 1998).

\subsection{Installation Techniques of Different DD Piles}

\subsubsection{APGD Pile}

The APGD piling technology, which is patented by the Berkel \& Company Contractors, Inc., is a modification of the Auger Pressure-Grouted (APG) piling system (Brettmann and NeSmith 2005). The original APG pile is a type of CFA pile which is constructed by pumping fluid grout under pressure during the withdrawal of the continuous-flight auger. During the installation of an APGD pile (Figure 2.2), the surrounding soil is displaced laterally as the drilling tool is advanced into the ground. There are two types of APGD piles: i) auger pressure-grouted with partial soil displacement and ii) auger pressuregrouted with full soil displacement. The APGD pile rigs are capable of producing both a torque and a downward crowd force, facilitating the drilling operations. Once the desired depth is reached, high-strength grout is pumped under pressure through the drill stem and the drilling tool is withdrawn as it rotates clockwise. The reinforcement cage is inserted into the grout column to complete the pile installation process.

The full-displacement APGD piles, which are typically installed in loose to medium dense sands (corresponding to SPT blow count $N<25$ ), can be $0.3-0.45 \mathrm{~m}$ in diameter and up to $24 \mathrm{~m}$ in length (Brettmann and NeSmith 2005). The diameter of the partial-displacement APGD pile ranges from $0.3 \mathrm{~m}$ to $0.5 \mathrm{~m}$. These piles reach up to 17 
$\mathrm{m}$ in length and are used in loose to dense sands with $N<50$ (Brettmann and NeSmith 2005).

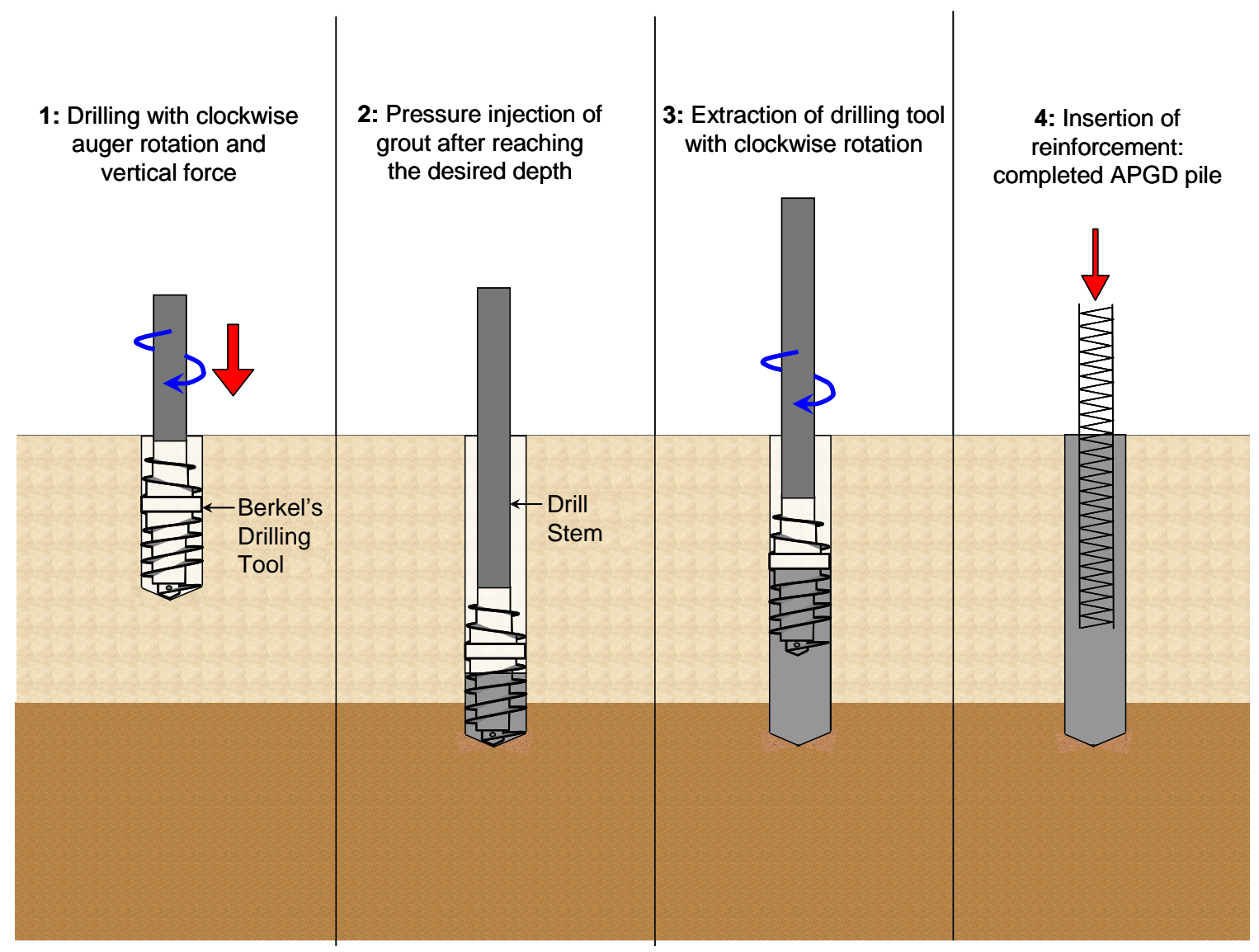

Figure 2.2 Installation stages for APGD piles

\subsubsection{Atlas Pile}

The Atlas pile is a drilled, dual-displacement, cast-in-place concrete pile (De Cock and Imbo 1994). Lateral displacement of soil occurs both during drilling and extraction of the auger (this is the reason why it is called a dual-displacement pile). These piles are installed using a purpose-built drilling rig with a base rotary drive (Bottiau 2006). The rig has two hydraulic rams that can work independently (one ram taking over from the other after its full stroke is achieved) to allow a continuous drilling operation. In the case of hard soils, the two hydraulic rams can be used simultaneously. The rig can be operated at 
dual rotational speeds. This helps control the drilling tool penetration rate in different soil types.

A sacrificial tip (a lost pile shoe) is attached to a displacement body, which, in turn, is attached to a steel casing or mandrel (Figure 2.3). The displacement body consists of a cast-iron dismountable helical head with an enlarged helical flange. The joint between the displacement body and the sacrificial tip is made watertight. The combined action of the torque and the vertical thrust forces the casing down into the ground with a continuous, clockwise, helical penetrating movement. After the desired depth is reached, the steel shoe is detached from the casing by rotating the casing counter-clockwise (thereby opening the connection between the steel shoe and the casing). Subsequently, the steel reinforcing cage is inserted into the casing, and high-slump concrete is poured through a hopper placed on top of the casing to cast the pile shaft. As the casing and the displacement body are extracted by a vertical pulling force and counter-clockwise rotation, concrete completely fills the helical bore formed by the upward-moving displacement screw. This way, a screw-shaped shaft is formed. The flange thickness of the screw-shaped shaft varies depending on the extraction procedure (i.e, ratio of rotational to translational speeds during extraction; De Cock and Imbo 1994, Geoforum 2008). After concrete placement is complete, it is possible to push a supplementary reinforcing cage into the concrete.

The diameter of the displacement body (which is the same as the minimum diameter of the pile shaft) typically ranges from $0.31 \mathrm{~m}$ to $0.56 \mathrm{~m}$, while that of the enlarged helical flange ranges from $0.45 \mathrm{~m}$ to $0.81 \mathrm{~m}$ (Bustamante and Gianeselli 1998; De Cock and Imbo 1994). The Atlas pile length can reach up to 22-25 m. In highly compressible soils or in soils with large cavities or voids, a thin-walled casing is often attached to the screw head of the Atlas piles (Bustamante and Gianeselli 1998). The casing is left in the ground with the sacrificial tip. 


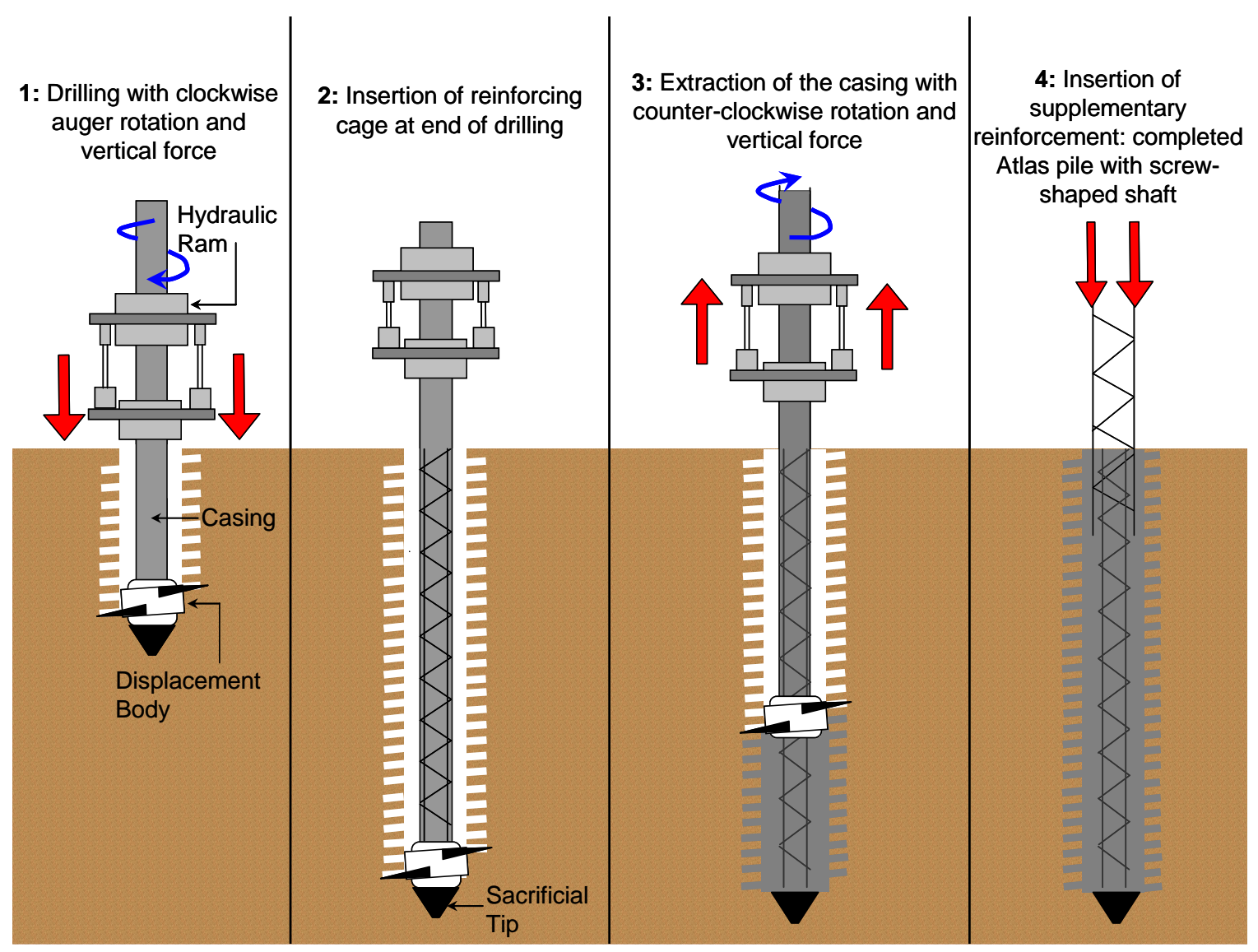

Figure 2.3 Installation stages for Atlas piles

\subsubsection{De Waal Pile}

The drilling tool used to install the De Waal pile consists of a sacrificial tip, a partialflight auger and a displacement body (Figure 2.4). The tool is attached to a casing that has additional helices welded near the top. The partial-flight auger is closed at the bottom with the sacrificial tip. To install the De Waal pile, the drilling tool is rotated clockwise to the required depth with a torque and a vertical force, the sacrificial tip is released and the reinforcement cage is installed. Concrete is injected as the casing is extracted with clockwise rotation and a vertical force. Unlike the Atlas piles, installation of the De Waal pile creates a nearly smooth shaft. 


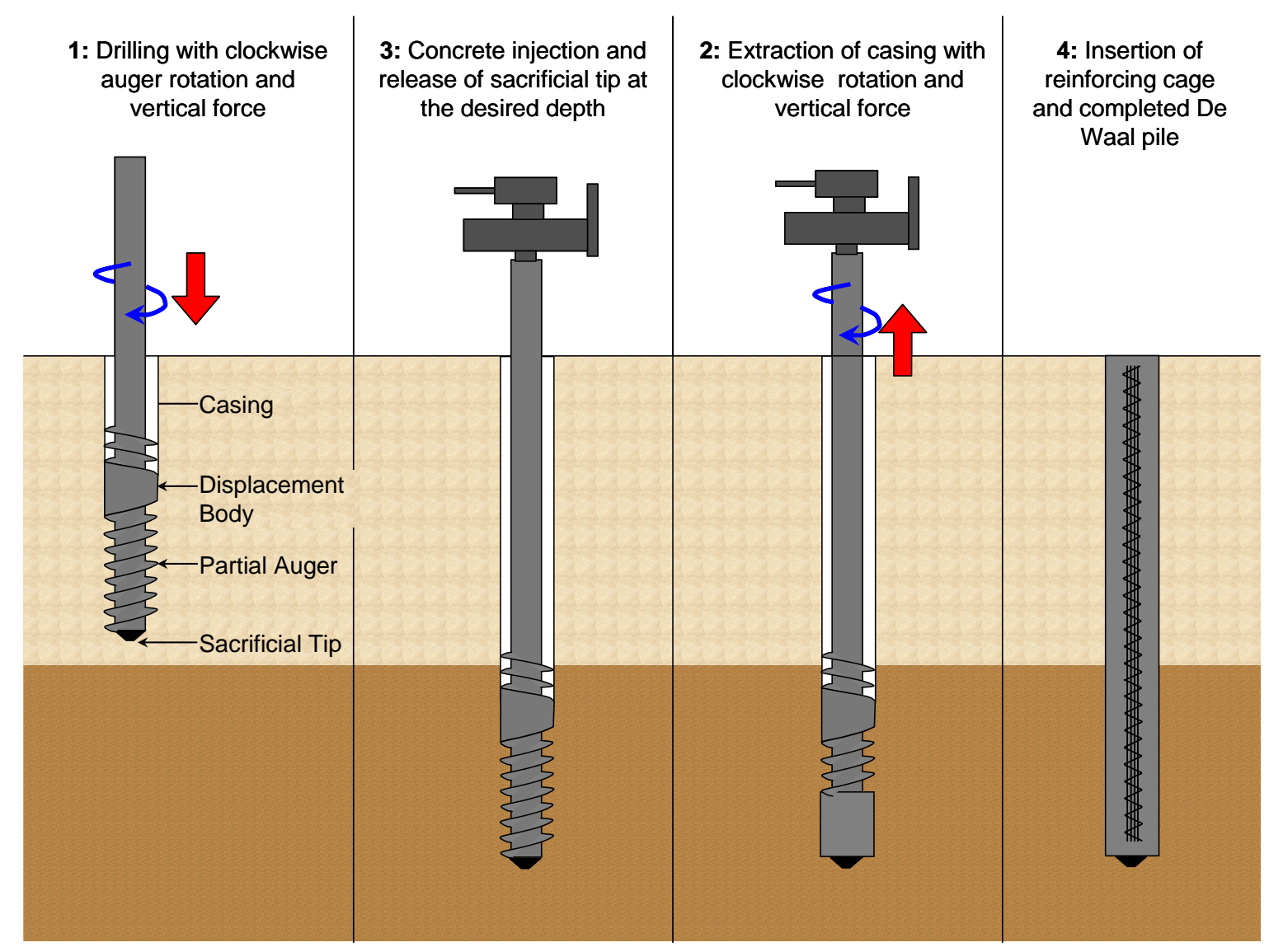

Figure 2.4 Installation stages for De Waal piles

\subsubsection{Fundex Piles}

In the Fundex pile installation, a casing/tube with a conical auger tip attached to its end is rotated clockwise and pushed down into the soil (Figure 2.5). The joint between the casing and the conical tip is made watertight. As the casing penetrates into the ground, soil is displaced laterally. In dense or hard layers, drilling can be combined with grout injection or water jetting through the conical tip. After the desired depth is reached, the sacrificial conical tip, which forms an enlarged pile base, is released. The reinforcement cage is then inserted into the casing, and concrete is placed. As the concrete is placed, the casing is extracted in an oscillating upward and downward motion with alternate $180^{\circ}$ clockwise and counter-clockwise rotations. The withdrawal of the casing with both clockwise and counter-clockwise rotations produces a nearly smooth shaft. 
The diameter of the conical tip ranges from $0.45 \mathrm{~m}$ to $0.67 \mathrm{~m}$, while that of the casing ranges from $0.38 \mathrm{~m}$ to $0.52 \mathrm{~m}$ (American Pile Driving Inc. 2007; Geoforum 2008). The length of the Fundex pile can reach up to 25-35 m.

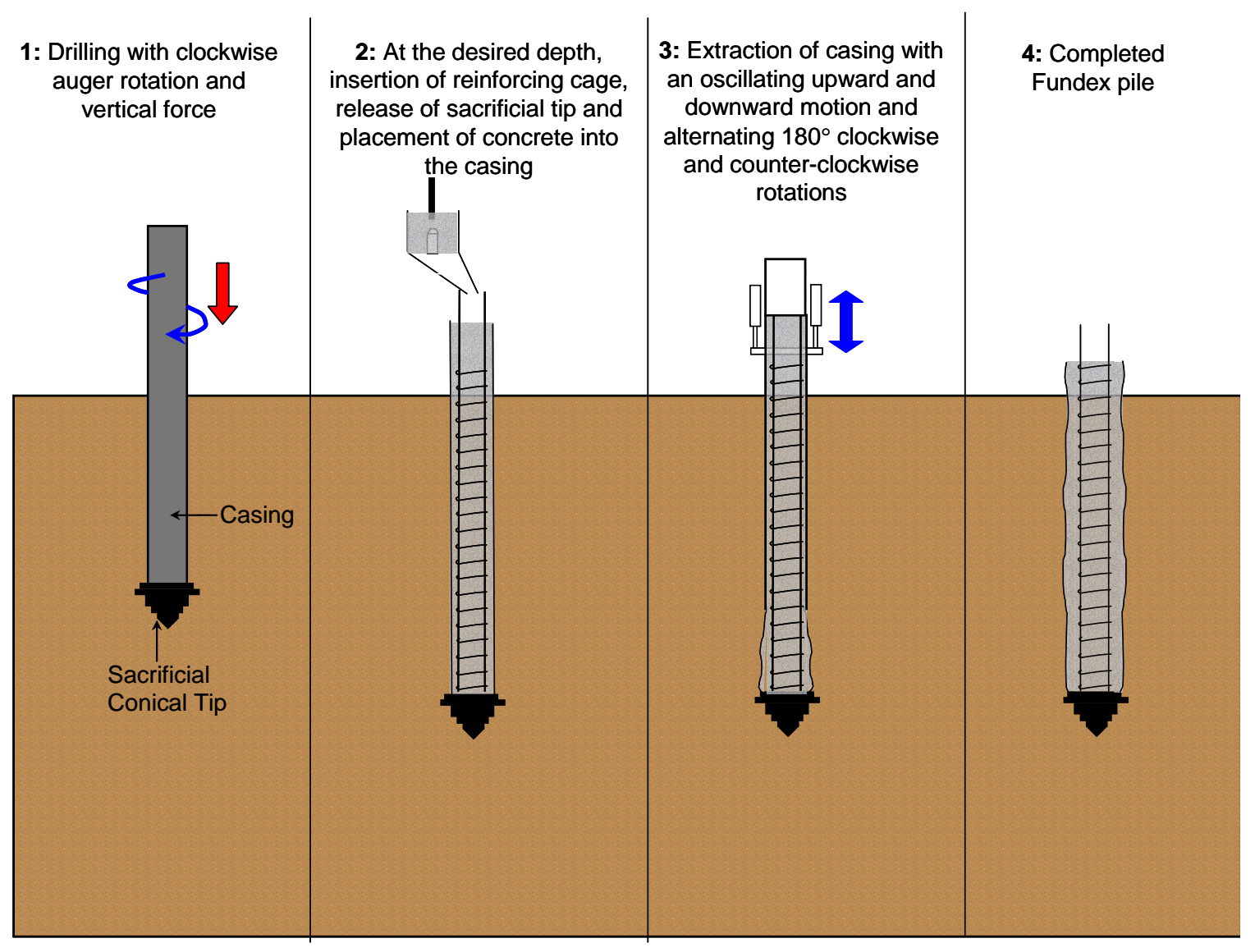

Figure 2.5 Installation stages for Fundex piles

\subsubsection{Oliver Piles}

The installation of the Olivier pile is similar to that of the Atlas pile (Figure 2.6). However, the drilling rigs used to install the Olivier piles are different from those of the Atlas piles (the rotary drives are different; the Atlas pile rig has bottom-type rotary drive with fixed rate of penetration, while the Olivier pile rig uses a top-type rotary drive with variable rate of penetration). A lost tip is attached to a partial-flight auger which, in turn, is attached to a casing. The casing, which is rotated clockwise continuously, penetrates into the ground by the action of a torque and a vertical force. At the desired installation 
depth, the lost tip is released, and the reinforcing cage is inserted into the casing. Concrete is then placed inside the casing through a funnel. The casing and the partialflight auger are extracted by counter-clockwise rotation. Similar to the Atlas pile, the shaft of the Olivier pile has the shape of a screw.

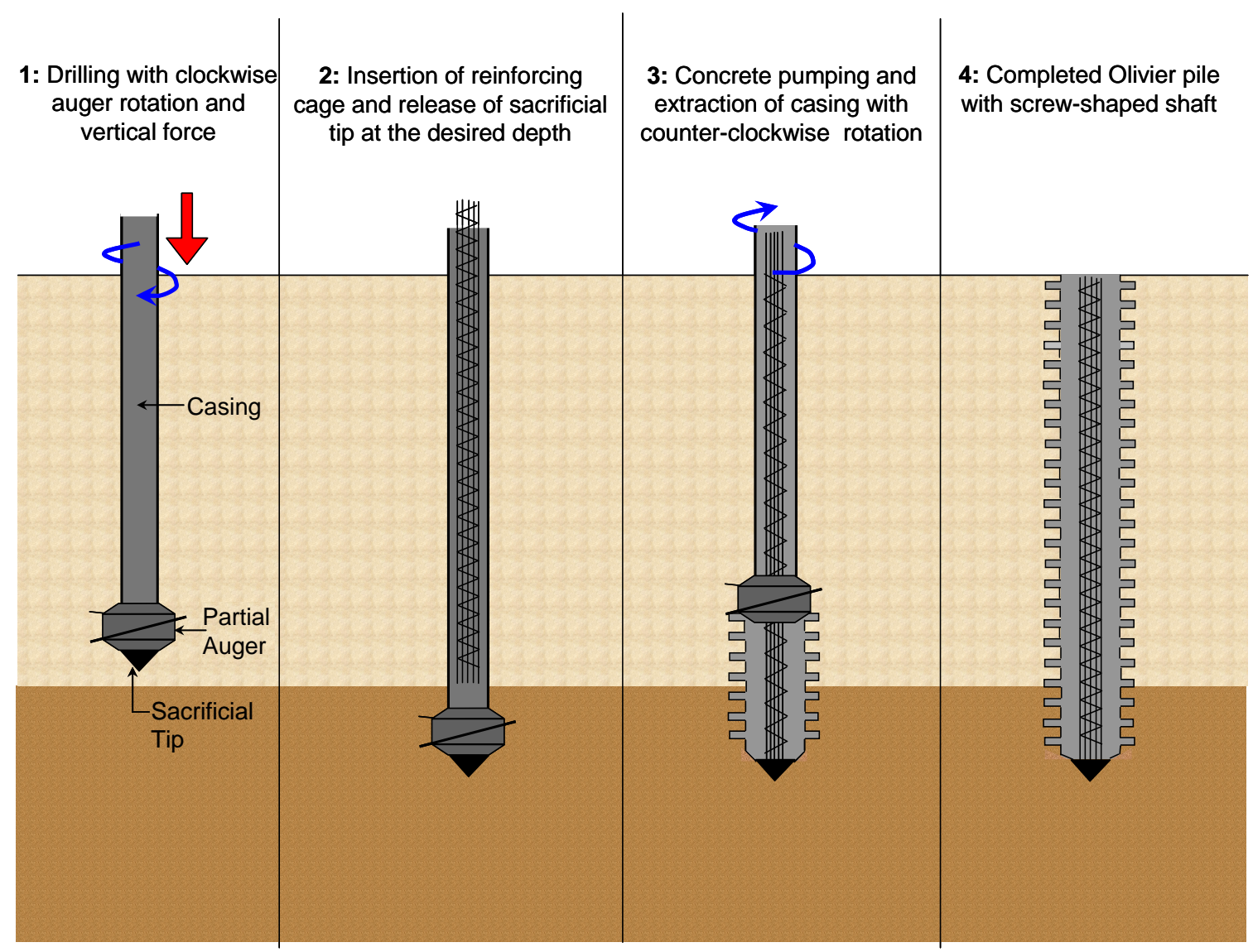

Figure 2.6 Installation stages for Olivier piles

\subsubsection{Omega Piles}

In the case of the Omega pile, drilling is done by a displacement auger (with varying flange diameter), which is closed at the bottom with a sacrificial tip (Figure 2.7). The flange diameter of the auger segments increases gradually from both ends and becomes equal to the diameter of the central displacement body. A casing is attached to the upper end of the displacement auger. Unlike the other DD piles that we describe in this report, during installation of Omega piles concrete is injected under pressure into the casing even 
before the desired depth is reached. After reaching the required depth, the sacrificial tip is released, and the auger is slowly rotated clockwise and pulled up to produce a nearly smooth shaft. The reinforcement cage is then vibrated down into the fresh concrete.

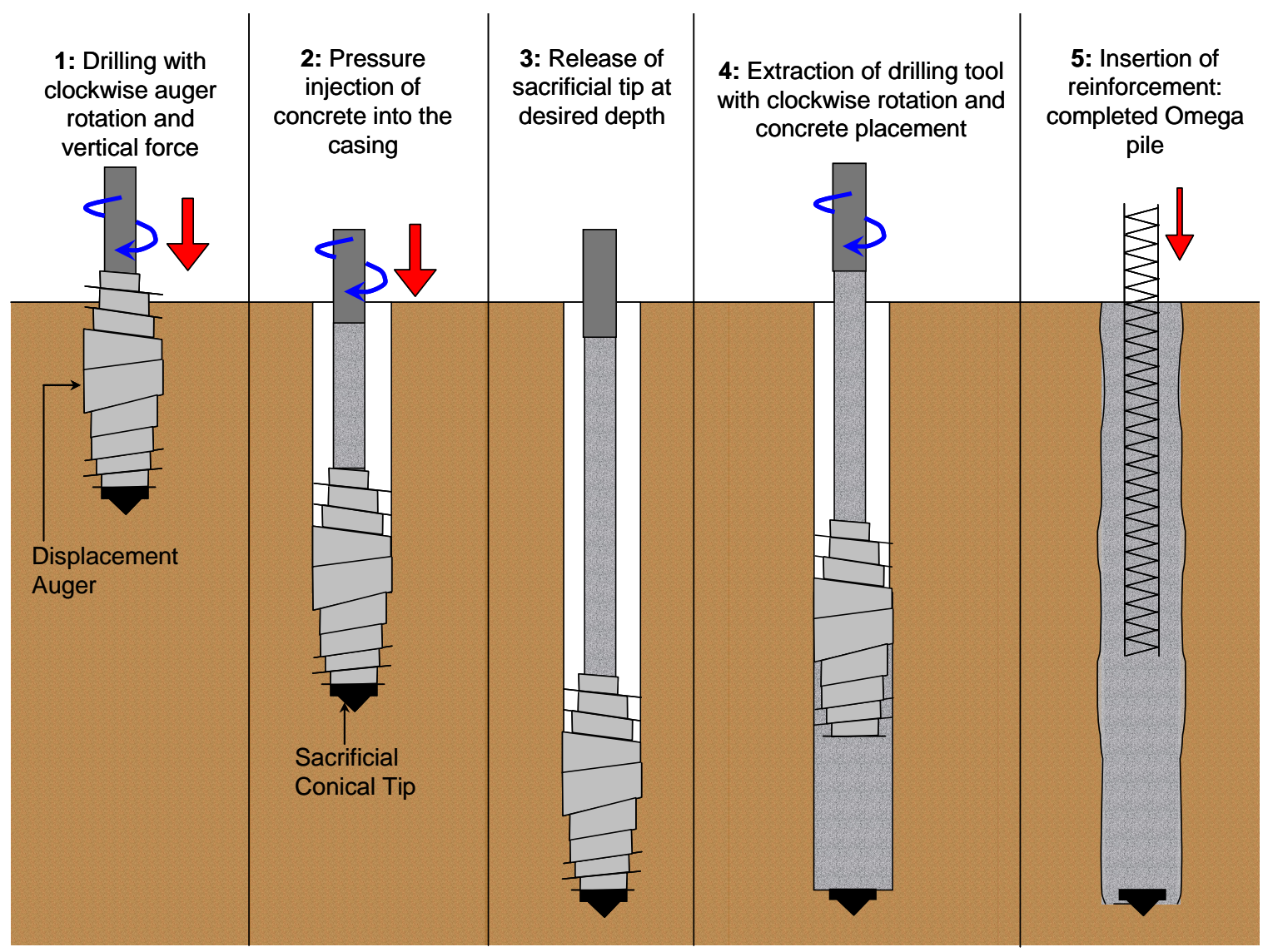

Figure 2.7 Installation stages for Omega piles

\subsubsection{SVB Piles}

The SVB pile (Schnecken-Verdrängungsbohrpfahl), which was developed by Jebens $\mathrm{GmbH}$, is a partial-displacement DD pile. The drilling is done by a large-stem auger, which also acts as a casing. Both a torque and a crowd force are used during drilling. The bottom of the casing is sealed off with a disposable plate (Figure 2.8). During pile installation, soil is partly transported along the helices to the ground surface and is partly displaced laterally. When the desired depth is reached, the reinforcement is inserted, and concrete is pumped into the casing. The casing is extracted by a pull-out force and a 
torque, leaving the bottom plate in the ground. Since the casing is rotated clockwise during extraction, a nearly smooth shaft is formed. The SVB pile can have diameters ranging from $0.40 \mathrm{~m}$ to $0.67 \mathrm{~m}$ with a maximum length of $24 \mathrm{~m}$ (Geoforum 2008).

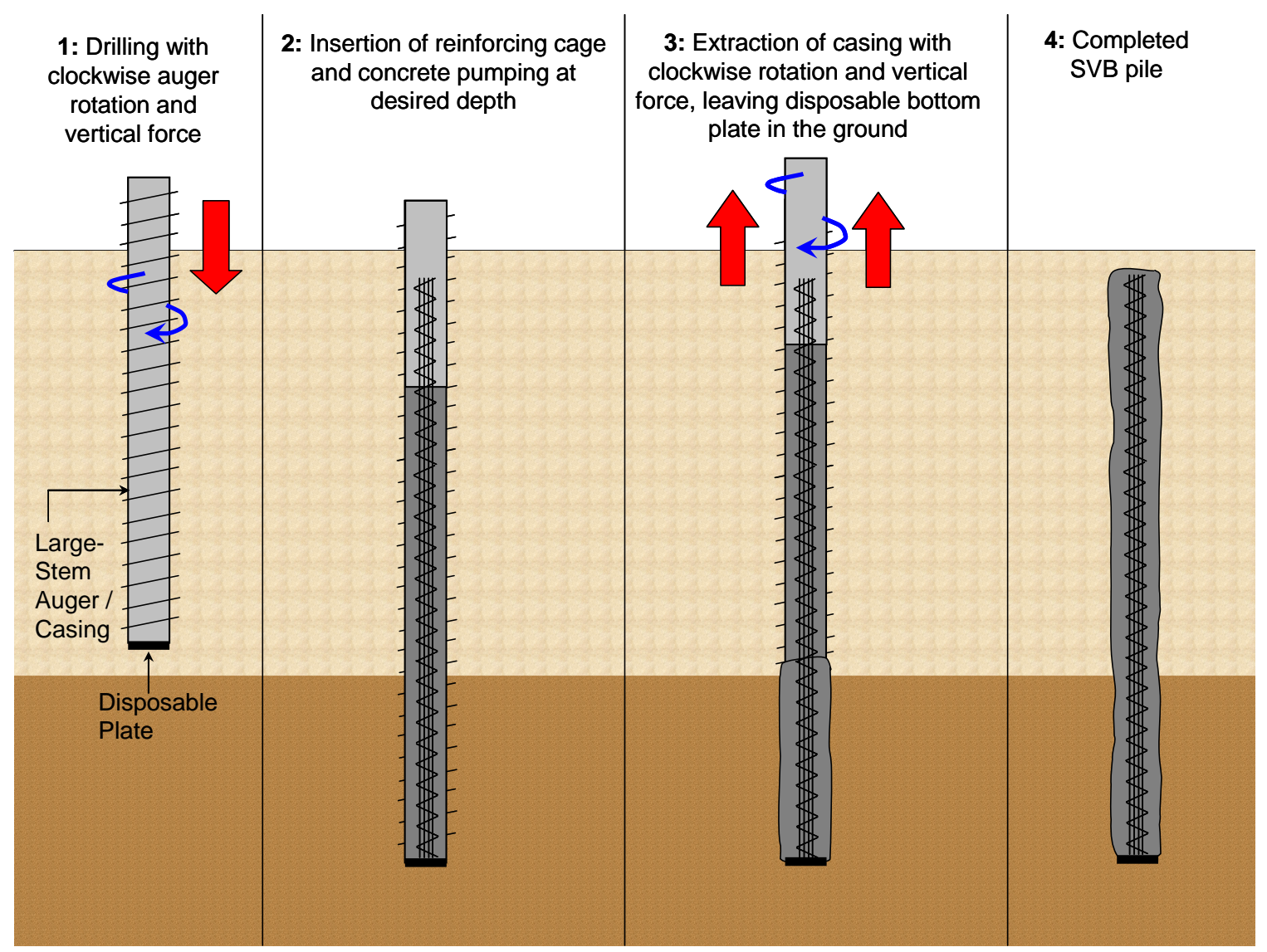

Figure 2.8 Installation stages for SVB piles

\subsubsection{SVV Piles}

The SVV pile (STRABAG Vollverdrängungsbohrpfahl), also developed by Jebens $\mathrm{GmbH}$, is a large-displacement DD pile (Figure 2.9). The pile is installed using a patented casing that has a segment with an enlarged diameter and a drill head. The installation procedure of the SVV pile is similar to that of the SVB pile. The SVV pile typically has a diameter of $0.44 \mathrm{~m}$ and a length of up to $20 \mathrm{~m}$ (Geoforum 2008). 


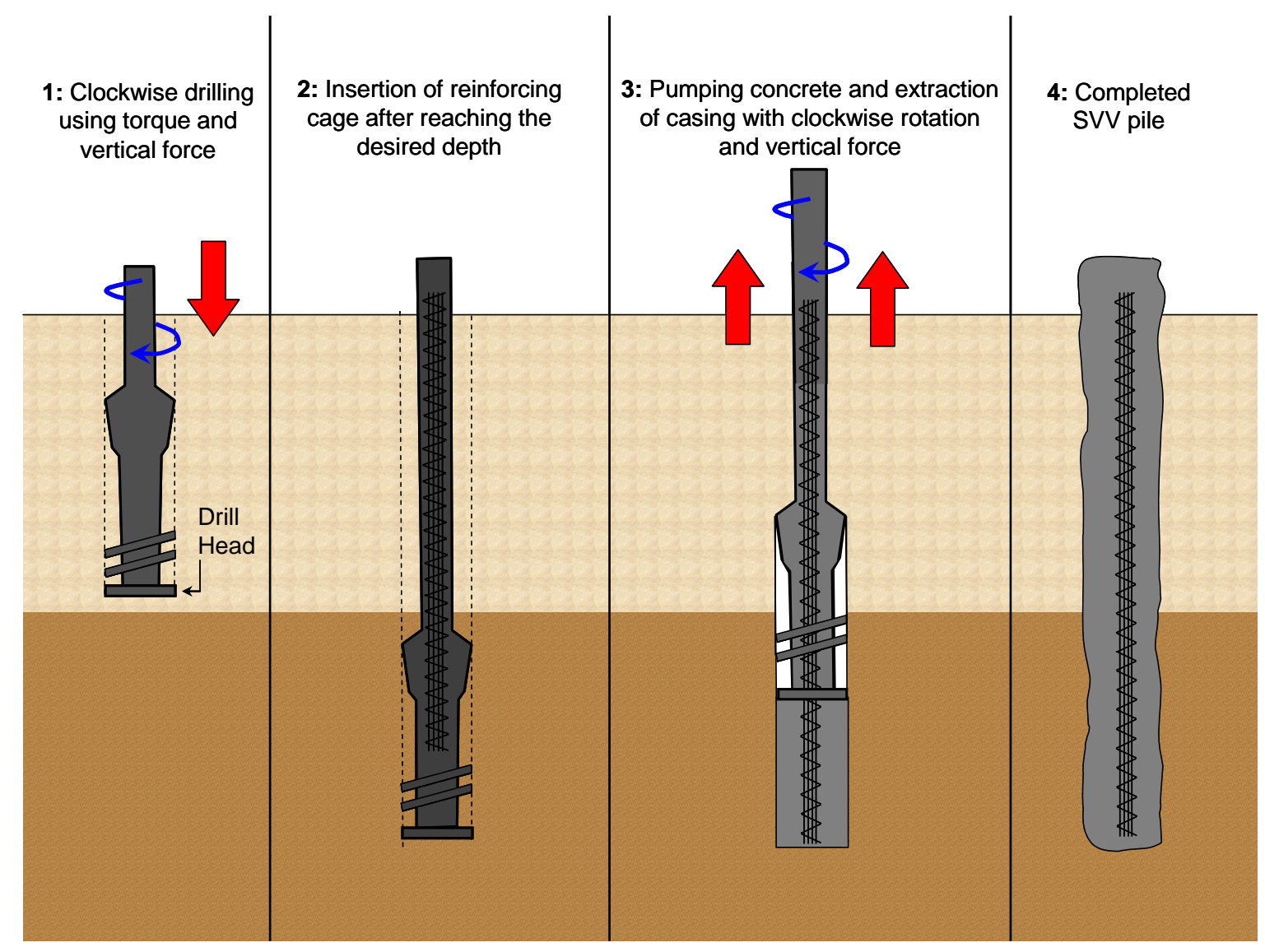

Figure 2.9 Installation stages for SVV piles

\subsection{Installation Monitoring for DD Piles}

Continuous monitoring during the installation of auger piles is important to assure pile integrity. The data obtained through monitoring of the installation process also provide indications regarding the subsurface condition and allow determination of the exact position of the pile base. Depending on the equipment available, some or all of the following quantities can be measured or calculated during the installation of auger piles: the rate of auger rotation, the rate of auger penetration, the torque, the concrete pumping rate, and the auger extraction rate (Mandolini et al. 2002). Similar automated monitoring systems are available for the DD pile rigs as well. These can be used to continuously monitor the depth of penetration, the vertical force, the torque, and the rate of auger/casing penetration and rotation. A specific energy term can be calculated from the variables mentioned above and other machine-specific installation parameters. The 
specific energy along the depth of the pile can be correlated with in situ test results; it can also be used to visualize the effects of pile installation and to help predict pile load capacity (De Cock and Imbo 1994).

In the past, quality control (QC) of auger piles was performed mostly by field inspectors, based mainly on the industry standards published by the Deep Foundations Institute (DFI) in the 1990's (Brettmann 2003). Currently, automated systems are attached to many pile rigs throughout the world. Although these monitoring systems can provide valuable information on the integrity of the piles, they are not meant to replace qualified field inspectors. Automated QC monitoring techniques are based on measurements of either volume or pressure of the grout/concrete. Typical automated systems measure: i) time, depth and hydraulic pressure during drilling, and ii) time, depth, grout/concrete volume or grout/concrete pressure during casting. Continuous, real time graphs of relevant data are available to the operator during the installation of DD piles (this facilitates any impromptu adjustments that may be needed). These files can also be stored electronically for future reference (Bretmann and NeSmith 2005).

\subsection{Presently Available Design Methods for DD piles}

The ultimate pile capacity $Q_{\text {ult }}$ can be expressed as:

$$
Q_{\mathrm{ult}}=Q_{\mathrm{b}, \mathrm{ult}}+Q_{\mathrm{sL}}
$$

where $Q_{\mathrm{b} \text {,ult }}$ and $Q_{\mathrm{sL}}$ are the ultimate base and limit shaft capacities. These quantities are calculated from:

$$
\begin{aligned}
& Q_{\mathrm{b}, \mathrm{ult}}=q_{\mathrm{b}} A_{\mathrm{b}} \\
& Q_{\mathrm{sL}}=A_{\mathrm{s}} \sum_{i=1}^{n} q_{\mathrm{si}} h_{\mathrm{si}}
\end{aligned}
$$

where the subscript $i$ represents a particular soil layer $(i=1,2,3, \ldots)$ for which shaft capacity is calculated; $\mathrm{n}$ is the total number of layers crossed by the pile; $q_{\mathrm{b}}$ and $q_{\mathrm{si}}$ are the 
unit base and shaft resistances; $A_{\mathrm{b}}\left(=\pi D_{\mathrm{b}}^{2} / 4\right)$ is the representative pile base area; $A_{\mathrm{s}}$ $\left(=\pi D_{\mathrm{s}}\right)$ is the pile shaft perimeter; $D_{\mathrm{b}}$ and $D_{\mathrm{s}}$ are the nominal diameters of the pile base and shaft, respectively; and $h_{\mathrm{si}}$ is the thickness of the $\mathrm{i}^{\text {th }}$ soil layer.

According to the guidelines provided by Huybrechts and Whenham (2003), the nominal shaft and base diameters depend on the drilling tool geometry. For the Atlas and Olivier piles, $D_{\mathrm{b}}$ and $D_{\mathrm{s}}$ are assumed to be equal to the measured maximum diameter $D_{\mathrm{f}}$ of the drilling auger screw blade (see Figure 2.10). Bustamante and Gianeselli (1993, 1998), however, suggested that the nominal diameter of the Atlas pile is equal to $0.9 D_{\mathrm{f}}$, except for the thick-flanged Atlas piles, for which they suggested a nominal diameter equal to $D_{\mathrm{f}}$. For the Fundex pile, $D_{\mathrm{b}}$ is equal to the measured maximum diameter of the conical auger tip, and $D_{\mathrm{s}}$ is equal to the measured maximum diameter of the casing/tube (Huybrechts and Whenham 2003). For other piles that also have a nearly smooth shaft, such as the De Waal and Omega piles, both $D_{\mathrm{s}}$ and $D_{\mathrm{b}}$ are taken as the diameter of the soil displacement body (which is equal to the maximum diameter of the screw blade; Huybrechts and Whenham 2003). No specific guidelines are given in the literature on nominal diameter values for use in the design of other types of DD piles.

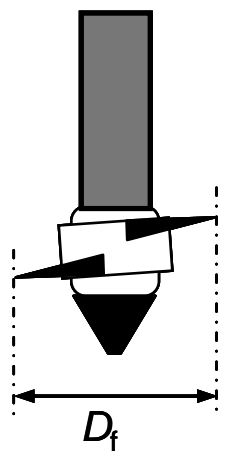

Atlas

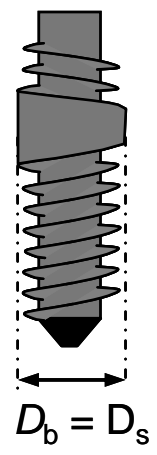

De Waal

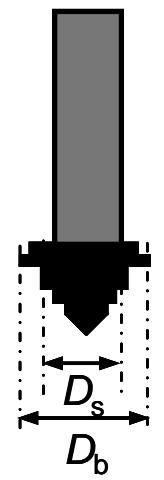

Fundex

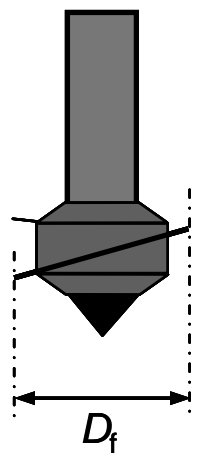

Olivier

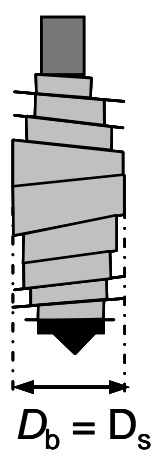

Omega

Figure 2.10 Design dimensions for some DD piles

Available empirical design methods for DD piles are mostly based on in situ test results. In this approach, the unit base and shaft resistances of piles are typically related to the 
cone penetration test (CPT) tip resistance $q_{\mathrm{c}}$, the standard penetration test (SPT) blow count $N$ or the pressuremeter test (PMT) limit pressure $p_{1}$.

\subsubsection{Calculations of Unit Base and Shaft Resistances: Method A}

Bustamante and Gianeselli $(1993,1998)$ developed a design method based on the results of 24 load tests on Atlas piles. They defined the ultimate pile load capacity as the load corresponding to $10 \%$ relative settlement (i.e., the load corresponding to a pile head settlement equal to $10 \%$ of the pile diameter). According to this method, the unit base resistance is given by

$$
q_{\mathrm{b}}=K \alpha
$$

where $K$ is a coefficient that depends on the soil type (Table 2.1), and $\alpha$ represents an average of the in situ test results within an influence zone extending from a distance $a$ above to $a$ below the pile base (Table 2.2). For the SPT-based design, the parameter $\alpha$ is the average (geometric mean) of $N_{1}, N_{2}$ and $N_{3}$ (see Table 2.2). For the PMT-based design, the parameter $\alpha$ is the average (geometric mean) of $p_{11}, p_{12}$ and $p_{13}$ (see Table 2.2). To obtain $\alpha$ from a CPT profile, the in situ $q_{\mathrm{c}}$ profile is modified within the influence zone. This is done in four successive stages: (i) the in situ $q_{\mathrm{c}}$ profile is smoothened to remove local irregularities within the influence zone, (ii) an arithmetic mean $q_{\mathrm{ca}}$ is calculated within the influence zone, (iii) a $q_{\mathrm{ce}}$ profile is obtained within the influence zone by applying bounds to the minimum and maximum resistances in the $q_{\mathrm{c}}$ profile: for the zone above the pile base, the resistance values are clipped between $0.7 q_{\mathrm{ca}}$ and $1.3 q_{\mathrm{ca}}$, and for the zone below the pile base, an upper bound of $1.3 q_{\mathrm{ca}}$ is applied, and (iv) the arithmetic mean $q_{\mathrm{ce}}$ value is calculated from the $q_{\mathrm{ce}}$ profile obtained in (iii).

To estimate the unit shaft resistance $q_{\mathrm{sL}}$, a design curve $\left(\mathrm{Q}_{1}, \mathrm{Q}_{2}, \mathrm{Q}_{3}, \mathrm{Q}_{4}\right.$, or $\left.\mathrm{Q}_{5}\right)$ is first selected depending on the soil type and the guidelines given in Table 2.3. Figure 2.11 is then used to estimate $q_{\mathrm{sL}}$ from the design curve selected. 
Table 2.1 Values of $K$ for different soil types (Bustamante and Gianeselli 1998)

\begin{tabular}{|c|c|c|c|}
\hline \multirow{2}{*}{$\begin{array}{c}\text { Soil } \\
\text { Type }\end{array}$} & \multicolumn{3}{|c|}{ In situ Tests } \\
\cline { 2 - 4 } Clay & $1.6-1.8$ & $0.55-0.65$ & $0.9-1.2$ \\
\hline Sand & $3.6-4.2$ & $0.50-0.75$ & $1.8-2.1$ \\
\hline${ }^{1}$ Gravel & $\geq 3.6$ & $\geq 0.5$ & - \\
\hline${ }^{1}$ Marl & $2.0-2.6$ & $\geq 0.7$ & $\geq 1.2$ \\
\hline${ }^{1}$ Chalk & $\geq 2.6$ & $\geq 0.6$ & $\geq 2.6$ \\
\hline
\end{tabular}

Table 2.2 Values of $\alpha$ and $a$ for different in situ tests (Bustamante and Gianeselli 1998)

\begin{tabular}{|c|c|c|c|c|}
\hline In situ Tests & Description of $\alpha(\mathrm{MPa})$ & $a$ & \multirow{4}{*}{ Pile Base } & \multirow{4}{*}{$\begin{array}{ll}N_{1} & p_{11} \\
a & \\
N_{2} & p_{12} \\
a & \\
N_{3} & p_{13}\end{array}$} \\
\hline SPT & $\sqrt[\mathrm{a}]{1000 \times \sqrt[3]{N_{1} \times N_{2} \times N_{3}}}$ & $0.5 \mathrm{~m}$ & & \\
\hline CPT & Arithmetic Mean of $q_{\mathrm{ce}}$ & $1.5 D_{\mathrm{b}}$ & & \\
\hline PMT & $\sqrt[3]{p_{11} \times p_{12} \times p_{13}}$ & $0.5 \mathrm{~m}$ & & \\
\hline
\end{tabular}

${ }^{\mathrm{a}}$ The factor 1000 is to maintain consistency of units

Table 2.3 Guidelines for selection of a design curve to estimate $q_{\mathrm{s}}$ from Figure 2.11 (Bustamante and Gianeselli 1998)

\begin{tabular}{|c|c|c|c|c|}
\hline \multirow{2}{*}{ Soil Type } & \multirow{2}{*}{$\begin{array}{c}\text { Limit pressure } \\
\text { from PMT }(\mathbf{M P a})\end{array}$} & $\begin{array}{c}\text { Cone Resistance } \\
(\mathbf{M P a})\end{array}$ & \multicolumn{2}{|c|}{ Curves } \\
\cline { 3 - 5 } & $<0.3$ & $\mathbf{C}$ & $\mathbf{M}$ \\
\hline Clay & $>0.5$ & $>1.5$ & $\mathrm{Q} 1$ & $\mathrm{Q} 1$ \\
/Clayey Silt & $\geq 1.0$ & $\geq 3.0$ & $\mathrm{Q} 3$ & $\mathrm{Q} 2$ \\
/Sandy Clay & $<0.3$ & $<1.0$ & $\mathrm{Q} 2$ \\
\hline \multirow{2}{*}{ Sand / } & $>0.5$ & $>3.5$ & $\mathrm{Q} 4$ & $\mathrm{Q} 1$ \\
Gravel & $\geq 1.2$ & $>8.0$ & $\mathrm{Q} 5$ & $\mathrm{Q} 2$ \\
\hline \multirow{2}{*}{ Marl } & $<1.2$ & $<4.0$ & $\mathrm{Q} 4$ & $\mathrm{Q} 2$ \\
& $\geq 1.5$ & $>5.0$ & $\mathrm{Q} 5$ & $\mathrm{Q} 2$ \\
\hline \multirow{2}{*}{ Chalk } & $>0.5$ & $>4.5$ & $\mathrm{Q} 4$ & $\mathrm{Q} 2$ \\
& $\geq 1.2$ & $\mathrm{Q} 5$ & $\mathrm{Q} 2$ \\
\hline \multicolumn{2}{|c|}{ C $=$ Cast-in-place screw piles, M= Screw piles with lost casing } \\
\hline
\end{tabular}




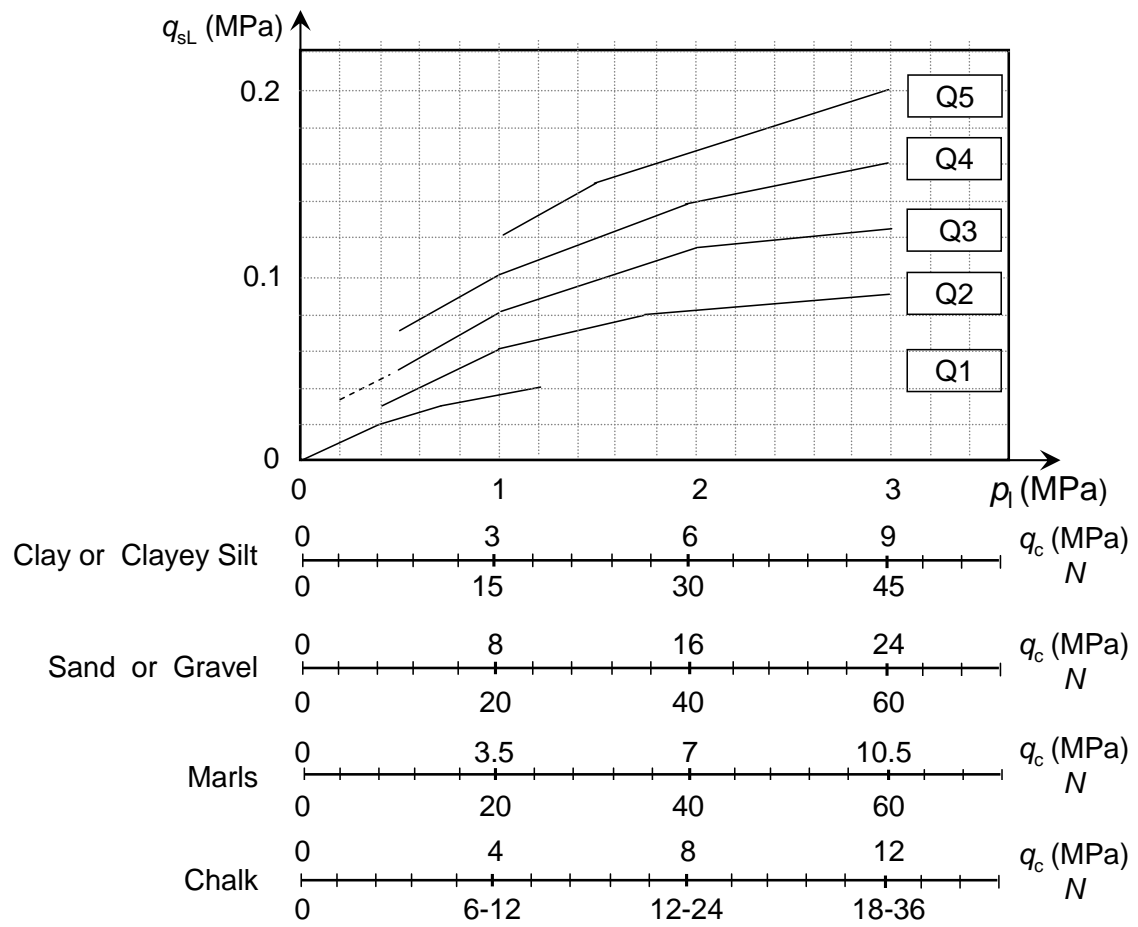

Figure 2.11 Values of unit shaft resistance $q_{\mathrm{sL}}$ as a function of $p_{1}, q_{\mathrm{c}}$, or $N$ (Bustamante and Gianeselli 1993, 1998)

The $q_{\mathrm{c}}$ value used to develop this method was obtained from penetration tests using an M1-type mechanical cone. When an electrical CPT cone is used, a correction factor $\beta$ is recommended as following

$$
q_{\mathrm{c}, \text { mech }}=\beta q_{\mathrm{c}, \text { elec }}
$$

where $q_{\mathrm{c} \text {,mech }}$ is the cone resistance measured with a mechanical cone, and $q_{\mathrm{c} \text {,elec }}$ is the cone resistance measured with an electrical cone. The coefficient $\beta$ is in the 1.4-1.7 range for clayey soils and is equal to 1.3 for saturated sands (Bustamante and Gianeselli 1993).

\subsubsection{Calculations of Unit Base and Shaft Resistances: Method B}

This design methodology was developed in the USA based on load tests performed on 28 APGD piles (NeSmith 2002; Brettmann and NeSmith 2005). The ultimate load (defined 
as 'interpreted failure load' by NeSmith 2002) was defined as the minimum of the loads corresponding to (i) a pile head settlement equal to $25.4 \mathrm{~mm}$ (1 inch) or (ii) a pile displacement rate equal to $0.057 \mathrm{~mm} / \mathrm{kN}$ (0.02 inch/ton). The specified value of the pile head settlement (i.e., $25.4 \mathrm{~mm}=1 \mathrm{inch}$ ) is equal to about $6 \%$ of the diameter of the piles tested [pile diameters ranged from $0.36 \mathrm{~m}$ to $0.46 \mathrm{~m}$ (14-18 inches), with $80 \%$ of the piles having a diameter equal to $0.41 \mathrm{~m}$ (16 inch)]. According to NeSmith (2002), the settlement-based criterion (pile head settlement equal to $25.4 \mathrm{~mm}$ ) controlled the determination of the ultimate load (or 'interpreted failure load'). Therefore, in this design method, the ultimate pile load capacity is based on a relative settlement of $6 \%$ (i.e., the load corresponding to a pile head settlement equal to $6 \%$ of the pile diameter). The unit base resistance $q_{\mathrm{b}}$ is given by:

$$
q_{\mathrm{b}}(\text { in } \mathrm{MPa})=0.4 q_{\mathrm{cm}}+w_{\mathrm{b}} \quad \text { for } q_{\mathrm{cm}} \leq 19 \mathrm{MPa}
$$

or

$$
q_{\mathrm{b}}(\text { in } \mathrm{MPa})=0.19 N_{\mathrm{m}}+w_{\mathrm{b}} \quad \text { for } N_{\mathrm{m}}<50
$$

where $q_{\mathrm{cm}}$ and $N_{\mathrm{m}}$ are representative values of $q_{\mathrm{c}}$ and uncorrected SPT blow count $N$ in the vicinity of the pile base, and $w_{\mathrm{b}}$ is a constant that depends on soil gradation and angularity. For soils containing uniform, rounded particles with up to $40 \%$ fines, $w_{\mathrm{b}}=0$, and the upper limit of $q_{\mathrm{b}}$ is $7.2 \mathrm{MPa}$. For soils with well-graded, angular particles having less than $10 \%$ fines, $w_{\mathrm{b}}=1.34 \mathrm{MPa}$, while, the upper limit for $q_{\mathrm{b}}$ is $8.62 \mathrm{MPa}$. Interpolation (based on percentage of fines) is suggested to determine the values of $w_{\mathrm{b}}$ for other types of soils (NeSmith 2002). $q_{\mathrm{cm}}$ and $N_{\mathrm{m}}$ are determined from the following equations (Fleming and Thorburn 1983):

$$
\begin{aligned}
& q_{\mathrm{cm}}=0.25 q_{\mathrm{c} 0}+0.25 q_{\mathrm{c} 1}+0.5 q_{\mathrm{c} 2} \\
& N_{\mathrm{m}}=0.25 N_{0}+0.25 N_{1}+0.5 N_{2}
\end{aligned}
$$


where $q_{\mathrm{c} 0}$ and $q_{\mathrm{c} 1}$ are the average and minimum cone resistances over a length of $4 D_{\mathrm{b}}$ below the pile base, respectively, and $q_{\mathrm{c} 2}$ is the average cone resistance over a length of $4 D_{\mathrm{b}}$ above the pile base after eliminating values greater than $q_{\mathrm{c} 1}(\mathrm{NeSmith} 2002) . N_{0}, N_{1}$ and $N_{2}$ refer to the corresponding uncorrected SPT values (equivalent to $q_{\mathrm{c} 0}, q_{\mathrm{c} 1}$, and $q_{\mathrm{c} 2}$ ).

The unit limit shaft resistance for any soil layer $i$ is given by:

$$
q_{\mathrm{sL}, \mathrm{i}}(\text { in } \mathrm{MPa})=0.01 q_{\mathrm{ci}}+w_{\mathrm{s}} \text { for } q_{\mathrm{ci}} \leq 19 \mathrm{MPa}
$$

Or

$$
q_{\mathrm{sL}, \mathrm{i}}(\text { in } \mathrm{MPa})=0.005 N_{\mathrm{i}}+w_{\mathrm{s}} \quad \text { for } N_{\mathrm{i}} \leq 50
$$

where $w_{\mathrm{s}}$ is a constant similar to $w_{\mathrm{b}}, q_{\mathrm{ci}}$ is the CPT cone resistance for soil layer $i$, and $N_{\mathrm{i}}$ is the uncorrected SPT blow count for soil layer $i$. For soils containing uniform, rounded particles with up to $40 \%$ fines, $w_{\mathrm{s}}=0$ and the limiting value of $q_{\mathrm{sL}, \mathrm{i}}$ is $0.16 \mathrm{MPa}$. For soils with well-graded, angular particles having less than $10 \%$ fines, $w_{\mathrm{s}}=0.05 \mathrm{MPa}$ and the limiting value of $q_{\mathrm{si}}$ is $0.21 \mathrm{MPa}$. Interpolation of $w_{\mathrm{s}}$ is suggested for intermediate soils.

This shaft capacity calculation method is recommended only for sandy soils, where pile installation results in soil densification. Note that, Brettmann and NeSmith (2005) recommended the use of energy-corrected SPT blow count $N_{60}$ values in Equations (2.10) and (2.11).

\subsubsection{Calculations of Unit Base and Shaft Resistances: Method C}

In this method (Belgian pile design practice), the capacity of DD piles are calculated using empirical expressions that were developed based mainly on CPT and pile load test results (Van Impe 1986, 1988, 2004; Bauduin 2001; Holeyman et al. 2001; De Vos et al. 2003; Maertens and Huybrechts 2003a). The design practice for DD piles was strongly influenced by the results of the pile load tests performed at the Sint-Katelijne-Waver and Limelette test sites (Holeyman 2001; Maertens and Huybrechts 2003b; Van Impe 2004); these load tests were supported by the Belgian Building Research Institute (BBRI). This 
method is applicable to all types of DD piles. The current Belgian practice follows the guidelines developed for the implementation of Eurocode 7 (Application de l'Eurocode 7 en Belgique 2008). The ultimate unit base resistance corresponding to $10 \%$ relative settlement is given by:

$$
q_{\mathrm{b}}=\lambda \alpha_{\mathrm{b}} \varepsilon_{\mathrm{b}} q_{\mathrm{b}, \mathrm{CPT}}
$$

where $\lambda$ is a reduction factor accounting for what was referred to as the "soil relaxation" that may take place around the shaft during the drilling process due to the presence of an enlarged base, $\alpha_{\mathrm{b}}$ is an empirical factor that accounts for the pile installation technique and soil type, $\varepsilon_{\mathrm{b}}$ is a scaling coefficient expressed as a function of the ratio of the diameter of the pile base $D_{\mathrm{b}}$ to that of the standard electrical CPT cone $d_{\mathrm{CPT}}(=35.7 \mathrm{~mm})$, and $q_{\mathrm{b}, \mathrm{CPT}}$ is the representative base resistance calculated from CPT resistance $q_{\mathrm{c}}$ profile according to the method proposed by De Beer (De Beer 1971, 1972; Van Impe 1986; Van Impe et al. 1988).

According to the recent guidelines presented in the Application of Eurocode 7 in the Belgian practice (Application de l'Eurocode 7 en Belgique, 2008), the factor $\lambda=1$ for all the DD piles considered in this paper, except for the Fundex pile. For the Fundex pile, the value of $\lambda$ is obtained from :

$$
\lambda\left\{\begin{array}{lr}
=1.0 ; & \left(\frac{D_{\mathrm{b}}}{D_{\mathrm{s}}}\right)^{2} \leq 1.5 \\
=1-0.429\left[\left(\frac{D_{\mathrm{b}}}{D_{\mathrm{s}}}\right)^{2}-1\right] ; 1.5<\left(\frac{D_{\mathrm{b}}}{D_{\mathrm{s}}}\right)^{2}<1.7 \\
=0.7 ; & \left(\frac{D_{\mathrm{b}}}{D_{\mathrm{s}}}\right)^{2} \geq 1.7
\end{array}\right.
$$

The factor $\alpha_{\mathrm{b}}$ varies between 0.7 and 0.8 (see Table 2.4). The coefficient $\varepsilon_{b}=\max \left[1-0.01\left(D_{\mathrm{b}} / d_{\mathrm{CPT}}-1\right) ; 0.476\right]$ for stiff, fissured tertiary clay, while, for all other soil types, $\varepsilon_{\mathrm{b}}=1.0$. 
To obtain $q_{\mathrm{b}, \mathrm{CPT}}$ from the in situ profile of CPT cone resistance $q_{\mathrm{c}}$, the in situ $q_{\mathrm{c}}$ profile is modified in different stages. These modifications are aimed at predicting a resistance profile that would be obtained if a sounding rod having the diameter equal to the pile diameter were used (Van Impe 1986; Van Impe et al. 1988). When the pile/cone tip penetrates through a ground with interchanging layers of soft and stiff soils, the pile/cone tip resistance is likely to be affected by the stiffness of the layers above and below. The penetration resistance gradually increases when a stiffer layer of soil underlies a softer layer. When a softer layer is present below a stiffer layer, the cone resistance gradually decreases. According to Van Impe (1986) and Van Impe et al. (1988) the zone of influence extends to a greater depth for a penetrating body with a larger diameter. Thus, the influence zone for a pile base will be larger than that of a CPT cone and, hence, the CPT resistance profile to be used in the pile capacity calculation needs to be corrected to account for this effect. The in situ $q_{\mathrm{c}}$ profile is modified in four steps as described next.

\section{Step 1. Calculation of a 'Homogeneous Value' of cone resistance}

A 'Homogeneous value' $q_{\mathrm{rb}}$ of cone resistance $q_{\mathrm{c}}$ accounts for the scale effect resulting from the different pile and cone geometries (Van Impe 1986 and Van Impe et al. 1988). Through the calculation of $q_{\mathrm{rb}}$ down to a certain depth (also known as the critical depth $h_{\text {cr }}$ for the cone and $H_{\text {cr }}$ for the pile), the in situ resistance is reduced. These $q_{\mathrm{rb}}$ values are calculated at every $0.2 \mathrm{~m}$. At a particular depth, $q_{\mathrm{rb}}$ is calculated as:

$$
q_{\mathrm{rb}}=\frac{q_{\mathrm{c}}}{e^{2\left(\beta_{\mathrm{c}}-\beta_{\mathrm{p}}\right) \tan \phi_{\mathrm{CPT}}}}
$$

where $\beta_{\mathrm{c}}$ and $\beta_{\mathrm{p}}$ are angles (in radians) related to the failure mechanism below the cone and pile base, respectively, and $\phi_{\mathrm{CPT}}$ is a friction angle deduced from the in situ friction angle $\phi$ of the soil. There is no mention in the literature whether the peak or the criticalstate friction angle of the soil is to be used in these calculations. The value of $\phi_{\mathrm{CPT}}$ is calculated from the following relationship: 


$$
\frac{q_{\mathrm{c}}}{\sigma_{\mathrm{v} 0}^{\prime}}=1.3\left[\left\{e^{2 \pi \tan \phi_{\mathrm{CPT}}} \tan ^{2}\left(\frac{\pi}{4}-\frac{\phi_{\mathrm{CPT}}}{2}\right)-1\right\} \frac{\tan \phi}{\tan \phi_{\mathrm{CPT}}}+1\right] ; \phi_{\mathrm{CPT}} \leq \phi
$$

where $\sigma_{\mathrm{v} 0}^{\prime}$ is the in situ vertical effective stress at the corresponding depth. The values of $\beta_{\mathrm{c}}$ and $\beta_{\mathrm{p}}$ vary from zero (at very small penetration depth) to $\pi / 2$ (at depths greater than the critical penetration depth). For a particular value of $\phi_{\mathrm{CPT}}, \beta_{\mathrm{c}}$ (for the cone) or $\beta_{\mathrm{p}}$ (for the pile) are determined from Figure 2.12 based on the penetration depth-to-diameter ratio ( $h / d$ for the cone, and $H / D_{\mathrm{b}}$ for the pile). According to Figure 2.12, both the angles $\beta_{\mathrm{c}}$ and $\beta_{\mathrm{p}}$ become equal to $\pi / 2(=1.57)$ when both the penetration depth-to-diameter ratios (h/d or $H / D_{\mathrm{b}}$ ) are greater than the critical values. $\beta_{\mathrm{c}}$ becomes equal to $\pi / 2$ at a depth greater than the critical depth $h_{\mathrm{cr}}$, whereas $\beta_{\mathrm{p}}$ becomes equal to $\pi / 2$ at a relatively larger depth $H_{\mathrm{cr}}$. Thus, for any depth greater than $H_{\mathrm{cr}}, \beta_{\mathrm{c}}=\beta_{\mathrm{p}}$; consequently, from Equation $2.15, q_{\mathrm{rb}}=q_{\mathrm{c}}$.

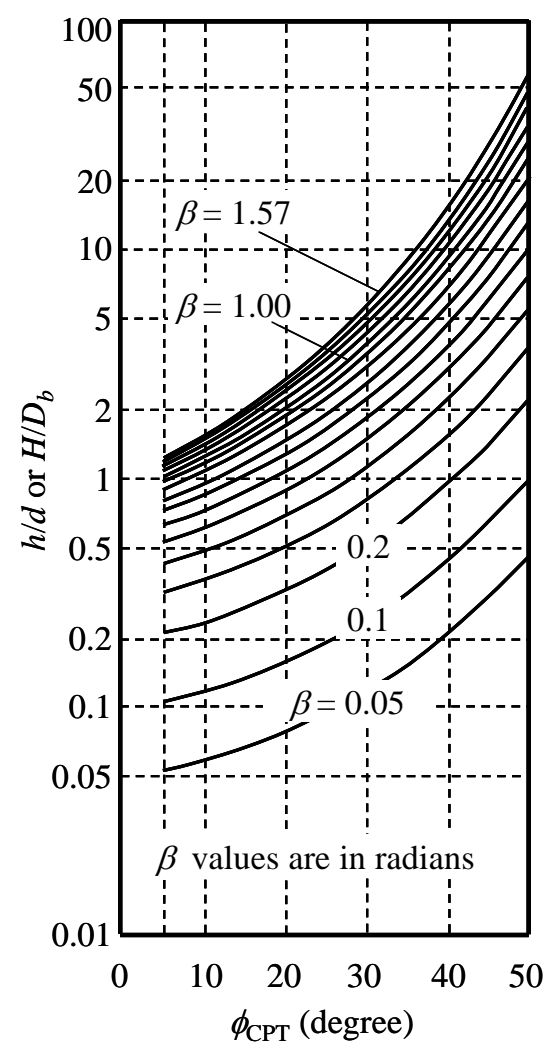

Figure 2.12 Values of $\beta$ for cone $\left(\beta_{\mathrm{c}}\right)$ and pile $\left(\beta_{\mathrm{p}}\right)$ based on $\phi_{\mathrm{CPT}}$ and penetration depth to diameter ratio (after Van Impe 1986; Van Impe et al. 1988) 
The resistance profile $q_{\mathrm{rb}}$ obtained in Step 1 does not account for the difference in the stiffness of the underlying or overlying soil layers. However, the stiffness of the soil layers may vary along depth and this variation in soil stiffness causes increase or decrease in the penetration resistance. The influence zone, which contributes to this variation of resistance, is greater for a bigger geometry; and therefore, the gradient of resistance increase (or decrease) for a pile should be different from that of a cone. To quantify the effect of varying soil stiffness with depth, further modifications of the 'homogeneous profile' are recommended. These modifications are described in the following steps.

\section{Step 2. Calculation of the 'Downward Value' of Cone Resistance}

'Downward values' of cone resistance $q_{\mathrm{rb}}{ }^{\mathrm{d}}$ are calculated to limit the gradient of the increase of resistance with depth (when the stiffness of soil layers increase with depth). The 'homogeneous profile' $q_{\mathrm{rb}}$ is replaced by 'downward value' profile. $q_{\mathrm{rb}}{ }^{\mathrm{d}}$ at any particular depth is restricted to a maximum value equal to $q_{\mathrm{rb}}$ at that depth. Mathematically, $q_{\mathrm{rb}}{ }^{\mathrm{d}}$ is given by:

$$
q_{\mathrm{rb}, \mathrm{j}+1}^{\mathrm{d}}=q_{\mathrm{rb}, \mathrm{j}}+\frac{d}{D_{\mathrm{b}}}\left[\left(\frac{\sigma_{\mathrm{v} 0, \mathrm{j}}^{\prime}+\frac{\gamma z D_{\mathrm{b}}}{2 d}}{\sigma_{\mathrm{v} 0, \mathrm{j}}^{\prime}+\frac{\gamma z}{2}}\right) q_{\mathrm{rb}, \mathrm{j}+1}-q_{\mathrm{rb}, \mathrm{j}}\right] \leq q_{\mathrm{rb}, \mathrm{j}+1}
$$

where the indices ' $\mathrm{j}$ ' and ' $\mathrm{j}+1$ ' represent two points at a distance $z$ (arbitrarily suggested to be equal to $0.2 \mathrm{~m}$ ) apart from each other with the counter $\mathrm{j}$ increasing with depth (i.e., the point ' $\mathrm{j}+1$ ' is at a greater depth than the point ' $\mathrm{j}$ '). $\sigma_{\mathrm{v} 0}^{\prime}$ is the in situ vertical effective stress at the depth under consideration, as denoted by the counter $\mathrm{j}$, and $\gamma$ is the average unit weight of the soil.

\section{Step 3. Calculation of the 'Upward Value' of Cone Resistance}

The 'upward values' $q_{\mathrm{rb}}^{\mathrm{u}}$ at different depths are calculated using 'downward values' $q_{\mathrm{rb}}{ }^{\mathrm{d}}$ obtained in Step 2 . This correction to the 'downward values' are done to limit the gradient of decreasing resistance (which is the case when the stiffness decreases with depth). The corrections to the resistance values are started from the bottom most point 
(where 'upward value' is considered to be the same as 'downward value') proceeding upward to the ground surface with an objective to limit the upward gradient of resistance (if the resistance decreases with depth, moving from bottom to top will result in increasing resistance; and the same correction philosophy, as used in Step 2, can be used). Corrections are made at each previous calculation points (apart by a distance of $0.2 \mathrm{~m}$ ) and the resistance profile is updated at those points by replacing the 'downward values' by the 'upward values'. For two successive points ' $q$ ' and ' $q+1$ ' (the point ' $q$ ' is at a greater depth than the point ' $\mathrm{q}+1$ ') $z$ distance apart, the upward value at point ' $\mathrm{q}+1$ ' is calculated as:

$$
q_{\mathrm{rb}, \mathrm{q}+1}^{\mathrm{u}}=q_{\mathrm{rb}, \mathrm{q}}+\frac{2 d}{D_{\mathrm{b}}}\left[q_{\mathrm{rb}, \mathrm{q}+1}{ }^{\mathrm{d}}-q_{\mathrm{rb}, \mathrm{q}}\right] \leq q_{\mathrm{rb}, \mathrm{q}+1}{ }^{\mathrm{d}}
$$

\section{Step 4. Blending the Values of the Updated Resistance Profile}

To obtain a representative resistance $q_{\mathrm{b}, \mathrm{CPT}}$ at the pile base, the 'blended' or 'mixed' value is calculated by taking an arithmetic mean of the resistance values from the $q_{\mathrm{rb}}{ }^{\mathrm{u}}$ profile over a distance equal to the diameter of the pile below the pile base. This average value $\mathrm{q}_{\mathrm{b}, \mathrm{CPT}}$ is finally used to calculate the ultimate unit base resistance $q_{\mathrm{b}}$.

The unit shaft resistance $q_{\mathrm{SL}, \mathrm{i}}$ for the $\mathrm{i}^{\text {th }}$ soil layer is related to the average cone resistance $q_{\mathrm{ci}}$ (obtained using a standard electrical cone) of that layer by:

$$
q_{\mathrm{sL}, \mathrm{i}}=\alpha_{\mathrm{si}} \eta_{\mathrm{p}}^{*} q_{\mathrm{ci}}
$$

where $\alpha_{\mathrm{si}}$ and $\eta_{\mathrm{p}}{ }^{*}$ are empirical factors. $\alpha_{\mathrm{si}}$ depends on the method of installation in a particular soil and the roughness of the pile shaft (see Table 2.4). Table 2.5 shows the values of $\eta_{\mathrm{p}}{ }^{*}$, which depends on soil type and $q_{\mathrm{ci}}$. Beyond a certain value of $q_{\mathrm{ci}}$, a maximum design value is prescribed for $q_{\mathrm{si}}$ (Table 2.5). Note that, in the shaft capacity calculations, contributions of soil layers with $q_{\mathrm{ci}}<1 \mathrm{MPa}$ are neglected. 
Table 2.4 Values of $\alpha_{\mathrm{b}}$ and $\alpha_{\mathrm{si}}$ for use in Equations (2.12) and (2.18) (from Application de l'Eurocode 7 en Belgique 2008)

\begin{tabular}{|c|c|c|c|c|}
\hline \multirow{2}{*}{ Pile Types } & \multicolumn{2}{|c|}{$\alpha_{\mathbf{b}}$} & \multicolumn{2}{c|}{$\alpha_{\text {si }}$} \\
\cline { 2 - 5 } & $\begin{array}{c}\text { Tertiary } \\
\text { Clay }\end{array}$ & Other Soils & $\begin{array}{c}\text { Tertiary } \\
\text { Clay }\end{array}$ & Other Soils \\
\hline $\begin{array}{c}\text { Piles cast } \text { in situ } \\
\text { using concrete }\end{array}$ & 0.8 & 0.7 & 0.9 & 1.0 \\
\hline $\begin{array}{c}\text { Piles cast using lost } \\
\text { casing }\end{array}$ & 0.8 & 0.8 & 0.6 & 0.6 \\
\hline
\end{tabular}

Table 2.5 Values of $\eta_{\mathrm{p}}{ }^{*}$ for use in Equation (2.18) (from Application de l'Eurocode 7 en Belgique 2008)

\begin{tabular}{|c|c|c|c|}
\hline Soil Type & $\begin{array}{c}\text { Average Cone Resistance } \boldsymbol{q}_{\mathbf{c i}} \\
(\mathbf{M P a})\end{array}$ & $\boldsymbol{\eta}_{\mathbf{p}}{ }^{*}$ & Maximum $\boldsymbol{q}_{\mathbf{s i}}(\mathbf{M P a})$ \\
\hline Clay & $1-4.5$ & 0.0333 & $\begin{array}{c}0.150 \text { for } q_{\mathrm{ci}}>4.5 \\
\mathrm{MPa}\end{array}$ \\
\hline Silt & $1-6$ & 0.0167 & 0.100 for $q_{\mathrm{ci}}>6 \mathrm{MPa}$ \\
\hline $\begin{array}{c}\text { Sandy Silt/Clay } \\
\text { or } \\
\begin{array}{c}\text { Clayey } \\
\text { Silt/Sand }\end{array}\end{array}$ & $1-10$ & 0.0125 & 0.125 for $q_{\mathrm{ci}}>10 \mathrm{MPa}$ \\
\hline \multirow{2}{\text{Sand}}{} & $1-10$ & 0.0111 & - \\
\cline { 2 - 4 } & $10-20$ & - & $0.110+0.004\left(q_{\mathrm{ci}}-10\right)$ \\
\cline { 2 - 4 } & $>20$ & - & 0.150 \\
\hline
\end{tabular}

The Belgian practice for DD piles, as described in this section, relies on the $q_{\mathrm{c}}$ values obtained using an electrical cone. A reduction factor $\omega$ is suggested (see Table 2.6) for $q_{\mathrm{c}}$ values obtained from CPTs performed in tertiary clay using a mechanical cone (i.e., $\left.q_{\mathrm{c}, \text { elec }}=q_{\mathrm{c}, \mathrm{mech}} / \omega\right)$.

Table 2.6 Reduction factor $\omega$ (from Application de l'Eurocode 7 en Belgique 2008)

\begin{tabular}{|c|c|c|}
\hline Type of Mechanical Cone & Tertiary Clay & Other Types of Soil \\
\hline M1 & 1.3 & 1.0 \\
\hline M2 & 1.3 & 1.0 \\
\hline M4 & 1.15 & 1.0 \\
\hline
\end{tabular}


The available empirical design methods were developed based on field load tests either on a particular type of DD pile (e.g., Methods A and B) or at particular sites (e.g., Method C). Therefore, these methods are strictly valid for conditions for which they were developed. Additionally, Method C, in particular, involves many complicated steps which were introduced with the objective of producing good match between predictions and measurements. The regular use of this method in practice would certainly require the aid of a computer program developed specifically for this method.

\subsection{Capacity Calculations Using Existing Design Methods}

We selected the soil profiles of two well documented pile load test sites to evaluate the different methods of pile capacity calculation described above. The first test site is at Limelette, Belgium; this site was used for the load test program supported by the BBRI. The second test site is located at the Georgia Institute of Technology campus; this test site was used for a load test program on drilled shafts.

\subsubsection{Test Site at Limelette, Belgium}

The pile load test site at Limelette, Belgium, consists of a silty and sandy clay layer down to a depth of $8.2 \mathrm{~m}$; this layer is underlain by a clayey sand layer (Van Alboom and Whenham 2003). The water table at the site is located at a depth well below the base of the test piles. Five different types of DD piles were installed and subjected to static load tests (SLTs). The pile geometries, as obtained from Huybrechts and Whenham (2003), are given in Table 2.7. All the test piles, except the Fundex piles, have the same nominal shaft and base diameters $\left(D_{\mathrm{s}}\right.$ and $\left.D_{\mathrm{b}}\right)$ for calculation of base and shaft resistances (the nominal design diameters were selected following the guidelines described in the previous section of this chapter). 
Table 2.7 Pile geometries (Huybrechts and Whenham 2003)

\begin{tabular}{|c|c|c|c|c|}
\hline \multirow{2}{*}{ Pile Tag } & \multirow{2}{*}{ Pile Type } & $D_{\mathrm{s}}$ & $D_{\mathrm{b}}$ & $L$ \\
\hline & & (m) & (m) & (m) \\
\hline B3 & \multirow{2}{*}{ Atlas } & \multirow{2}{*}{0.51} & \multirow{2}{*}{0.51} & \multirow{2}{*}{9.43} \\
\hline B4 & & & & \\
\hline A4 & \multirow{2}{*}{ DeWaal } & \multirow{2}{*}{0.41} & \multirow{2}{*}{0.41} & \multirow{2}{*}{9.53} \\
\hline $\mathrm{C} 4$ & & & & \\
\hline A1 & \multirow{2}{*}{ Fundex } & \multirow{2}{*}{0.39} & \multirow{2}{*}{0.45} & 9.59 \\
\hline $\mathrm{C} 1$ & & & & 9.65 \\
\hline $\mathrm{A} 2$ & \multirow{2}{*}{ Olivier } & \multirow{2}{*}{0.55} & \multirow{2}{*}{0.55} & 9.20 \\
\hline $\mathrm{C} 2$ & & & & 9.13 \\
\hline A3 & \multirow{2}{*}{ Omega } & \multirow{2}{*}{0.41} & \multirow{2}{*}{0.41} & \multirow{2}{*}{9.45} \\
\hline C3 & & & & \\
\hline
\end{tabular}

We used the average cone resistance profiles [obtained from CPTs using an electrical cone (for use in Methods B and C) and a mechanical M1-type cone (for use in Method A)], reproduced in Figure 2.13, to calculate the ultimate pile capacities. Figure 2.13 also shows the modified cone resistance profile used for obtaining $q_{\mathrm{b}, \mathrm{CPT}}$ for use in design method C. The calculated ultimate capacities of the test piles are given in Table 2.8, which also includes the reported ultimate capacities of the piles obtained from the SLT results (Maertens and Huybrechts 2003a). For piles A2, B3, B4, C1 and C2, SLTs could not be continued up to a pile head settlement of $10 \%$ of the pile diameter. For these piles, Chin's method of extrapolation (Chin 1970) was used to extend the load-settlement curves; the ultimate capacities of these piles were obtained from the extrapolated curves as the loads corresponding to a pile head settlement equal to $10 \%$ of the pile diameter (Maertens and Huybrechts 2003a). 


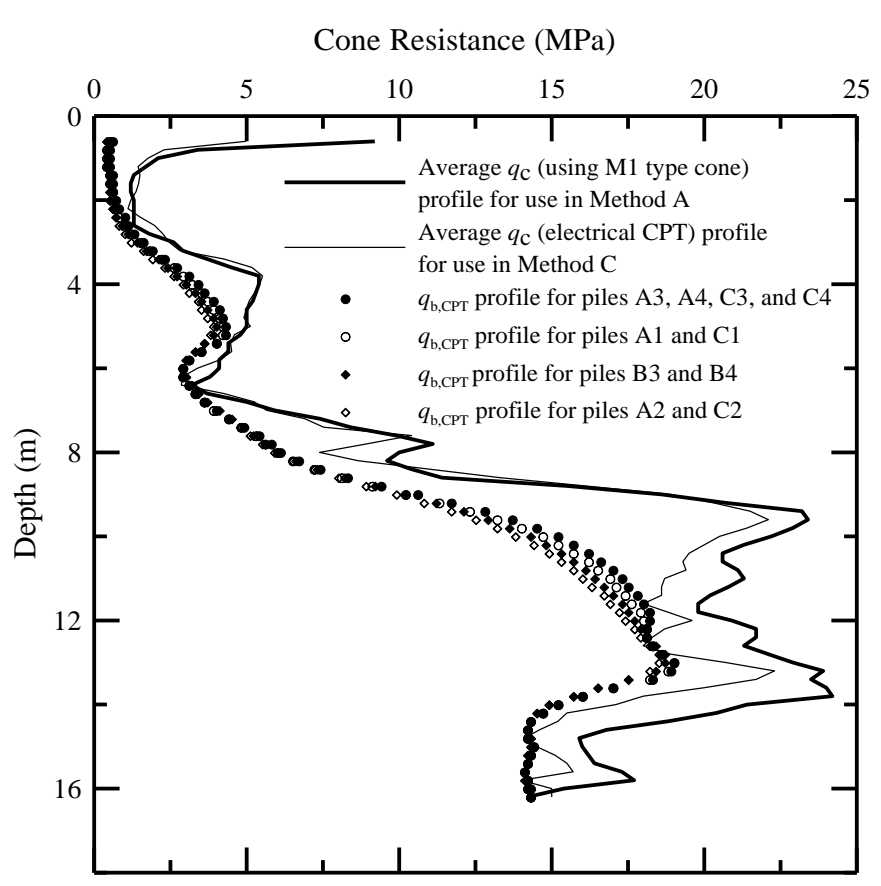

Figure 2.13 Average and modified cone resistance profiles at the Limelette test site

As can be seen in Table 2.8, the smallest base capacity estimates were obtained with Method A (originally developed for APGD piles). Note that method A could not be used for shaft capacity calculations at this site because the test piles were installed mostly in clayey soils, for which method A is not applicable. Base capacity estimates obtained with method B, (originally developed for the Atlas pile) were larger than those (by 2638\%) calculated using method C. However, the shaft capacity estimates of methods B and $\mathrm{C}$ were in good agreement (within 3\%).

The total ultimate capacities calculated using method B are consistently higher than the capacities obtained from the SLTs; maximum difference was obtained for DeWaal and Olivier piles (for these two pile types, the total ultimate capacities estimated using method B were larger than the SLT capacities by $17 \%$ and 20\%, respectively). For the Olivier pile A2, the total ultimate capacity calculated using method $\mathrm{C}$ is in good 
agreement (the difference is $\sim 1 \%$ ) with the ultimate capacity obtained from the extrapolated load-settlement curve. For the Atlas, Omega and Fundex A1 piles, the total ultimate capacities estimated using method C were smaller (by 11\%, 13\% and 14\%, respectively) than the SLT capacities. For the DeWaal piles, the total ultimate capacities obtained with method C were larger (by 5\%) than the SLT capacities.

Table 2.8 Ultimate capacities of different DD piles at the Limelette test site, Belgium

\begin{tabular}{|c|c|c|c|c|c|c|c|c|c|}
\hline \multirow[t]{3}{*}{$\begin{array}{l}\text { Pile } \\
\text { Tag }\end{array}$} & \multirow[t]{3}{*}{$\begin{array}{c}\text { Pile } \\
\text { Type }\end{array}$} & \multicolumn{3}{|c|}{$\begin{array}{c}\text { Calculated Base } \\
\text { Capacity } \\
(\mathbf{k N})\end{array}$} & \multicolumn{2}{|c|}{$\begin{array}{c}\text { Calculated } \\
\text { Shaft Capacity } \\
(\mathbf{k N})\end{array}$} & \multicolumn{2}{|c|}{$\begin{array}{c}\text { Calculated } \\
\text { Total } \\
\text { Capacity } \\
(\mathbf{k N})\end{array}$} & \multirow{3}{*}{$\begin{array}{l}\text { Capacity } \\
\text { Obtained } \\
\text { from SLT } \\
\quad(\mathbf{k N})\end{array}$} \\
\hline & & \multicolumn{7}{|c|}{ Different Design Methods } & \\
\hline & & $\mathbf{A}$ & $\mathbf{B}$ & $\mathbf{C}$ & $\mathbf{A}$ & $\mathbf{C}$ & $\mathbf{A}$ & $\mathbf{C}$ & \\
\hline B3 & \multirow{2}{*}{ Atlas } & \multirow{2}{*}{2160} & \multirow{2}{*}{1220} & \multirow{2}{*}{1460} & \multirow{2}{*}{1648} & \multirow{2}{*}{1671} & \multirow{2}{*}{3808} & \multirow{2}{*}{3131} & ${ }^{\mathrm{a}} 3528$ \\
\hline B4 & & & & & & & & & a3454 \\
\hline A4 & \multirow{2}{*}{$\begin{array}{c}\text { De } \\
\text { Waal }\end{array}$} & \multirow{2}{*}{1456} & \multirow{2}{*}{832} & \multirow{2}{*}{1079} & \multirow{2}{*}{1351} & \multirow{2}{*}{1363} & \multirow{2}{*}{2807} & \multirow{2}{*}{2442} & 2400 \\
\hline $\mathrm{C} 4$ & & & & & & & & & 2248 \\
\hline A1 & \multirow{2}{*}{ Fundex } & 1776 & \multirow{2}{*}{992} & 1312 & 1300 & 1309 & 3076 & 2621 & 2988 \\
\hline $\mathrm{C} 1$ & & 1808 & & 1344 & 1313 & 1318 & 3121 & 2662 & $\mathrm{a}, \mathrm{b} 1778$ \\
\hline A2 & \multirow{2}{*}{ Olivier } & 2496 & 1440 & 1560 & 1714 & 1757 & 4210 & 3317 & a 3354 \\
\hline $\mathrm{C} 2$ & & 2400 & 1416 & 1488 & 1694 & 1742 & 4094 & 3230 & a, b2908 \\
\hline A3 & \multirow{2}{*}{ Omega } & \multirow{2}{*}{1456} & \multirow{2}{*}{806} & \multirow{2}{*}{1079} & \multirow{2}{*}{1333} & \multirow{2}{*}{1350} & \multirow{2}{*}{2789} & \multirow{2}{*}{2429} & 2786 \\
\hline C3 & & & & & & & & & 2723 \\
\hline \multicolumn{10}{|c|}{$\begin{array}{l}{ }^{\mathrm{a}} \text { Values (corresponding to a pile head settlement equal to } 10 \% \text { of the pile diameter) are } \\
\text { obtained from extrapolated load-settlement curves (Maertens and Huybrechts 2003a) } \\
\text { b Low ultimate capacities of } \mathrm{C} 1 \text { and } \mathrm{C} 2 \text { are attributed to the segregation of concrete and } \\
\text { structural rupture (Maertens and Huybrechts 2003a) }\end{array}$} \\
\hline
\end{tabular}

\subsubsection{Test Site at Georgia Institute of Technology, USA}

We used the residual soil profile at the Georgia Institute of Technology test site to calculate and compare the capacities of a DD pile (using design methods A, B and C), a full-displacement pile and a nondisplacement pile. Stratigraphic information for this site 
is available from the results of in situ and laboratory tests performed as a part of the site characterization program (FHWA Technical Report 1993). The subsurface at this site consists of a silty sand (SM) layer extending down to depths ranging from $15.8 \mathrm{~m}$ to 19.7 $\mathrm{m}$; this silty sand layer is underlain by a partially-weathered rock bed. A fill layer (0.6-3.7 $\mathrm{m}$ thick), comprised mostly of silt and sand, is present above the silty sand layer. The ground water table was recorded (at the time of site characterization) at depths ranging from $16.7 \mathrm{~m}$ to $19.1 \mathrm{~m}$ from the ground surface. Particle size analysis of the collected samples revealed that the site consists of mostly uniform sand particles (median $D_{50}=$ $0.14 \mathrm{~mm}$ ) with $33 \%$ fines. The average total unit weight assumed in calculations was 19.2 $\mathrm{kN} / \mathrm{m}^{3}$ (FHWA Technical Report 1993). Figure 2.14 shows an average CPT profile of this site; this figure also shows the modified cone resistance profile used to obtain $q_{\mathrm{b}, \text { CPT }}$ for use in design method $\mathrm{C}$.

The DD, full-displacement, and nondisplacement piles were assumed to be 10-m long with nominal base and shaft diameter equal to $0.4 \mathrm{~m}$. We used CPT-based methods (Aoki and Velloso 1975; Schmertmann 1978; Lopes and Laprovitera 1988; and Franke 1989) to calculate the base and shaft capacities of the full-displacement and nondisplacement piles in sand. Table 2.9 shows the calculated capacities for all these piles. It is interesting to note that the capacity of the DD pile calculated using method A is larger than that of the full-displacement pile with the same geometry. The DD pile capacity obtained with Method B, however, lies between the capacities calculated for the full-displacement and nondisplacement piles (this is in agreement with the notion that the soil displacement produced during the installation of a DD pile is in the range of that of a partial- to that of a full-displacement pile). The DD pile capacity calculated using Method C matches closely the capacity of the full-displacement pile calculated with the Aoki and Velloso (1975) and Schmertmann (1978) methods. Note that general conclusions can not be reached based on the calculations presented in Table 2.9; they provide only a sitespecific comparison of capacities. 


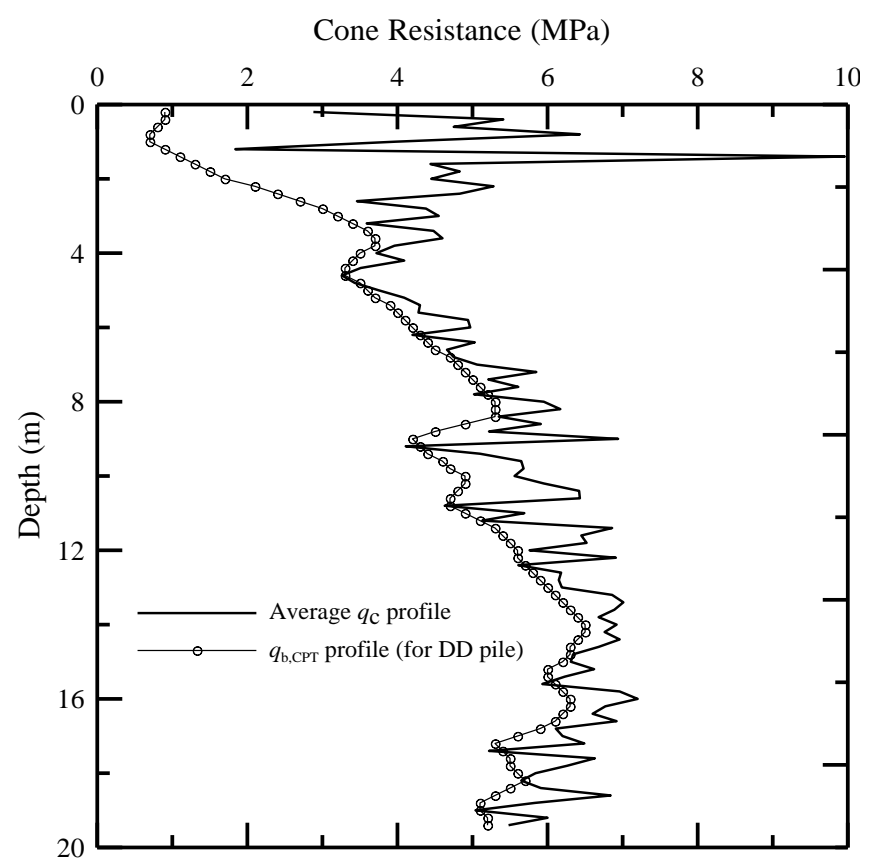

Figure 2.14 Average and modified cone resistance profiles at the Georgia Institute of Technology test site

Table 2.9 Calculated capacities for a DD pile, a full-displacement pile, and a nondisplacement pile (soil profile of the Georgia Institute of Technology test site)

\begin{tabular}{|c|c|c|c|c|c|c|c|c|c|}
\hline \multirow[t]{2}{*}{ Pile Types } & \multicolumn{3}{|c|}{$\begin{array}{l}\text { Shaft Capacity } \\
(\mathbf{k N})\end{array}$} & \multicolumn{3}{|c|}{$\begin{array}{c}\text { Base Capacity } \\
(\mathbf{k N})\end{array}$} & \multicolumn{3}{|c|}{$\begin{array}{l}\text { Total Capacity } \\
\qquad(k N)\end{array}$} \\
\hline & \multicolumn{3}{|c|}{ Method } & \multicolumn{3}{|c|}{ Method } & \multicolumn{3}{|c|}{ Method } \\
\hline \multirow{2}{*}{ DD Pile } & A & B & $\mathrm{C}$ & A & B & $\mathrm{C}$ & A & B & $\mathrm{C}$ \\
\hline & 955 & 596 & 668 & 459 & 236 & 387 & 1414 & 832 & 1055 \\
\hline \multirow{2}{*}{$\begin{array}{l}\text { Full-displacement } \\
\text { Pile }\end{array}$} & \multicolumn{3}{|c|}{$\begin{array}{l}\text { Schmertmann } \\
\text { (1978) }\end{array}$} & \multicolumn{3}{|c|}{$\begin{array}{c}\text { Aoki and Velloso } \\
\text { (1975) }\end{array}$} & \\
\hline & \multicolumn{3}{|c|}{704} & \multicolumn{3}{|c|}{427} & \multicolumn{3}{|c|}{1131} \\
\hline \multirow[t]{2}{*}{$\begin{array}{l}\text { Nondisplacement } \\
\text { Pile }\end{array}$} & \multicolumn{3}{|c|}{$\begin{array}{l}\text { Lopes and } \\
\text { Laprovitera } \\
\text { (1988) }\end{array}$} & \multicolumn{3}{|c|}{ Franke (1989) } & \multicolumn{3}{|c|}{ - } \\
\hline & \multicolumn{3}{|c|}{251} & \multicolumn{3}{|c|}{151} & \multicolumn{3}{|c|}{402} \\
\hline
\end{tabular}




\subsection{Summary of Existing Knowledge}

Drilled displacement piles are increasingly used in geotechnical practice. The advantages of these piles are that their construction is fast, economical and environmentally friendly. Depending on the method of installation, DD piles can be classified as partialdisplacement piles, with capacities sometimes approaching that of full-displacement piles. Different DD pile installation methods (with different drilling tools) produce different changes in the state of the soil surrounding the pile, leading to different pile load-carrying capacities. Additionally, for the same degree of soil disturbance, a screwshaped shaft may develop a larger shaft capacity than a smooth shaft. The design methods described in this chapter were developed based on pile load tests performed at particular test sites. Consequently, these methods have biases and may not be strictly applicable to other sites without proper calibration. Bustamante and Gianeselli (1998) pointed out that there is lack of experience with DD piling technologies in soils like marls, gravels and chalk.

In order to illustrate the capabilities of currently available design methods, we used these methods to estimate the capacities of the DD piles load-tested at the Limelette test site in Belgium. Additionally, we compared the capacities of DD, full-displacement and nondisplacement piles for a residual soil profile of granite. The comparisons of the calculated and measured pile capacities show that improvements in the design methods are necessary. In particular, future development of DD pile design methods should include (1) parameters that reflect the pile installation method and their impact on the state of the soil around the pile; (2) interaction of the pile and soil in a way that reflects the stress-strain response of the soil; (3) limit states that must be prevented. 


\section{CHAPTER 3. THE FINITE ELEMENT METHOD APPLIED TO THE SHAFT RESISTANCE PROBLEM}

\subsection{Introduction}

In this chapter we describe different aspects of the one-dimensional (1-D) finite element (FE) model that we use to model installation and loading of a DD pile in sand. We consider installation in sand to be a fully drained process. These analyses are valid for DD piles installed using drilling tools that have enlarged (large-diameter) displacement bodies. The finite element analysis (FEA) uses a two-surface plasticitybased constitutive model for sand.

\subsection{Mathematical Formulation}

We perform 1-D FEA to model the installation and the subsequent loading of a DD pile in sand. As the installation of DD piles is a complex process to model, we idealized the installation through a sequence of modeling stages. The FEA involves three distinct stages: (i) insertion of the drilling tool into the ground (drilling), (ii) removal of the drilling tool from the ground, and (iii) loading of the pile.

\subsubsection{Simulation of Pile Installation and Loading}

Figure 3.1 shows schematically the idealized stages involved in the installation and loading of a DD pile. The insertion (drilling) of the drilling tool (that has a large-diameter displacement body) into the ground and its extraction cause shearing of the soil through a combination of three loading modes: i) cavity expansion, ii) torsional shearing (on the borehole wall), and iii) vertical shearing (either on the borehole wall during drilling and 
extraction of the drilling tool, or along the pile shaft-soil interface during loading of the pile).

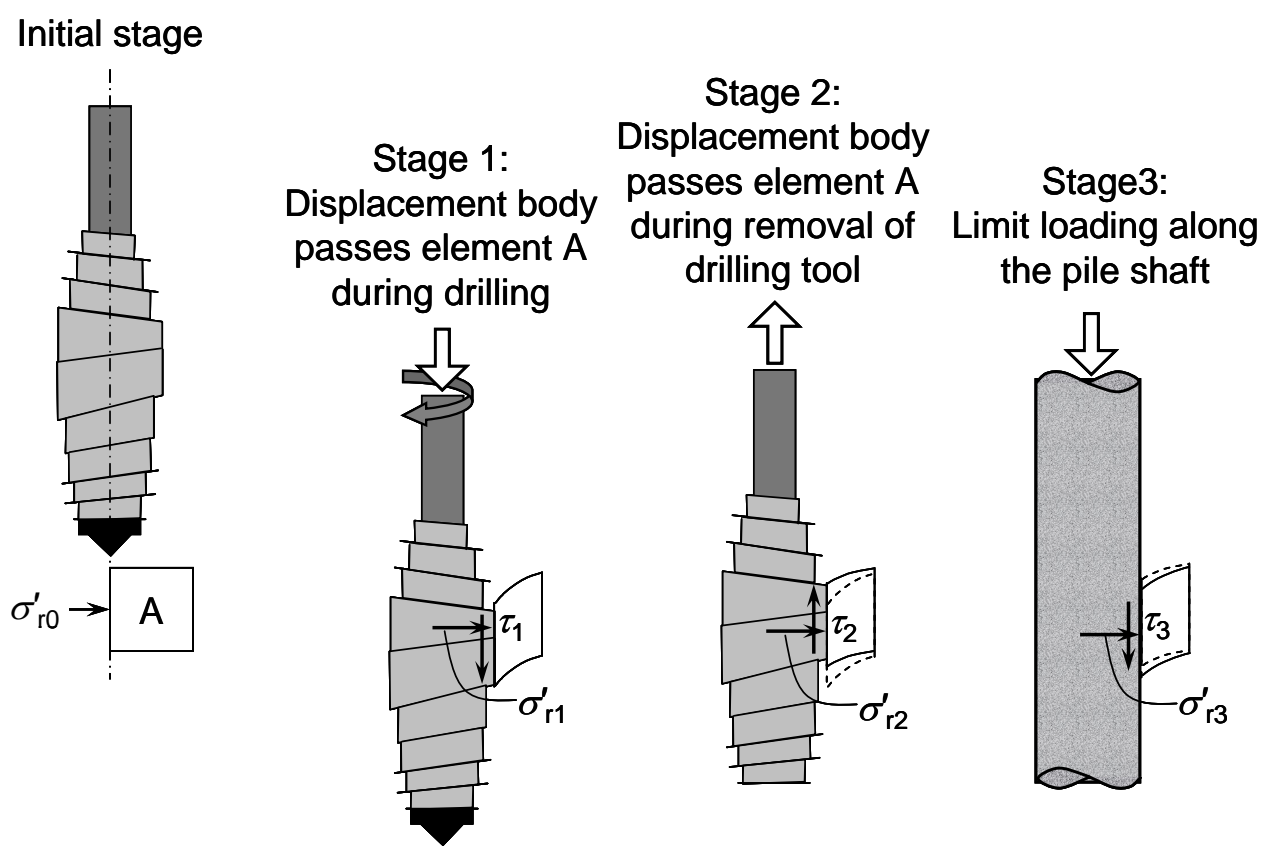

Torsional shear stress acting on the soil element in the Stage 1 is not shown

Figure 3.1 Idealization of the installation and loading of a DD pile

Before the drilling tool is inserted into the ground, the soil element A shown in Figure 3.1 is subjected to the in situ stress state. As the drilling tool passes element A (Stage 1), this element is pushed away (in the radial direction) from the path of the drilling tool. Along with the radial displacement, element A also undergoes torsional and vertical shearing in Stage 1. We model the radial displacement of the soil (caused by the passing of the largediameter displacement body at a given elevation) around the drilling tool by simulating a cylindrical cavity expansion within the ground. At the end of the cavity expansion, the left boundary of element A merges with the wall of the displacement body. After the cavity expansion phase is complete, we simultaneously apply torsional and vertical shearing to soil element $\mathrm{A}$ (which is adjacent to the wall of the displacement body). This part of the analysis indirectly accounts for any torsional and vertical shearing (loading components that are not part of the cylindrical cavity expansion process) that may occur 
when the drilling tool passes element A. During drilling, the rotational motion of the auger causes some soil to enter the spaces in between the auger flights. The soil within the auger flights will provide some passive resistance to the soil adjacent to it. However, our model does not account for the soil within the auger flights. Therefore, this passive resistance offered by the soil within the flights of the auger segment is neglected in our analysis. By the end of Stage 1, a limit state (critical state) is reached, and a shear band is formed around the drilling tool.

We perform some additional analyses, referred to as coupled analyses, in which cylindrical cavity expansion is coupled with vertical and torsional shearing to model the drilling process. The main uncertainties involved in these coupled analyses are related to the ratios of radial, vertical and torsional displacements. For this reason, we perform a parametric study to quantify the effect of the coupled displacement application during Stage 1 on the limit unit shaft resistance of the pile.

Stage 2 represents the extraction of the drilling tool from the ground. During this process, the displacement body applies an upward vertical shearing to the soil adjacent to it. We model this stage by applying upward vertical shearing on the left boundary of element A until a limit state is reached. This limit state is different from the one reached at the end of drilling. In the subsequent stage (Stage 3), we model the loading of the pile by re-applying downward vertical shearing on the left boundary of element A, which is now adjacent to the pile shaft-soil interface. A limit condition is once again reached at the left boundary of element $\mathrm{A}$ at the end of Stage 3. This stage represents either the application of the structural load or the performance of a static pile load test.

Between Stage 1 (when the large diameter displacement body clears element A) and Stage 2 (extraction of the drilling tool), soil element A looses radial support from the large-diameter displacement body. This is because the casing attached to the top of the displacement body usually has a diameter smaller than that of the displacement body. As a result, element A may undergo some negative (i.e., towards the pile axis) radial displacement. However, during the extraction of the drilling tool (Stage 2), the soil is again pushed away from the path of the drilling tool. During this process, element A returns to its previous position, and its left boundary merges with the wall of the 
displacement body. We do not model the caving in (at the end of Stage 1) and pushing back (during Stage 2) of the soil element. We assume that the effects of these two intermediate stages counterbalance each other out for practical purposes and do not impose any net change on the state of the soil surrounding the pile. As the drilling tool is extracted from the ground, we assume that the fresh concrete pumped into the borehole provides lateral support to the surrounding soil and no further change in the lateral stress in the soil adjacent to the pile occurs as the concrete hardens.

\subsubsection{Mesh and Boundary Conditions}

We consider a disk of soil around the pile shaft at a depth sufficiently away from the ground surface and from the pile base. We investigate the effect of installation of a DD pile on the stress state of this soil disk around the pile and model the pile shaft-soil interaction during the loading of the pile. A similar approach was used to investigate the shaft resistance of nondisplacement piles in clays and sands (Randolph and Wroth 1978; Potts and Martins 1982; Loukidis and Salgado 2008) and also of jacked piles in sands and clays (Basu et al. 2009a; Basu et al. 2009b).

Figure 3.2 shows the FE mesh, boundary conditions, and nodal constraints used for the analyses. The mesh consists of a row of 8-noded rectangular quasi-axisymmetric elements. In addition to the in-plane (vertical and radial) degrees of freedom, each node of these elements has an out-of-plane degree of freedom. This out-of-plane degree of freedom at every node was required to simulate the torsional shearing associated with the drilling. The elements used in this study represent an axisymmetric geometry; however, the presence of the additional out-of-plane degree of freedom at each node separates these elements from purely 8-noded axisymmetric rectangular elements. Such quasiaxisymmetric elements were also used by Gens and Potts (1984) to solve boundary value problems with axisymmetric geometry subjected to non-axisymmetric loading. We implemented the quasi-axisymmetric element in the finite element code SNAC (Abbo and Sloan 2000).

We assume that the vertical normal strain in the soil disk is negligible. The same approach was also used in the analysis of shaft resistance of drilled shafts in sands 
(Loukidis and Salgado 2008) and for jacked piles in sands and in clays (Basu et al. 2009a, Basu et al. 2009b). All degrees of freedom of nodes lying along a vertical line are tied together to enforce the condition of zero normal vertical strain. Imposition of this constraint guarantees that there is no bending deformation of the sides of any element during shearing in the vertical and in the angular (torsional) directions. The constraint applied at the nodes also makes the analysis independent of the height of the rectangular elements. Boundary conditions are applied at the nodes on the left and right boundaries of the domain, as shown in Figure 3.2. At the end of the cavity expansion (but before the vertical and torsional shearing start), we ensure that the thickness of the leftmost element is consistent with the shear band thickness typically observed in sand (i.e., 5 to 20 times $\left.D_{50}\right)$.

In reality, the vertical normal strain at depths very close to the pile tip may not be negligible. There is some compression of the soil just below the drilling tool during drilling and then unloading of the same soil element as the drilling tool passes it. Near the ground surface, the deformation of the soil is less constrained than at lower depths, and, consequently, rotation may occur in a soil element along with the development of nonnegligible vertical normal strain. Therefore, the assumptions in the 1-D analyses are not strictly valid near the pile tip and the ground surface. However, these assumptions closely resemble conditions existing at depths that are sufficiently removed from the ground surface and from the pile base. 


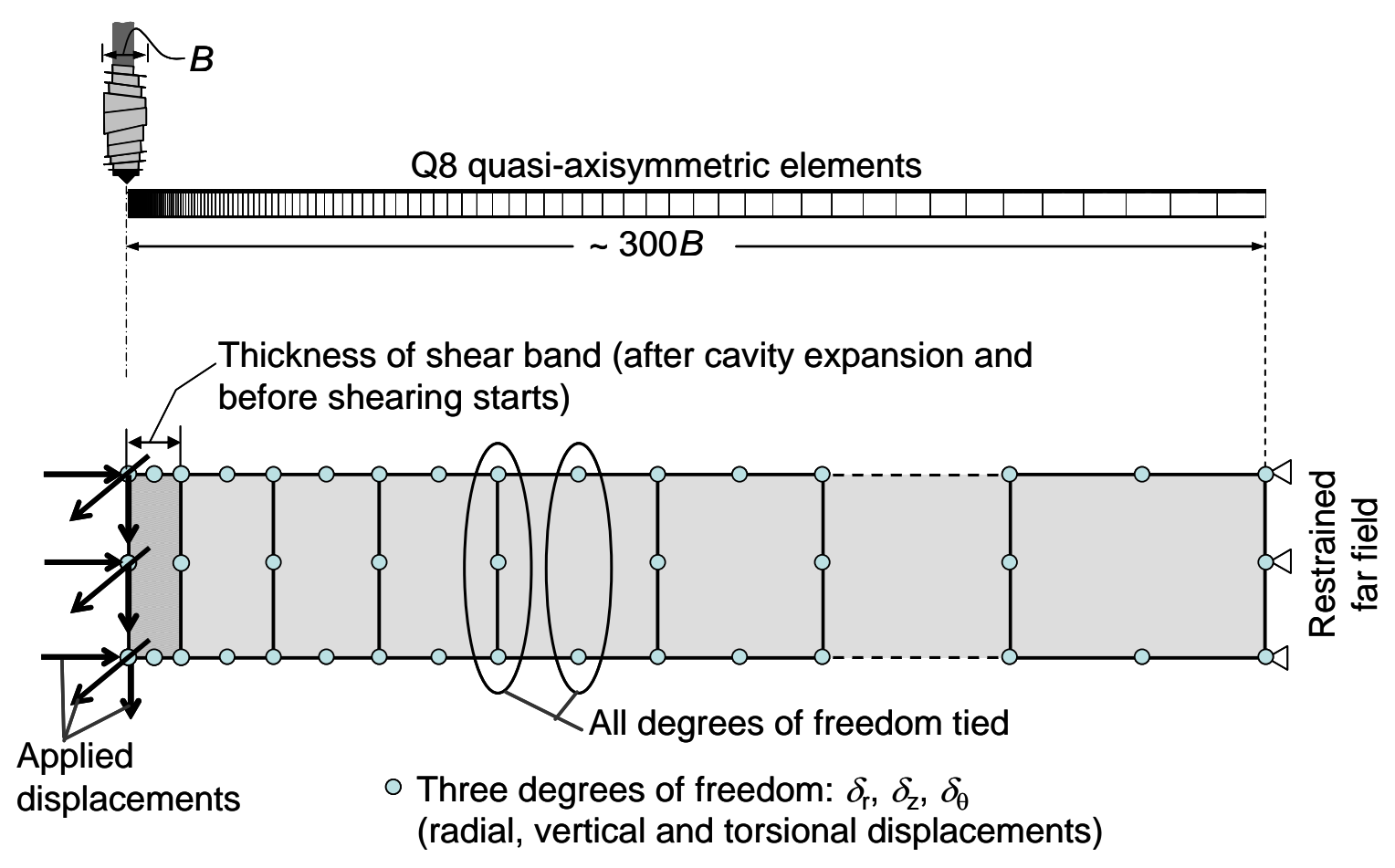

Out of the plane displacement is used to simulate torsional shear

Figure 3.2 One-dimensional domain considered in the analysis: (a) finite element mesh and (b) boundary conditions and applied displacements

\subsection{Solution Algorithms and Applied Displacement Increments}

The finite element code SNAC (Abbo and Sloan 2000) is used for the numerical simulations. The modified Newton-Raphson method is used as the solution scheme for the global nonlinear load-displacement system of equations. The elastic global stiffness matrix was used in the modified Newton-Raphson scheme. The constitutive model equations are integrated using a semi-implicit algorithm adapted with sub-incrementation and error control (Loukidis 2006, Chakraborty 2009) using relative stress error tolerance equal to $10^{-4}$.

Our analyses are based on the conventional, small-strain finite element formulation with node updating. SNAC was modified to update the position ( $\mathrm{x}$ and $\mathrm{y}$ coordinates) of the nodes after each solution increment (updated Lagrangian approach), which is needed for the proper simulation of a large-deformation problem like the one addressed in this report. The present approach of using small-strain FEA to solve large- 
deformation problems is similar to the approach followed by $\mathrm{Hu}$ and Randolph (1998) to successfully analyze a two-dimensional large-strain penetration problem. In our 1-D analysis with specific displacement constraints, the elements do not distort. Therefore, the remeshing and stress interpolation techniques used by $\mathrm{Hu}$ and Randolph (1998) are not necessary. Basu et al. (2009a) demonstrated the validity of the present FE approach by comparing the FEA results from cylindrical cavity expansion analysis in sand with the results obtained by other researchers (Yu and Houlsby 1991; Collins et al. 1992; and Salgado and Randolph 2001) who followed analytical and semi-analytical large-strain formulation. In our present analysis, during each load increment (between two successive node updates), the displacement gradient and the corresponding strain increments are very small. The convective terms in the strain definition are one order of magnitude smaller than the Cauchy (infinitesimal) strains. As a result, decreasing the Cauchy strain increments by one order of magnitude leads to a two order of magnitude decrease in the convective terms included in the definition of large strains. Thus, we minimize the error introduced by the omission of the convective terms (present in the large-strain FE formulations) by using sufficiently fine displacement incrementation.

We perform displacement-controlled analyses, and apply the displacement increments (horizontal for the cavity expansion phase, vertical and angular for the shearing phases) at the nodes on the left boundary of the domain. Figure 3.3 shows different displacement increments applied to the nodes on the left boundary of the domain at different stages of the analysis. The reactions are monitored at the nodes where displacement increments are applied. We update the position ( $\mathrm{x}$ and y coordinates) of the nodes after the application of each displacement increment in oder to proper simulate this large-deformation problem.

Horizontal displacement increments $\Delta \delta_{\mathrm{r}}$ are applied to the leftmost nodes of the domain to simulate the expansion associated with the penetration of the drilling tool (Figure 3.3a). Cavity expansion starts from a very small initial radius $r_{0}(=0.015 \mathrm{~m})$ and ends when the cavity radius becomes equal to the maximum radius $R(=B / 2=0.165 \mathrm{~m})$ of the displacement body (which also becomes the pile radius). With a sufficiently small initial cavity radius (compared to the final radius), the limit cavity pressure is closely 
approximated at the end of the cavity expansion process. At the end of the cavity expansion phase, vertical and torsional (angular) displacement increments $\left(\Delta \delta_{\mathrm{z}}\right.$ and $\Delta \delta_{\theta}$, respectively) are applied simultaneously at the nodes of the leftmost boundary of the domain to simulate vertical and torsional shearing during drilling (Figure 3.3b). No interface elements are placed at the left boundary. Any slippage between the drilling tool (when the displacement body completely passes the soil disk) and soil is simulated by the formation of a shear band inside the soil adjacent to the displacement body. This condition corresponds to a perfectly rough interface. The vertical and torsional loading stage following the cavity expansion phase is stopped when normal, tangential and torsional reactions at the left boundary of the domain stabilize and a limit condition is reached along the borehole wall (created by drilling). This limit state represents the end of drilling.

Negative (upward) vertical displacement increments $\left(-\Delta \delta_{\mathrm{z}}\right)$ are applied at the nodes lying on the left boundary of the domain (Figure 3.3c) to simulate the extraction of the drilling tool from the ground. This stage is stopped when both the normal stress and vertical shear stress along the left boundary of the domain stabilize and another limit condition is reached. At this stage, the vertical shear stress on the left boundary of the domain reaches a negative limiting value. In practice, the drilling tool may be rotated clockwise during its extraction from the ground. However, in our analysis, we do not simulate this rotation of the drilling tool during the extraction process. The extraction stage is automatically stopped based on a convergence criterion: for three consecutive displacement increments, the corresponding reaction values (recorded at the nodes on the left boundary) differ only by a value equal to or less than $10^{-6}$. This criterion is applied simultaneously to both the normal and tangential reactions to guarantee that the limit state is reached. At the end of the extraction stage, the left boundary of the domain becomes the pile shaft-soil interface as concrete fills the borehole. Nodes lying on the left boundary of the domain now lie on the pile shaft.

Finally, positive (downward) vertical displacement increments $\Delta \delta_{\mathrm{z}}$ are now applied to the restrained nodes (now lying on the pile shaft) to simulate loading of the pile (Figure 3.3d). Any slippage between the pile shaft and soil is simulated by the 
formation of a vertical shear band inside the soil adjacent to the shaft wall. This condition corresponds to a perfectly rough interface. Such interface condition is expected in the case of a DD pile.

In the case of coupled analyses, during the cavity expansion phase, we also apply vertical and angular (torsional) displacement increments at the nodes on the left boundary of the domain (Figure 3.3e). Once the cavity radius becomes equal to the maximum radius of the displacement body, we no longer apply radial displacement increments. We continue to apply both vertical and angular (torsional) displacement increments until a limit state is reached. The next loading stages (corresponding to the extraction of the drilling tool and loading of the pile) remain the same, as shown in Figure 3.3(c) and Figure 3.3(d).

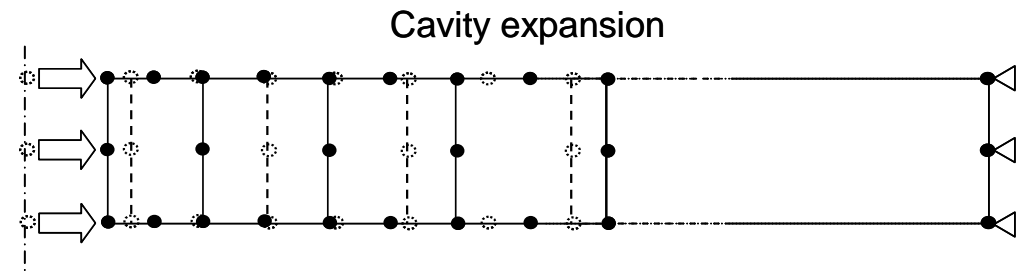

(a)

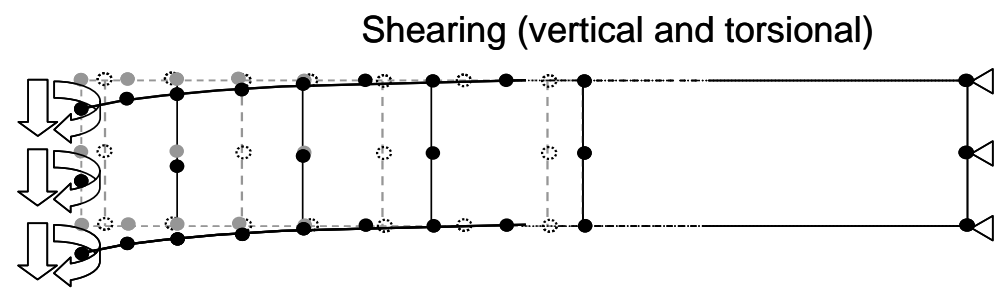

(b)

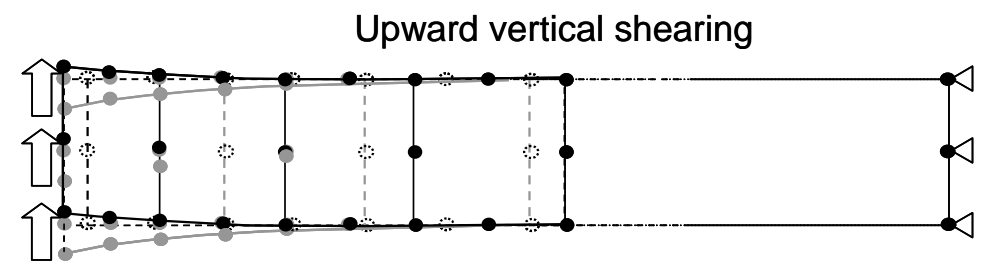

(c) 


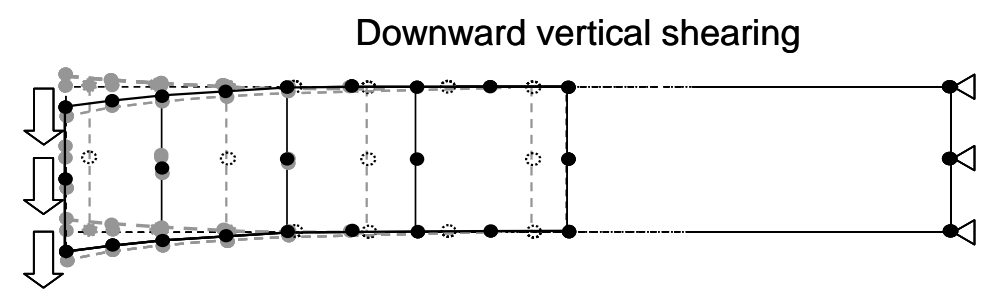

(d)

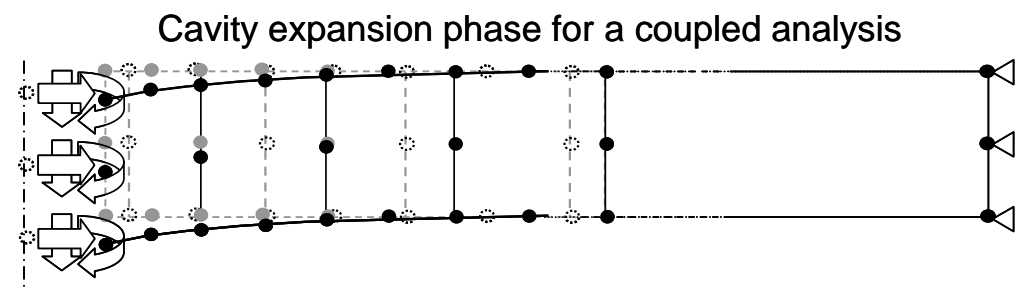

(e)

Figure 3.3 Different displacement increments: (a) cavity expansion, (b) shearing (vertical and torsional) associated with drilling, (c) upward (negative) vertical shearing during the extraction of the drilling tool, (d) downward vertical shearing during loading of the pile,

(e) simultaneous application of radial, vertical and torsional displacements during the cavity expansion phase for a coupled analysis

\subsection{Constitutive Model Used in the Finite Element Analysis}

We use a two-surface plasticity model (a modified version of bounding surface plasticity model) based on critical-state soil mechanics to simulate the mechanical response of the sand. The use of bounding surface plasticity was first introduced in geotechnical engineering by Dafalias and Hermann (1982) to model clay behavior. Following its first application, a number of researchers used bounding surface plasticity to closely simulate the behavior of clays and sands under cyclic and monotonic loading (Dafalias and Hermann 1986; Bardet 1986; Wang et al. 1990; Manzari and Dafalias 1997; Papadimitriou et al. 2001; Papadimitriou and Bouckovalas 2002). While the classical plasticity based constitutive models have limitations in capturing the pre-failure behavior of soils (sands in particular), bounding surface plasticity based models can successfully describe the pre- and post-failure behavior of highly non-linear materials like soil under both monotonic and cyclic loading conditions. 
The sand model accounts for stress-induced, as well as inherent (fabric) anisotropy, an important feature for the present study, as is demonstrated later in this report. This constitutive model for sand was originally proposed by Manzari and Dafalias (1997) and subsequently modified by Li and Dafalias (2000), Papadimitriou and Bouckovalas (2002), Dafalias et al. (2004), and Loukidis and Salgado (2009). In the present analyses, we use model parameter values calibrated for dry-deposited/airpluviated Toyoura sand. This constitutive model is particularly suitable for the analysis of installation and loading of DD piles because it can simulate sand response accurately from the early stages of loading all the way to critical state. The model also realistically captures sand behavior during shear stress reversals by using the small-strain shear modulus at the beginning of each shearing phase.

The deformation inside shear bands involves a significant amount of material rotation. The present constitutive model does not explicitly account for material rotation and does not include asymmetric stress tensors. This model was calibrated to correctly predict the stresses at the boundary of soil specimens used in laboratory tests such as drained biaxial compression tests, direct simple shear tests and torsional shear tests in the hollow cylinder apparatus. These tests involve formation of shear bands after a peak stress state is attained. Therefore, the model is able to adequately predict the tractions at the boundaries of shear bands but not the complex stress state inside the shear band. As a consequence, the size of the elements in the mesh should not be smaller than the shear band thickness that is observed in reality. 


\section{CHAPTER 4. ANALYSIS RESULTS}

\subsection{Introduction}

The installation of DD piles causes complex changes to the soil surrounding these piles. Quantification of the changes in the state (i.e., void ratio $e$ and mean effective stress $p^{\prime}$ ) of the soil surrounding these piles is important for satisfactory prediction of their capacity. However, results of analysis for DD piles are not presently available in the literature. The currently available in situ test-based design methods rely entirely on empirical relationships which were originally derived from the results of static load tests on DD piles. In the present study, we follow the soil property-based approach to calculate the shaft resistance of DD piles in sands. In this chapter we present and discuss the FEA results obtained at different stages of installation and loading of a DD pile. We also discuss the changes in the stress state of the soil during and after the installation of a DD pile.

\subsection{Soil Property-Based Method for Calculating Shaft Capacity of DD Piles}

In the soil property-based approach, the following expression is used for calculating the limit unit shaft resistance $q_{\mathrm{sL}}$ for an axially loaded pile:

$$
q_{\mathrm{sL}}=(K \tan \delta) \sigma_{\mathrm{v} 0}^{\prime}=\beta \sigma_{\mathrm{v} 0}^{\prime}
$$

where $K$ is the coefficient of lateral earth pressure, $\delta$ is the friction angle mobilized at the pile shaft-soil interface, and $\sigma_{\mathrm{v} 0}^{\prime}$ is the in situ vertical effective stress (before pile installation) at a depth where the shaft resistance is calculated.

The earth pressure coefficient $K$ depends on soil state (i.e., $e$ and $p^{\prime}$ ). The value of the limit interface friction angle $\delta$ is usually expressed in terms of the critical-state 
friction angle $\phi_{\mathrm{c}}$ of the soil because the large shear strains that develop near the pile shaft at ultimate load levels cause the soil adjacent to the pile shaft to reach critical state. In sandy soils, the friction angle $\delta$ mobilized at the interface is also a function of the pile surface roughness (Fioravante 2002; Colombi 2005). Uesugi and Kishida (1986) showed that the proper way to quantify the dependence of the friction coefficient $(\tan \delta)$ on the interface roughness is to consider the normalized (relative) roughness $R_{\mathrm{n}}$ (i.e., the ratio of the maximum roughness $R_{\max }$ to the average particle size $\left.D_{50}\right)$ instead of $R_{\max }$. The friction angle $\delta$ attains maximum and minimum values for a perfectly rough interface and a perfectly smooth interface, respectively. Interface direct shear tests between sand and structural materials such as steel, concrete or aluminum of various degrees of roughness show that, for $R_{\mathrm{n}}$ larger than a threshold value in the range of 0.06 to 0.3 (Uesugi and Kishida 1986; Uesugi et al. 1990; Porcino et al. 2003; Lings and Dietz 2005), an interface can be considered perfectly rough. For a perfectly rough interface, a shear band parallel to the pile shaft forms inside the sand mass adjacent to the shaft wall. The interface can be considered perfectly smooth for $R_{\mathrm{n}}$ values less than 0.02 (Fioravante 2002; Lings and Dietz 2005).

For perfectly rough interfaces, $\delta$ correlates with the critical-state friction angle $\phi_{\mathrm{c}}{ }^{\mathrm{SS}}$ under simple shear conditions according to $\tan \delta=\sin \phi_{\mathrm{c}}^{\mathrm{SS}}$ (Potts and Martins 1982). Given that, for most sands, $\phi_{\mathrm{c}}^{\mathrm{SS}}$ is $3^{\circ}$ to $5^{\circ}$ greater than the critical-state friction angle $\phi_{\mathrm{c}}^{\text {TXC }}$ under triaxial compression conditions (Loukidis and Salgado 2009) and that $\phi_{\mathrm{c}}{ }^{\text {TXC }}$ for sands is in the $28^{\circ}$ to $36^{\circ}$ range (Salgado 2008), $\delta / \phi_{\mathrm{c}}^{\mathrm{TXC}}$ ratios for perfectly rough interfaces are expected to be between 0.9 and 1.0. Data by Uesugi et al. (1990) show that, for Toyoura sand on a perfectly rough interface, the ratio $\delta / \phi_{\mathrm{c}}{ }^{\mathrm{TXC}}$ is in the 0.97 to 0.98 range. It is also possible to establish $\delta / \phi_{\mathrm{c}}{ }^{\mathrm{TXC}}$ values for roughness values typical of actual precast concrete and steel piles based on data reported by Uesugi et al. (1990), Lehane et al. (1993), Jardine and Chow (1998), and Subba Rao et al. (1998). For precast concrete piles, $\delta$ is of the order of $0.95 \phi_{\mathrm{c}}$, suggesting perfectly rough interface conditions. A slightly lower value of the order of $0.85-0.9 \phi_{\mathrm{c}}$ can be used for steel piles, implying an interface that is not perfectly rough (Salgado 2008). 
During the installation of a DD pile with a straight shaft, as the drilling tool is extracted from the ground, concrete or grout is pumped (sometimes under pressure) into the nearly cylindrical void space or borehole created by the drilling tool. The vertical wall of this borehole is not smooth; the augering action of the drilling tool creates several irregularities on the wall. Fluid concrete or grout fills these irregularities, producing a perfectly rough pile shaft-soil interface. Therefore, the value of $\delta$ appearing in Equation (4.1) can be chosen with reasonable accuracy. In contrast, $K$ depends not only on the initial relative density and confining stress of the soil (Salgado 2008), but also on the impact of the installation technique on these parameters. In this report, based on the FEA results, we propose values of $K / K_{0}$ (where $K_{0}$ is the in situ lateral earth pressure coefficient) for calculation of shaft resistance of DD piles in sand.

\subsection{Results of the Finite Element Analyses}

We performed effective stress analyses for normally consolidated Toyoura sand with different values of relative density $\left(D_{\mathrm{R}}=30,45,60,75\right.$ and $\left.90 \%\right)$, different values of initial effective stress $\left(\sigma_{\mathrm{v} 0}^{\prime}=25,50,100,200\right.$ and $\left.400 \mathrm{kPa}\right)$ and $K_{0}=0.45$ (a value appropriate for normally consolidated sand). Two different values of $\eta\left(10^{\circ}\right.$ and $\left.20^{\circ}\right)$ were considered. The pile diameter $B$ is equal to $0.33 \mathrm{~m}$. The main output of the FEA is the value of $K / K_{0}$ at the end of loading. We performed an additional set of analyses with $\eta=0^{\circ}$. The FEA with $\eta=0^{\circ}$ is necessary to obtain $K / K_{0}$ for DD piles installed with an $\eta$ value less than $10^{\circ}$ (by interpolating the values of $K / K_{0}$ obtained for $\eta=0^{\circ}$ and $10^{\circ}$ ). To assess the effect of inherent (fabric) anisotropy, which is due to the preferred orientation of the sand particles, on the pile-soil load-transfer behavior, two sets of analyses were done: i) considering fabric anisotropy, as observed in laboratory data for Toyoura sand, and ii) ignoring fabric anisotropy by switching off the constitutive model components pertaining to fabric anisotropy (i.e., by enforcing an isotropic fabric tensor). These two sets of analysis are performed because not all sands have fabrics that are as anisotropic as that of Toyoura sand. 
We quantify the effect of pile installation through the $K / K_{0}$ ratio for a DD pile with a nearly straight shaft installed using a drilling tool that has a large-diameter displacement body. To facilitate design, we express $K / K_{0}$ as a function of the initial vertical effective stress $\sigma_{\mathrm{v} 0}$ (before pile installation), relative density $D_{\mathrm{R}}$ and an installation parameter $\eta$. Mathematically, $\eta$ can be expressed as:

$$
\eta=\tan ^{-1}\left(\frac{\delta_{\mathrm{z}}}{\delta_{\theta}}\right)
$$

where $\delta_{\mathrm{z}}$ and $\delta_{\theta}$ are the vertical and rotational (torsional) displacements of the drilling tool used in pile installation. $\eta$ represents the ratio of the advancement (penetration) of the drilling tool into the ground and the rotation of the drilling tool (see Figure 4.1). Lower values of $\eta$ imply slower rate of penetration of the drilling tool into the ground during drilling (as we may expect for installation in dense sands), while higher values of $\eta$ imply easier drilling conditions (expected for installation in loose sands). For an optimal drilling condition (i.e., the auger rotates a single full rotation to penetrate a length equal to the pitch length of the auger), $\eta$ can be considered as the flight angle of the auger.

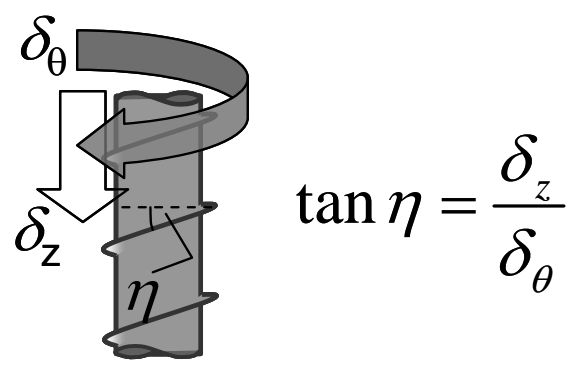

Figure 4.1 Schematic representation of the installation parameter $\eta$

\subsubsection{Evolution of Normal and Shear Stresses}

Figure 4.2 shows the variation of normal (radial) stress $\sigma_{\mathrm{r}}^{\prime}$ on the cavity wall during the cavity expansion phase (first phase of Stage 1) of the analysis (for $D_{\mathrm{R}}=60 \% ; \sigma_{\mathrm{v} 0}^{\prime}=25$, 50, 100, 200 and $400 \mathrm{kPa}$ ). The analyses performed for this study produce a cavity 
pressure at the end of the cavity expansion process that nearly matches the limit cavity pressure. The torsional and vertical shear stresses ( $\tau_{\theta}$ and $\tau_{\mathrm{z}}$ ) remain zero throughout the cavity expansion phase. Figure 4.3 and Figure 4.4 show the evolution of the normal (radial) stress $\sigma_{\mathrm{r}}^{\prime}$, torsional shear stress $\tau_{\theta}$ and vertical shear stress $\tau_{\mathrm{z}}$ at different stages of pile installation (i.e. drilling and extraction of drilling tool) and loading. These stresses act on the outer wall of the large-diameter displacement body during drilling and removal of the drilling tool and on the DD pile shaft during loading of the pile. The initial values of $\sigma_{\mathrm{r}}^{\prime}$ in Figure 4.3 and Figure 4.4 are equal to those at the end of the cavity expansion phase (point A), which precedes the shearing phase during drilling (Stage 1).

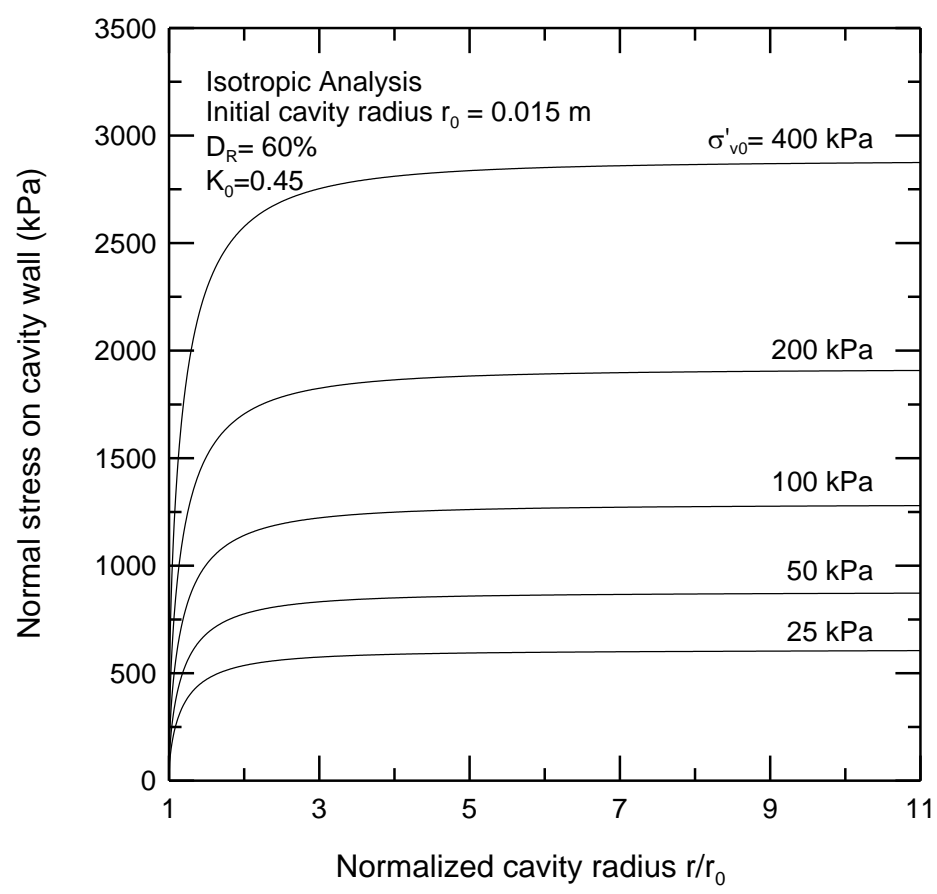

Figure 4.2 Variation of normal stress on cavity wall during expansion of the cavity; limit cavity pressure is reached at the end of the cavity expansion 

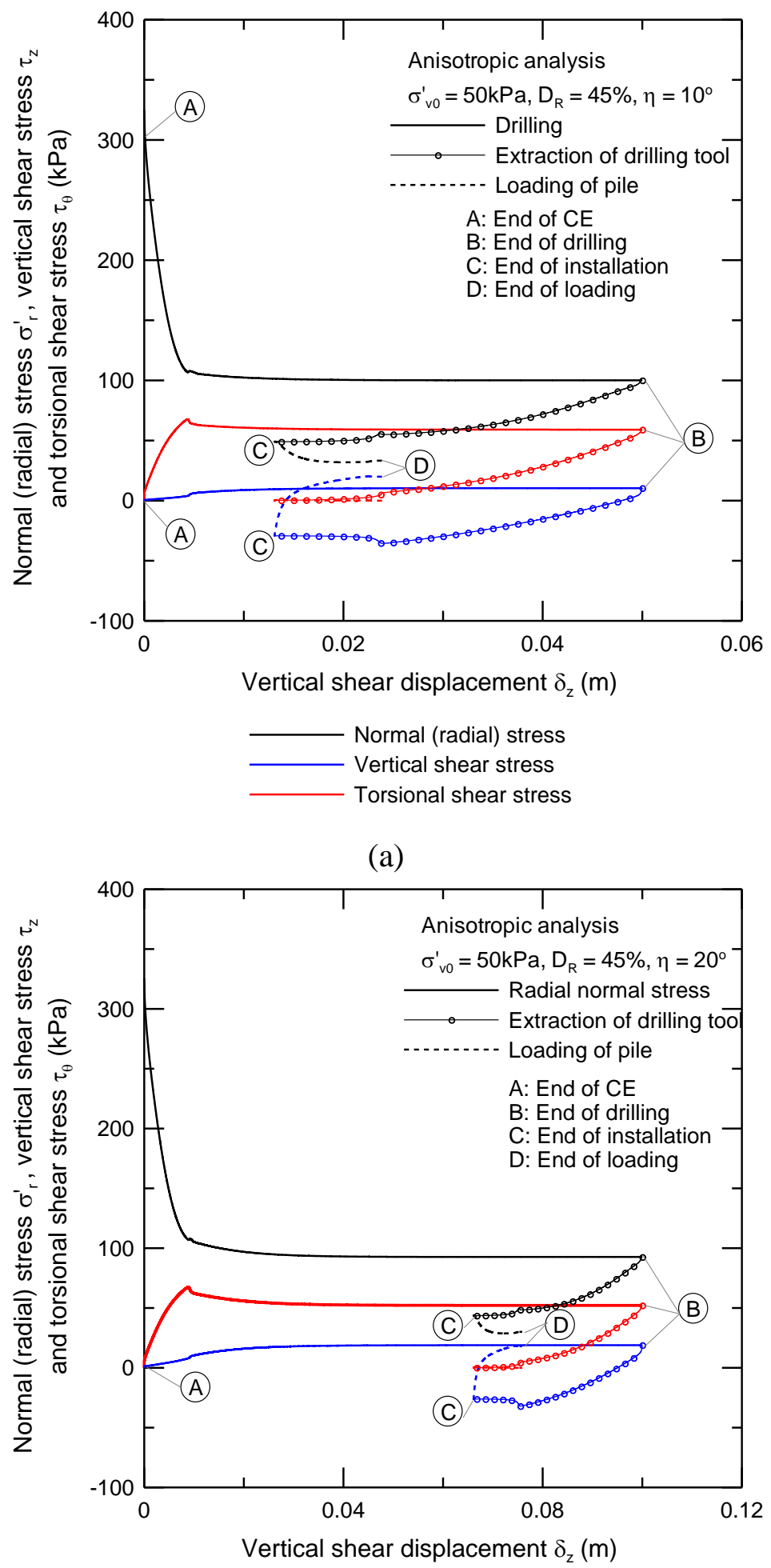

(b) 


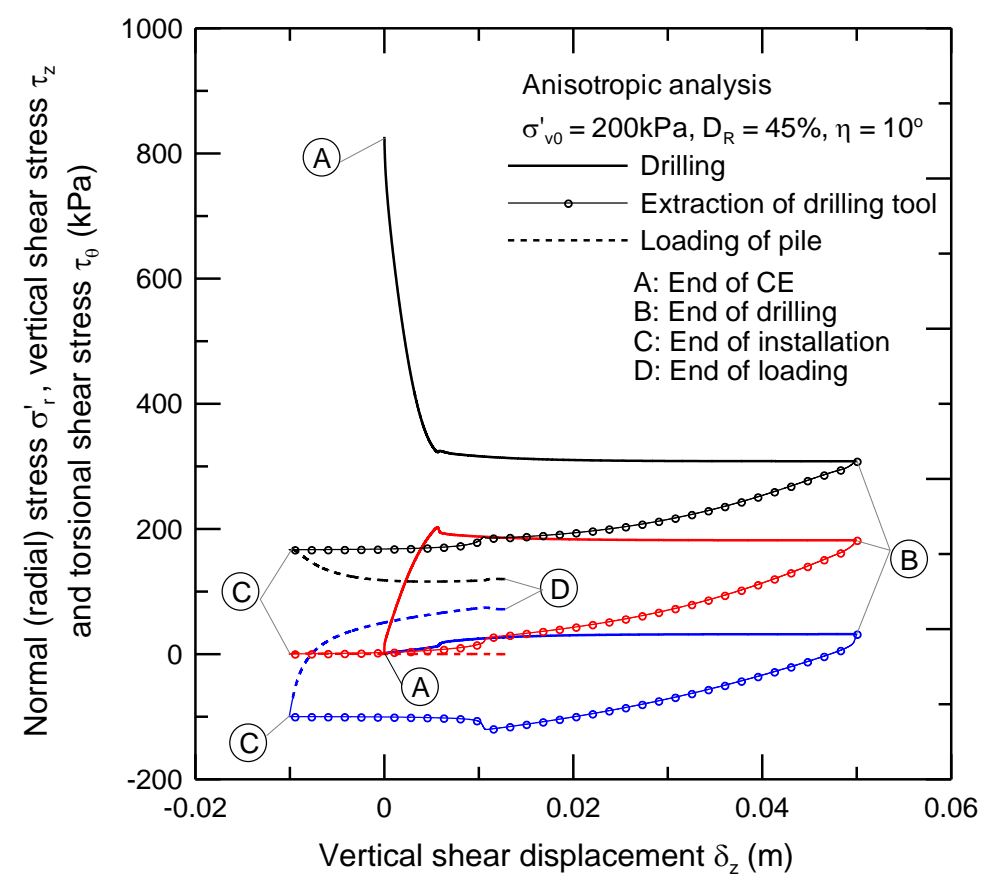

(c)

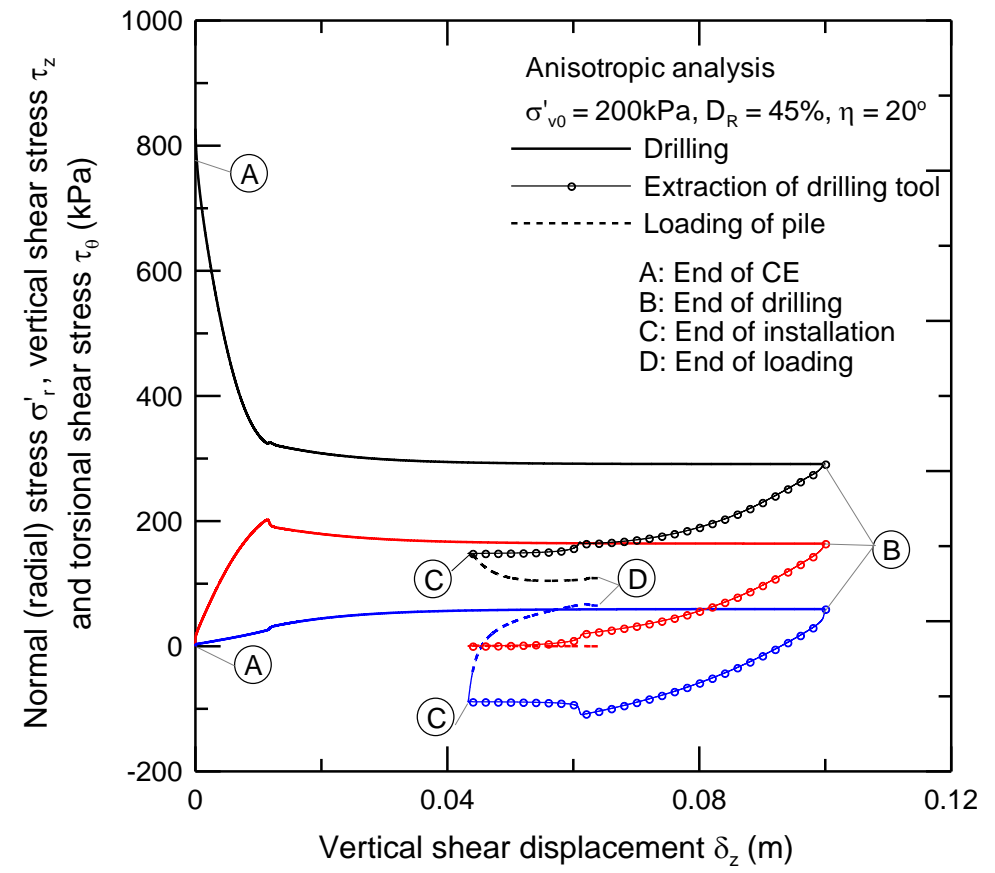

(d) 


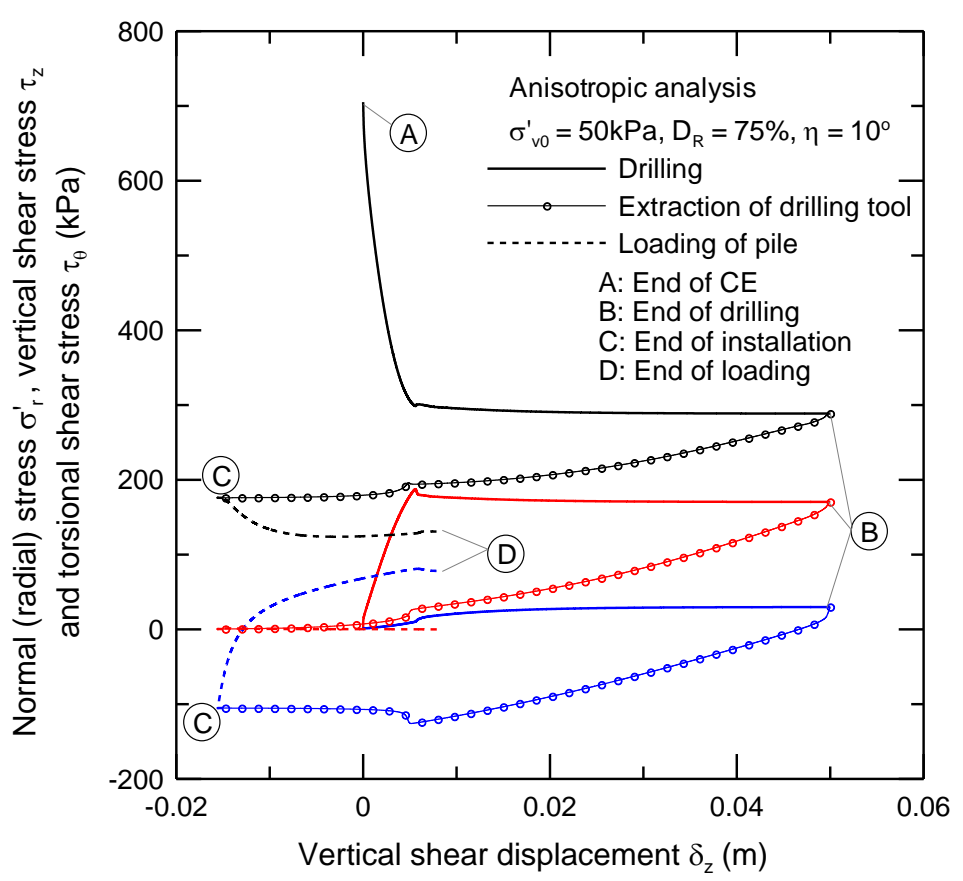

(e)

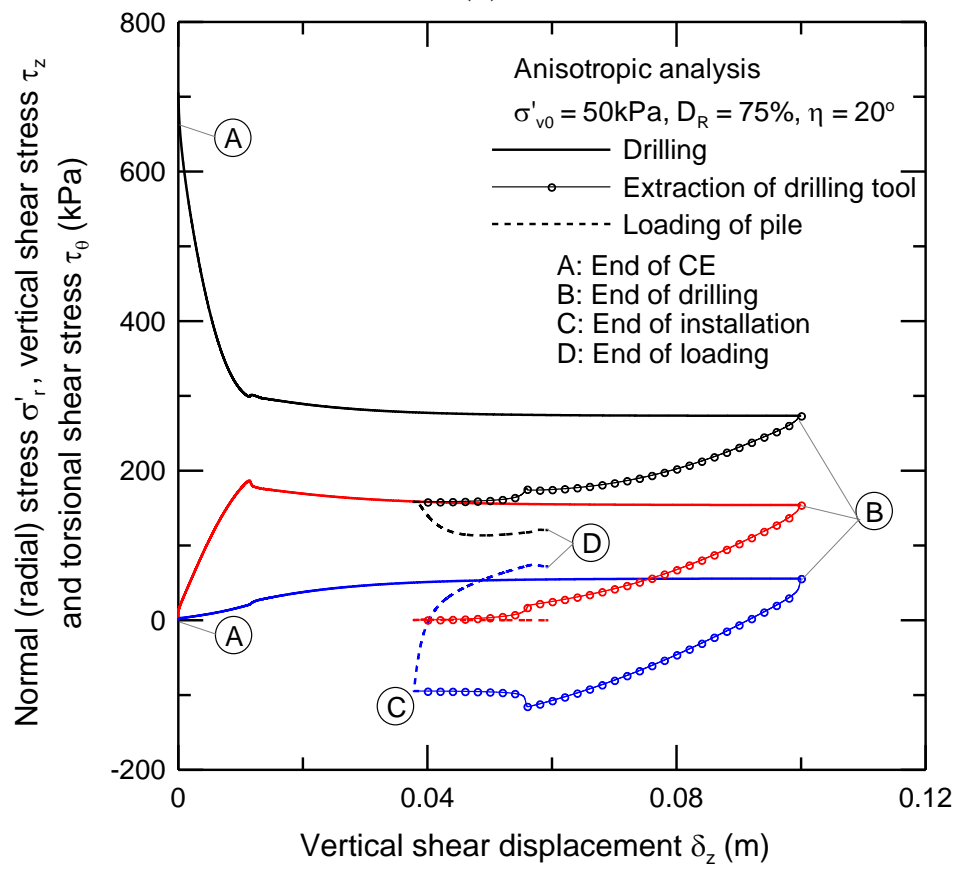

(f) 


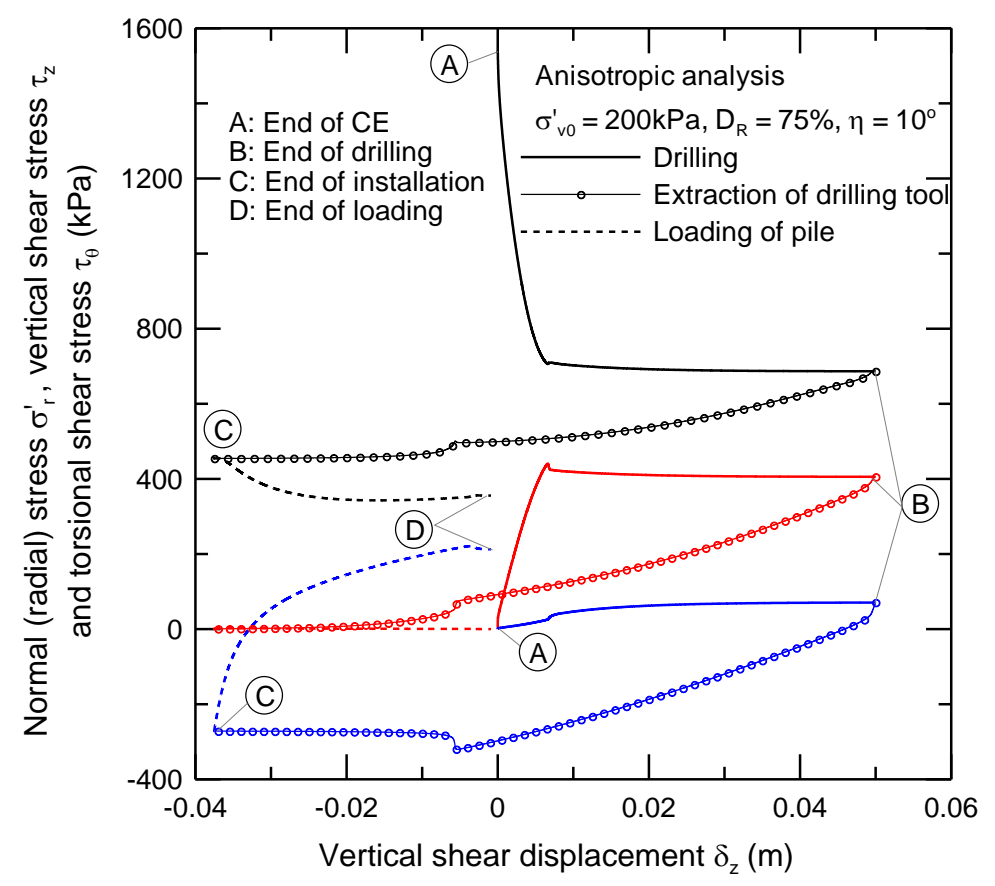

$(\mathrm{g})$

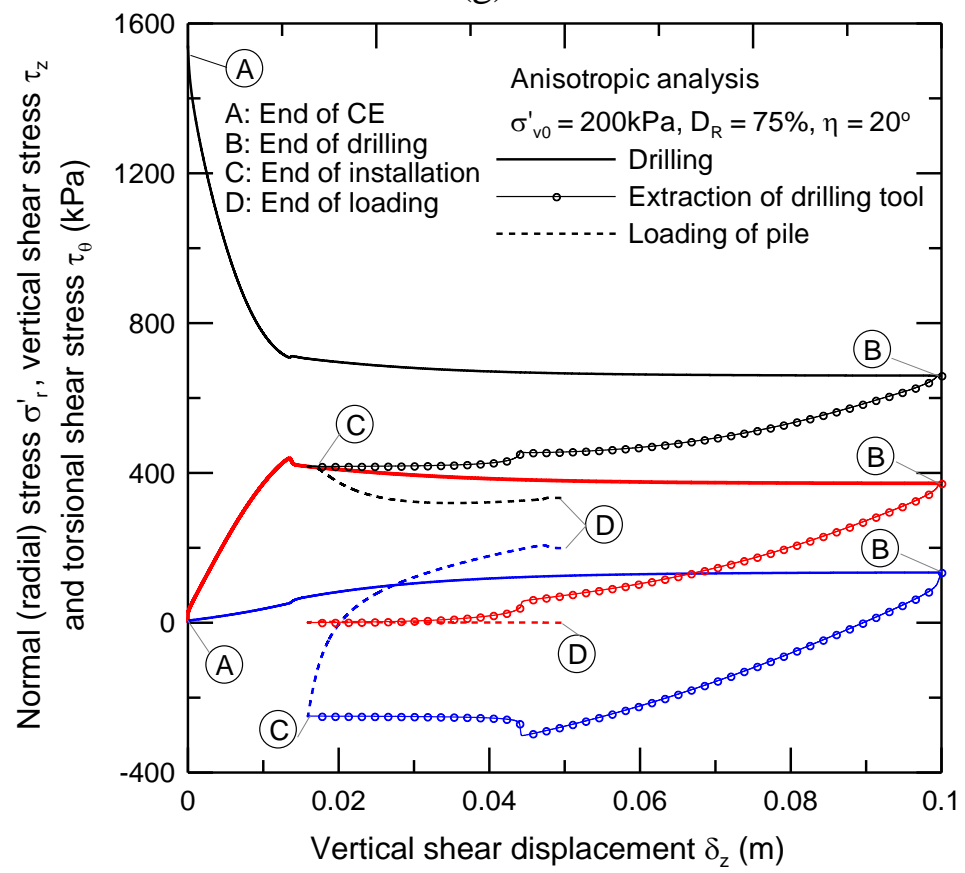

(h)

Figure 4.3 Evolution of normal (radial) effective stress, torsional shear stress and vertical shear stress (for anisotropic analysis) during installation and loading of a DD pile: (a) $\sigma_{\mathrm{v} 0}^{\prime}$ $=50 \mathrm{kPa}, D_{\mathrm{R}}=45 \%, \eta=10^{\circ}$; (b) $\sigma_{\mathrm{v} 0}^{\prime}=50 \mathrm{kPa}, D_{\mathrm{R}}=45 \%, \eta=20^{\circ}$; (c) $\sigma_{\mathrm{v} 0}^{\prime}=200 \mathrm{kPa}, D_{\mathrm{R}}$ $=45 \%, \eta=10^{\circ}$; (d) $\sigma_{\mathrm{v} 0}^{\prime}=200 \mathrm{kPa}, D_{\mathrm{R}}=45 \%, \eta=20^{\circ}$; (e) $\sigma_{\mathrm{v} 0}^{\prime}=50 \mathrm{kPa}, D_{\mathrm{R}}=75 \%, \eta=$ $10^{\circ}$; (f) $\sigma_{\mathrm{v} 0}^{\prime}=50 \mathrm{kPa}, D_{\mathrm{R}}=75 \%, \eta=20^{\circ} ;(\mathrm{g}) \sigma_{\mathrm{v} 0}^{\prime}=200 \mathrm{kPa}, D_{\mathrm{R}}=75 \%, \eta=10^{\circ}$; and (h)

$$
\sigma_{\mathrm{v} 0}^{\prime}=200 \mathrm{kPa}, D_{\mathrm{R}}=75 \%, \eta=20^{\circ}
$$




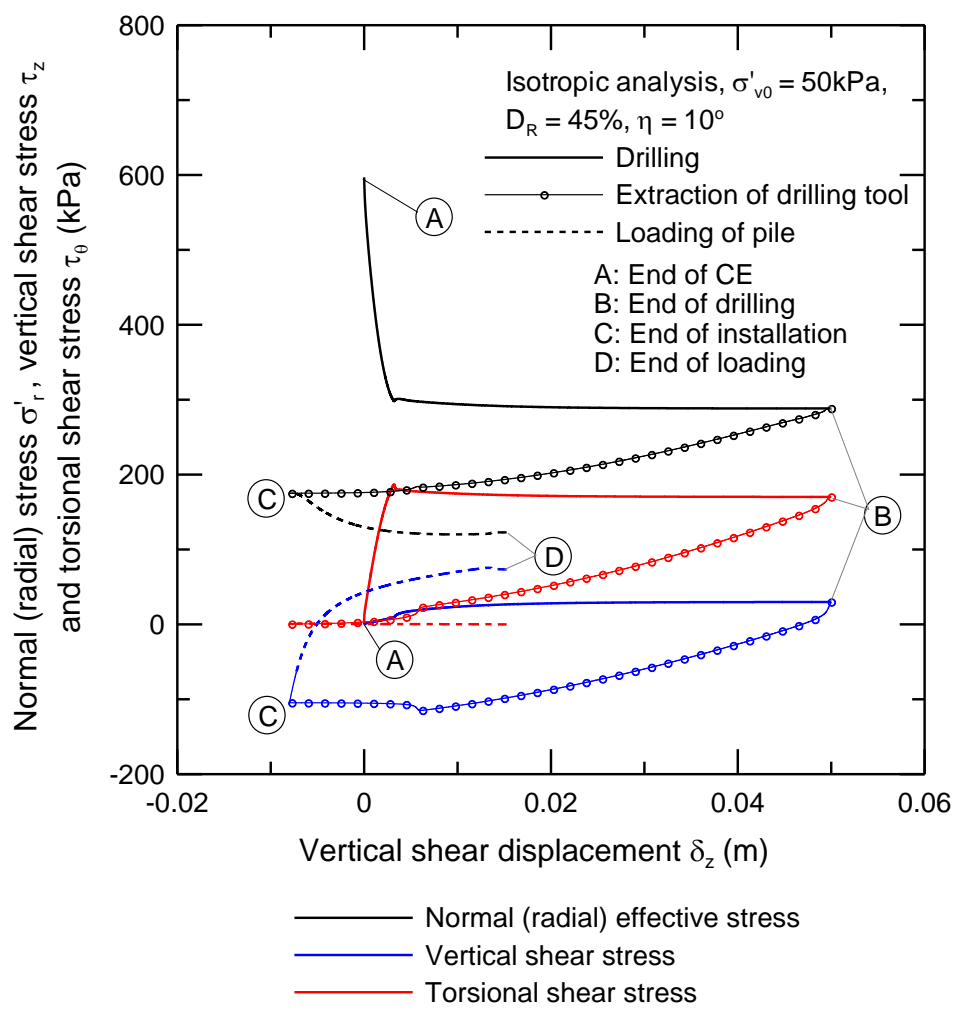

(a)

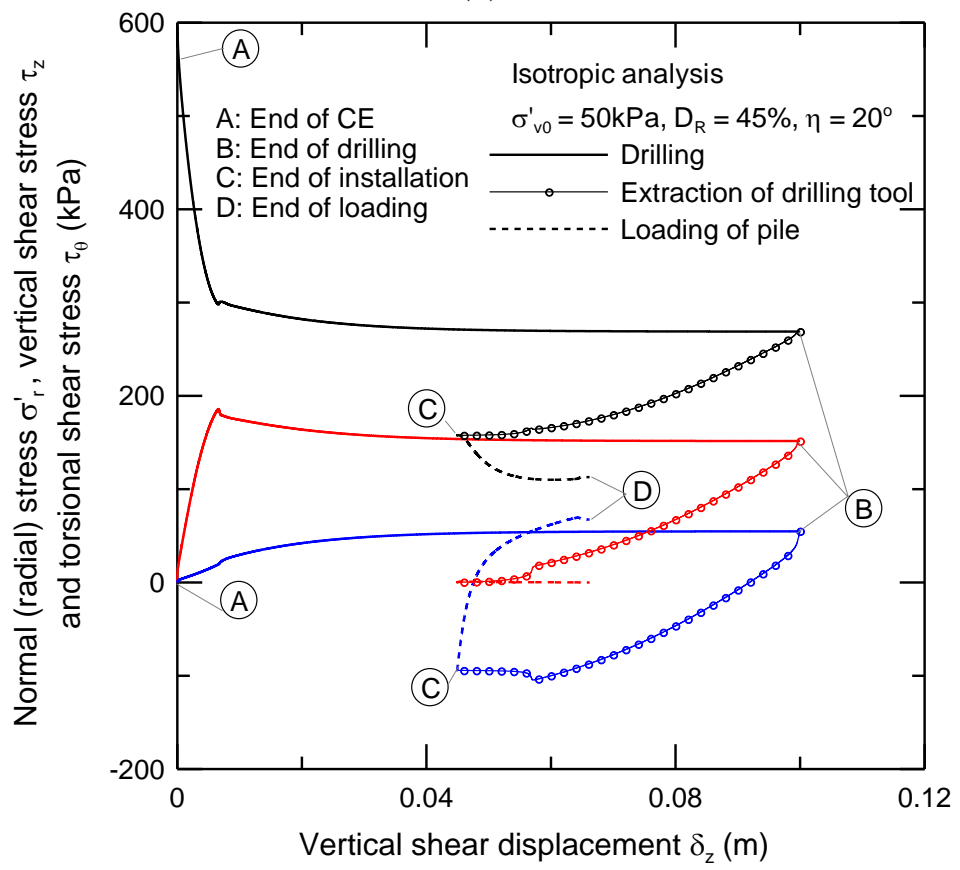

(b) 


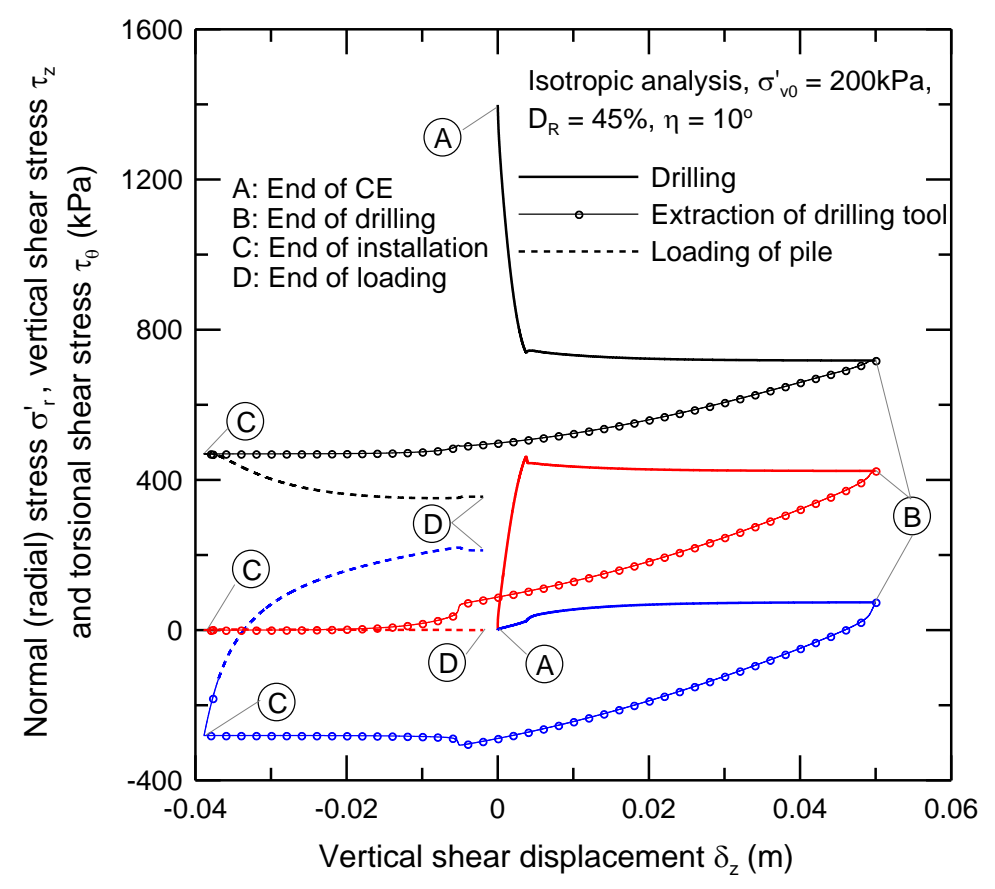

(c)

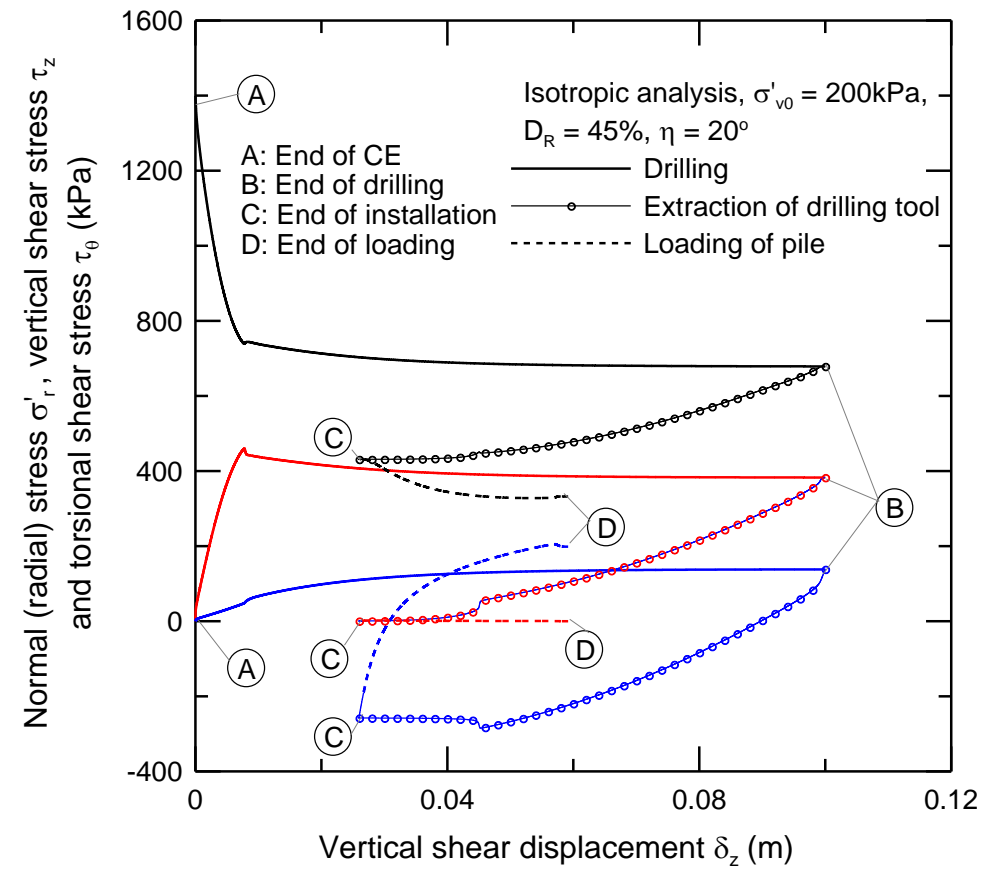

(d) 


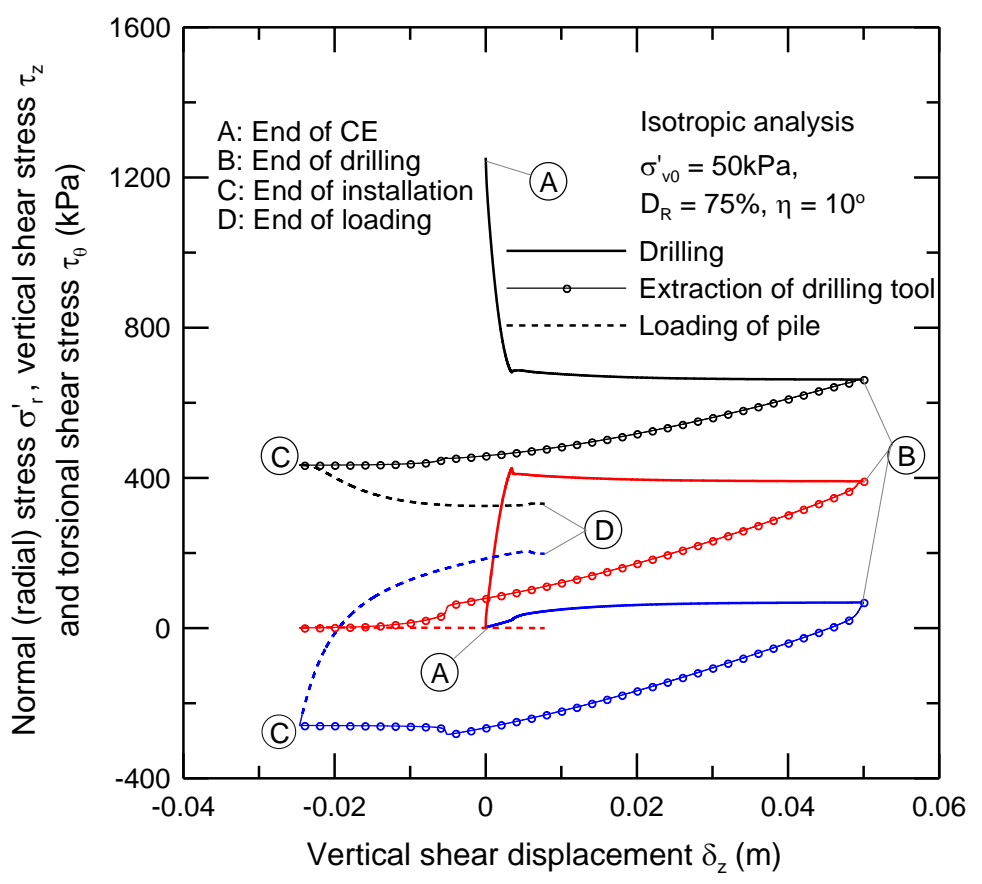

(e)

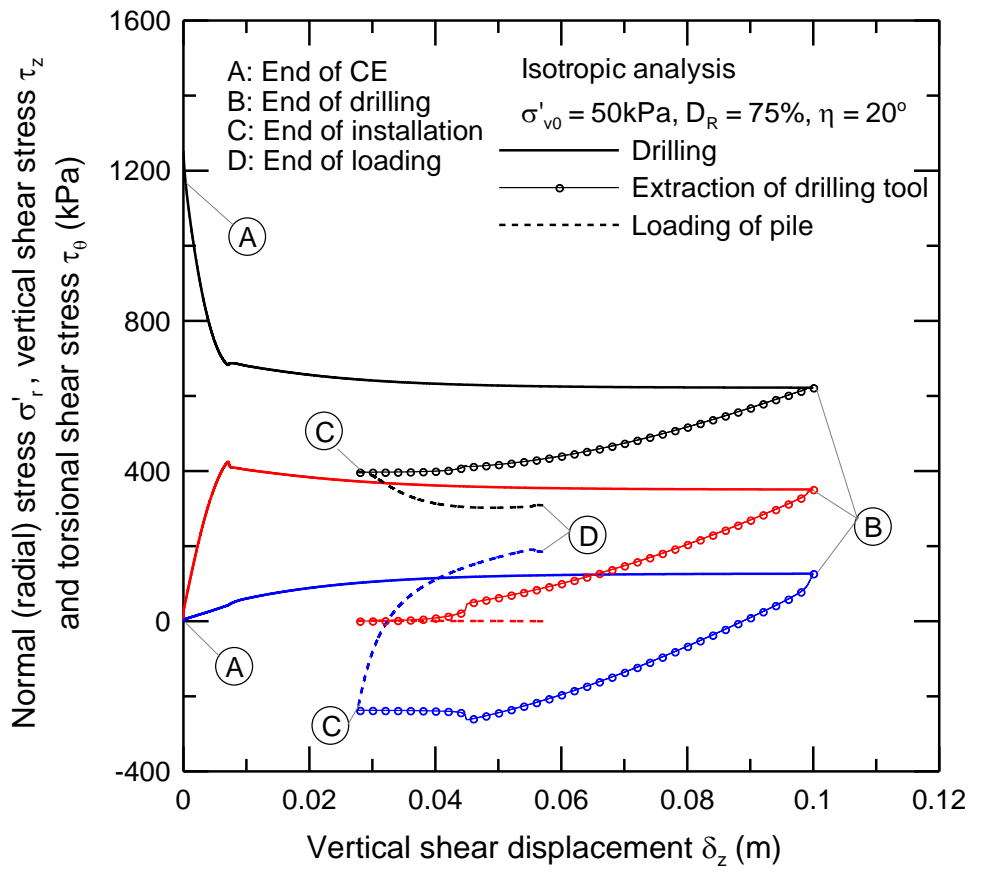

(f) 


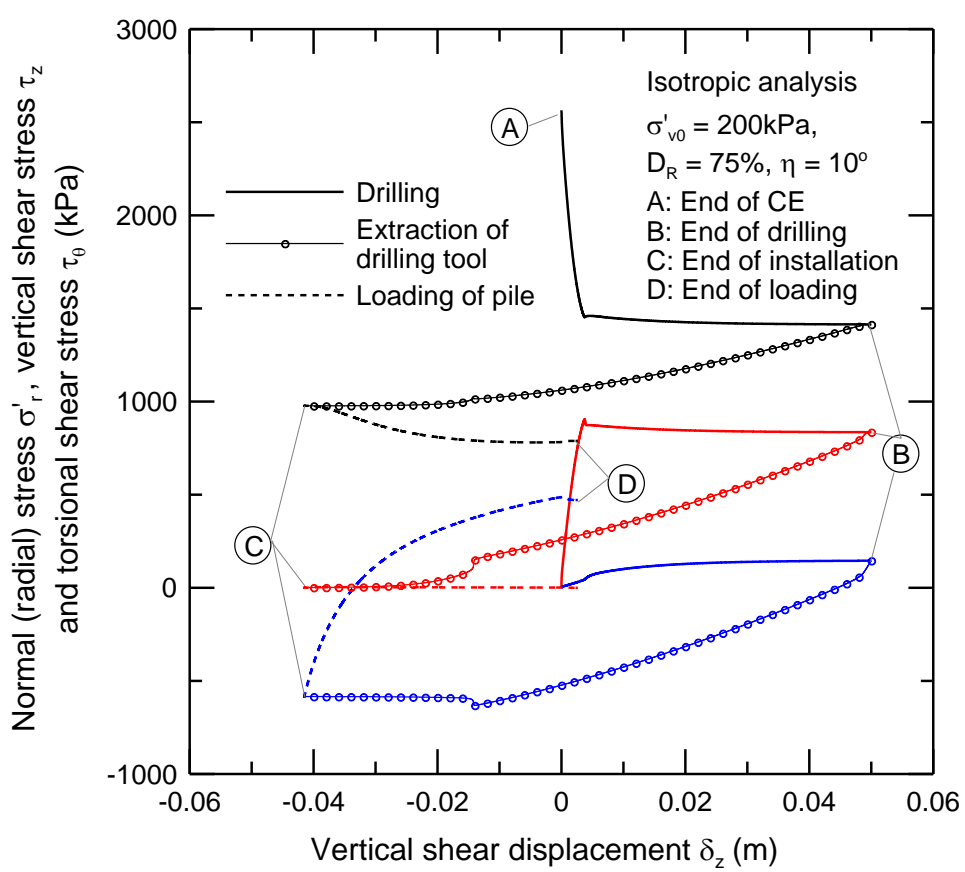

(g)

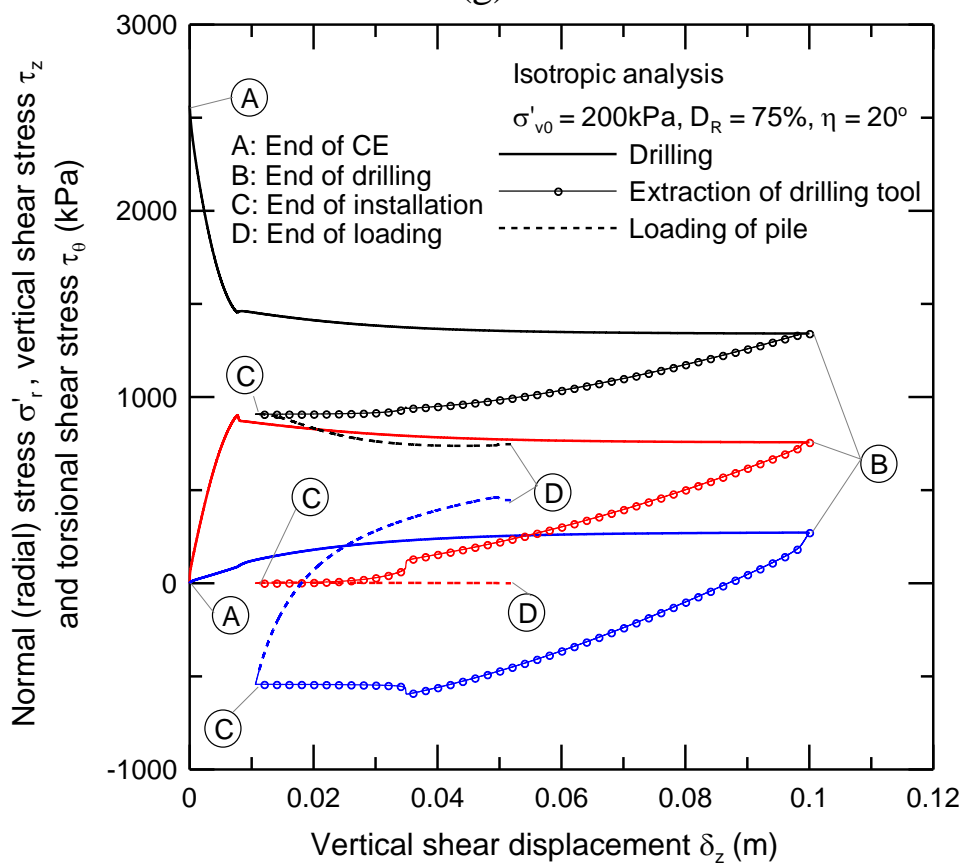

(h)

Figure 4.4 Evolution of normal (radial) effective stress, torsional shear stress and vertical shear stress (for isotropic analysis) during installation and loading of a DD pile: (a) $\sigma_{\mathrm{v} 0}^{\prime}=$ $50 \mathrm{kPa}, D_{\mathrm{R}}=45 \%, \eta=10^{\circ}$; (b) $\sigma_{\mathrm{v} 0}^{\prime}=50 \mathrm{kPa}, D_{\mathrm{R}}=45 \%, \eta=20^{\circ}$; (c) $\sigma_{\mathrm{v} 0}^{\prime}=200 \mathrm{kPa}, D_{\mathrm{R}}=$ $45 \%, \eta=10^{\circ}$; (d) $\sigma_{\mathrm{v} 0}^{\prime}=200 \mathrm{kPa}, D_{\mathrm{R}}=45 \%, \eta=20^{\circ}$; (e) $\sigma_{\mathrm{v} 0}^{\prime}=50 \mathrm{kPa}, D_{\mathrm{R}}=75 \%, \eta=$ $10^{\circ}$; (f) $\sigma_{\mathrm{v} 0}^{\prime}=50 \mathrm{kPa}, D_{\mathrm{R}}=75 \%, \eta=20^{\circ} ;(\mathrm{g}) \sigma_{\mathrm{v} 0}^{\prime}=200 \mathrm{kPa}, D_{\mathrm{R}}=75 \%, \eta=10^{\circ}$; and (h)

$$
\sigma_{\mathrm{v} 0}^{\prime}=200 \mathrm{kPa}, D_{\mathrm{R}}=75 \%, \eta=20^{\circ}
$$


Figure 4.5 shows the stress path in void ratio-mean effective stress space ( $e-p^{\prime}$ space) for the leftmost quadrature point in the first element of the mesh. The soil element adjacent to the displacement body dilates with an increase in $p^{\prime}$ at the end of cavity expansion. As the shearing (both torsional and vertical) phase (Stage 1) starts, the contractive behavior of sand leads to a loss of mean effective stress $p^{\prime}$. Towards the end of drilling, the soil element adjacent to the displacement body dilates (without any change in $p^{\prime}$ ) to reach the limiting condition at critical state (point B in Figure 4.5a). Note that the critical state (in $e-p^{\prime}$ space) reached at the end of drilling is similar to the one reached at the end of CE phase (point A in Figure 4.5a). However, the critical state at the end of CE (point A) and that at the end of drilling (point B) are significantly different from those reached at the end of extraction of drilling tool and at the end of loading of the pile (points $C$ and D, respectively, in Figure 4.5a). This is because the loading conditions imposed on the surrounding soil during different pile installation phases are different. Extraction of the drilling tool and axial loading of the pile impose simple shear loading condition along the pile shaft. Consequently, the points $\mathrm{C}$ and $\mathrm{D}$ fall on a critical-state line (in $e-p^{\prime}$ space) that corresponds to a simple shear loading condition. The loading conditions during CE and drilling are complex; these loading conditions correspond to a critical-state line (in $e-p^{\prime}$ space) that is different from the critical-state line corresponding to simple shear loading.

Up to point B, no variation is observed for different values of $\eta$. Beyond point $B$ (during extraction of the drilling tool and loading), the stress paths for different values of $\eta$ differ slightly from each other. As the value of $\eta$ increases, the soil response becomes more contractive leading to greater loss of $p^{\prime}$. Figure 4.5(b) shows the stress paths (in $e-p^{\prime}$ space) for quadrature points at distances approximately equal to $B, 2 B, 4 B$ and $10 B$ from the pile axis. We observe that at a distance of $10 \mathrm{~B}$ from the pile axis, the installation and loading of a DD pile impose only a small change in the in situ stress state of the soil. The stress path in $q-p^{\prime}$ space (Figure 4.6) also illustrates that the soil adjacent to the pile shaft reaches almost the same stress ratio $\left(q / p^{\prime}\right)$ at the end of different phases of installation and loading. 


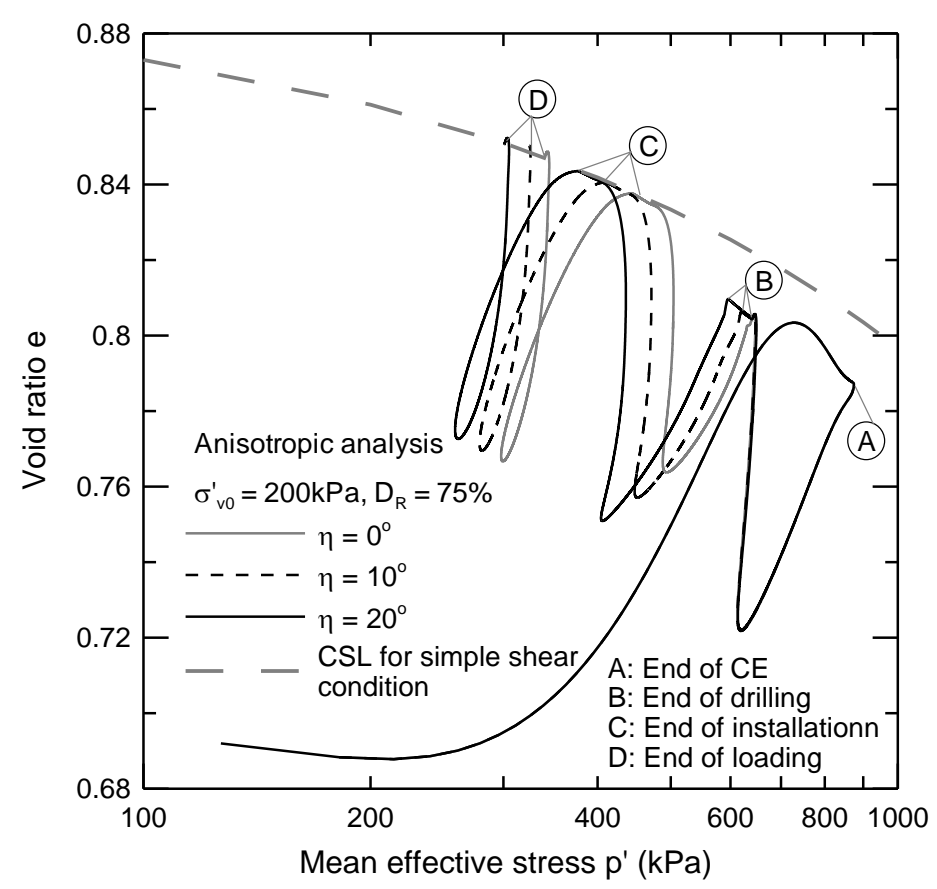

(a)

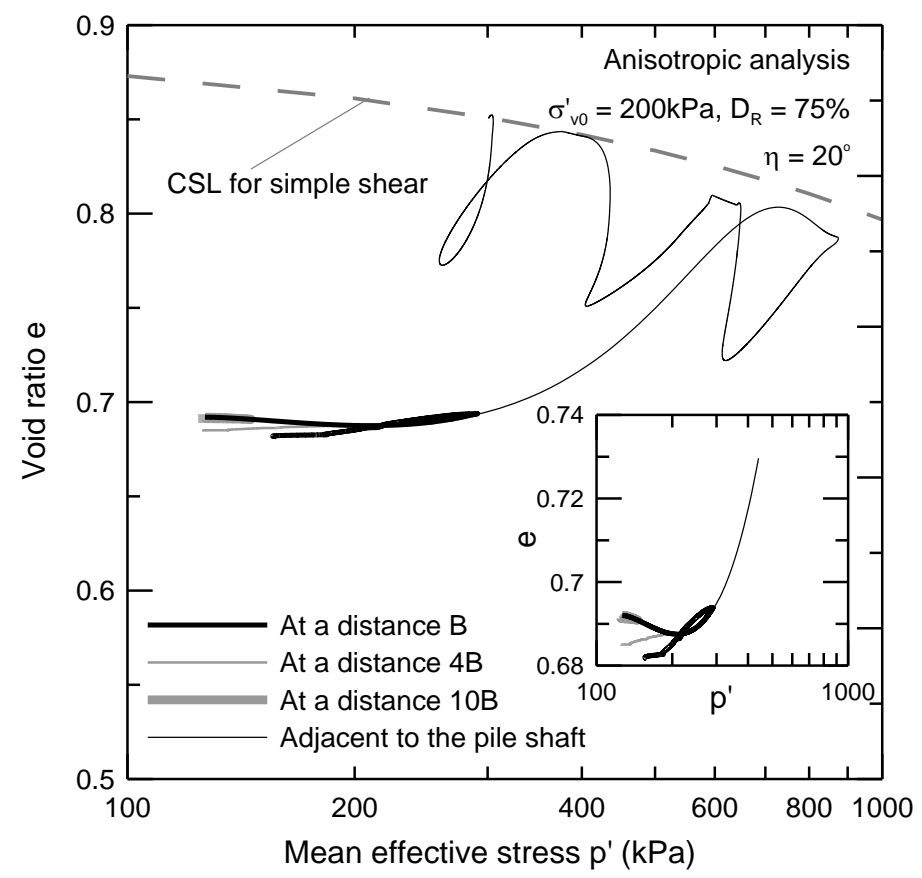

(b)

Figure 4.5 Stress paths in $e-p^{\prime}$ space: (a) for different values of $\eta$, and (b) at different distances from the pile axis for $\eta=20^{\circ}$ 


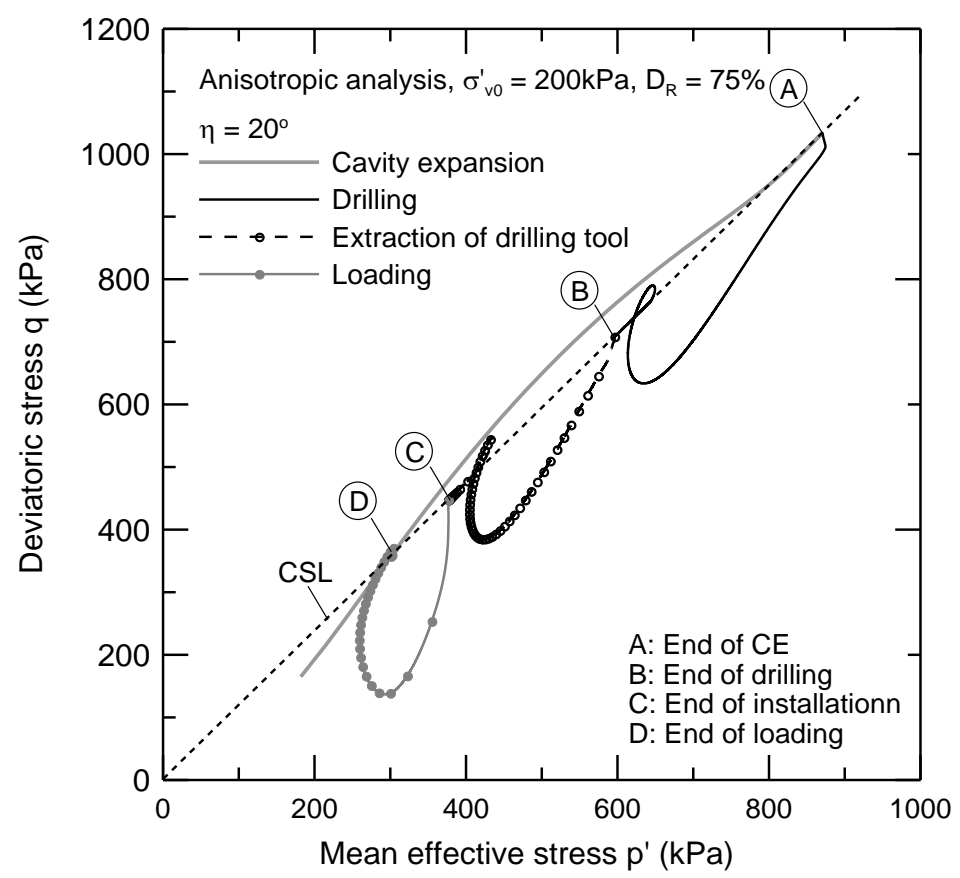

Figure 4.6 Stress path (in $q-p^{\prime}$ space) for the leftmost quadrature point in the first element of the mesh during installation and loading of a DD pile (for $\eta=20^{\circ}$ )

\subsubsection{Effect of Installation on the Surrounding Soil}

Installation of a DD pile causes significant changes to the in situ stress state of the soil surrounding the pile. For example, for $\sigma_{\mathrm{v} 0}^{\prime}=200 \mathrm{kPa}, \sigma_{\mathrm{r} 0}^{\prime}=90 \mathrm{kPa}$ and $D_{\mathrm{R}}=75 \%$, the normal (radial) stress $\sigma_{\mathrm{r}}^{\prime}$ acting at a point on the pile shaft at the end of pile installation in initially anisotropic and isotropic sand fabric are, respectively, 4.6 and 10 times the in situ normal stress $\sigma_{\mathrm{r} 0}^{\prime}$ acting at that depth before pile installation (Figure 4.7). For pile installation in an initially anisotropic sand fabric, beyond a distance of $20 \mathrm{~B}$ from the pile axis, the increase in $\sigma_{\mathrm{r}}^{\prime}$ due to pile installation becomes less than $0.13 \sigma_{\mathrm{r} 0}^{\prime}$; in case of an initially isotropic sand fabric, this increase in $\sigma_{\mathrm{r}}^{\prime}$ is $0.4 \sigma_{\mathrm{r} 0}^{\prime}$. 


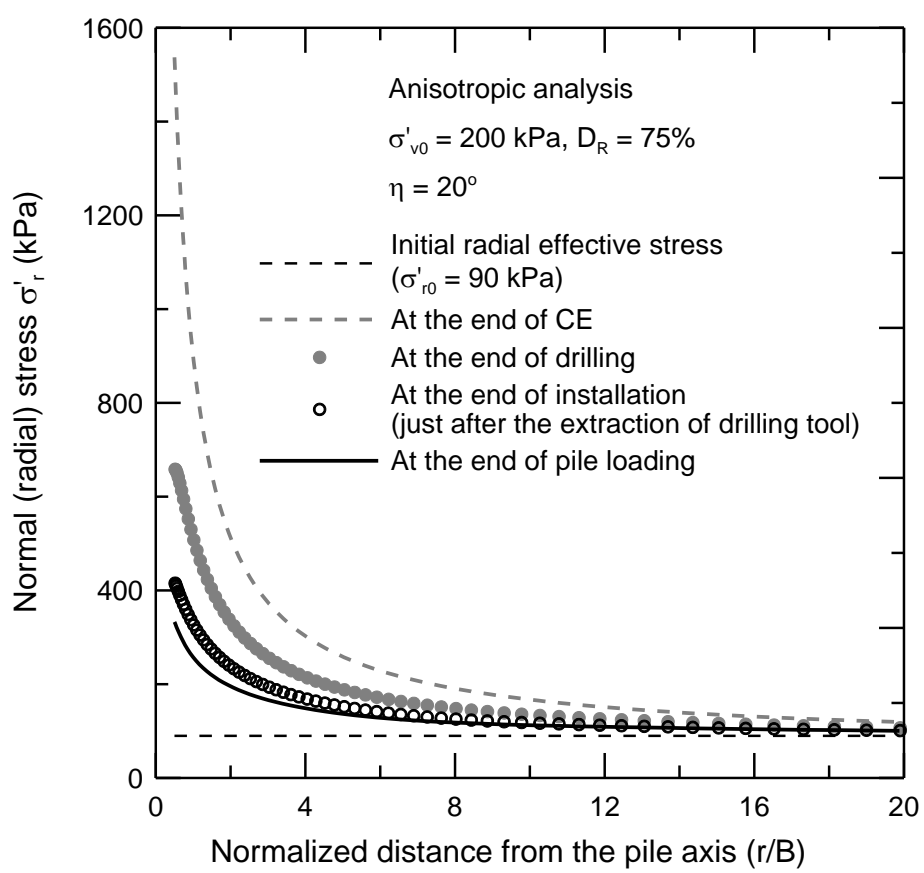

(a)

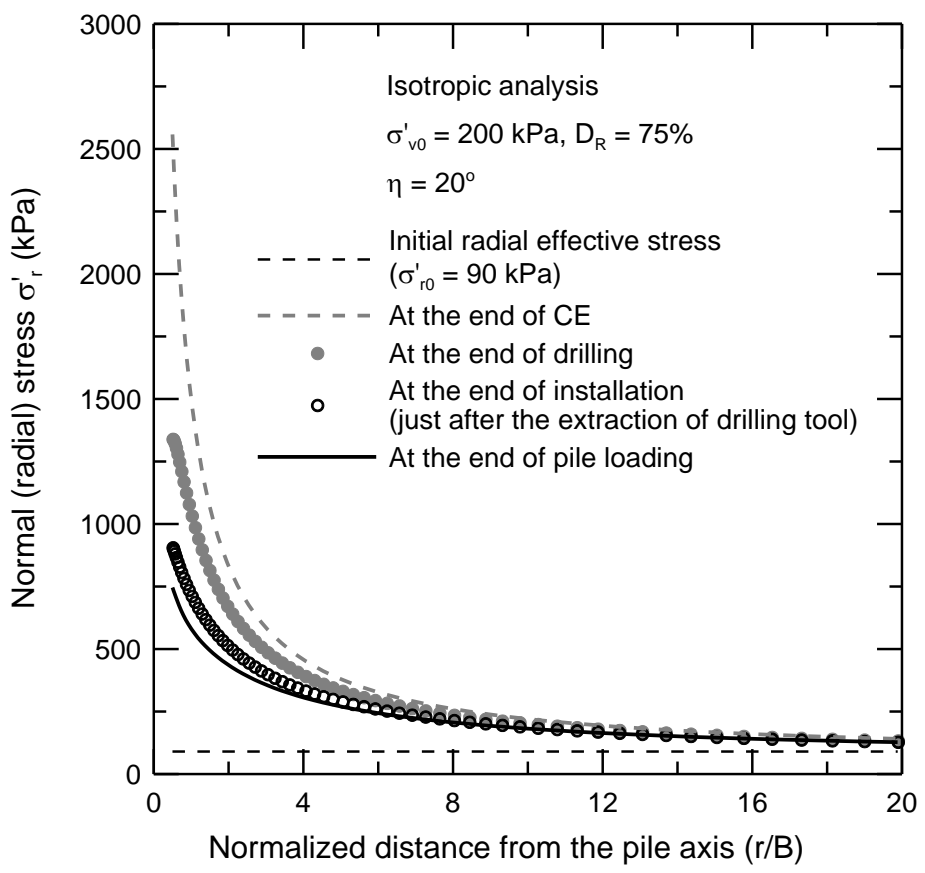

(b)

Figure 4.7 Effect of DD pile installation $\left(\eta=20^{\circ}\right)$ on the normal (radial) effective stress acting in the surrounding soil: (a) anisotropic analysis, and (b) isotropic analysis 
Figure 4.8 shows the influence of DD pile installation on the mean effective stress acting at different points within the surrounding medium. Results of an anisotropic analysis with $\sigma_{\mathrm{v} 0}^{\prime}=200 \mathrm{kPa}, p_{0}^{\prime}=126.67 \mathrm{kPa}$ and $D_{\mathrm{R}}=75 \%$ shows that within a zone of radius equal to $5 B$ around the pile axis the mean effective stress in the ground increases from its initial value. The maximum increase in $p^{\prime}$ is observed adjacent to the pile shaft; at this point $p^{\prime}$ becomes 3 times its initial value $p_{0}^{\prime}$ (Figure 4.8a). A small decrease in $p^{\prime}$ (from $p_{0}^{\prime}$ ) is observed within a zone between radii $5 B$ and $11 B$ from the pile axis; beyond a radial distance of $11 B$ from the pile axis, $p^{\prime}$ remains unchanged (Figure 4.8a). For an isotropic analysis with the same initial conditions the increase in $p^{\prime}$ becomes insignificant beyond a distance of $15 B$ from the pile axis (Figure $4.8 b$ ).

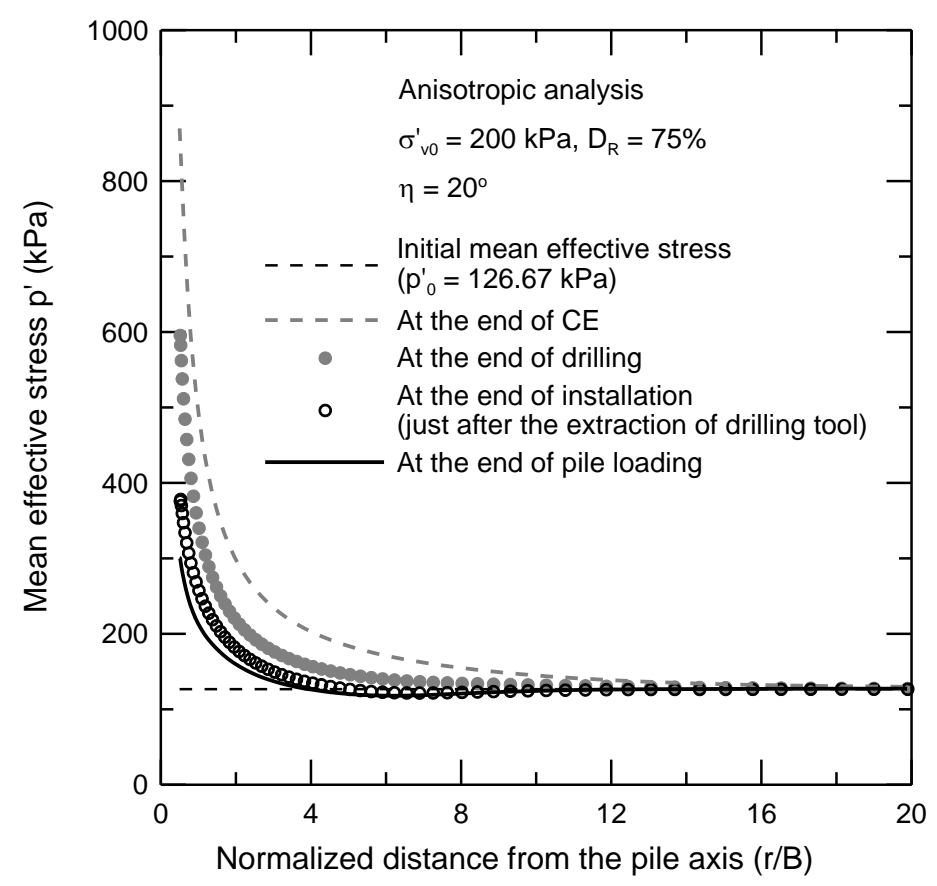

(a) 


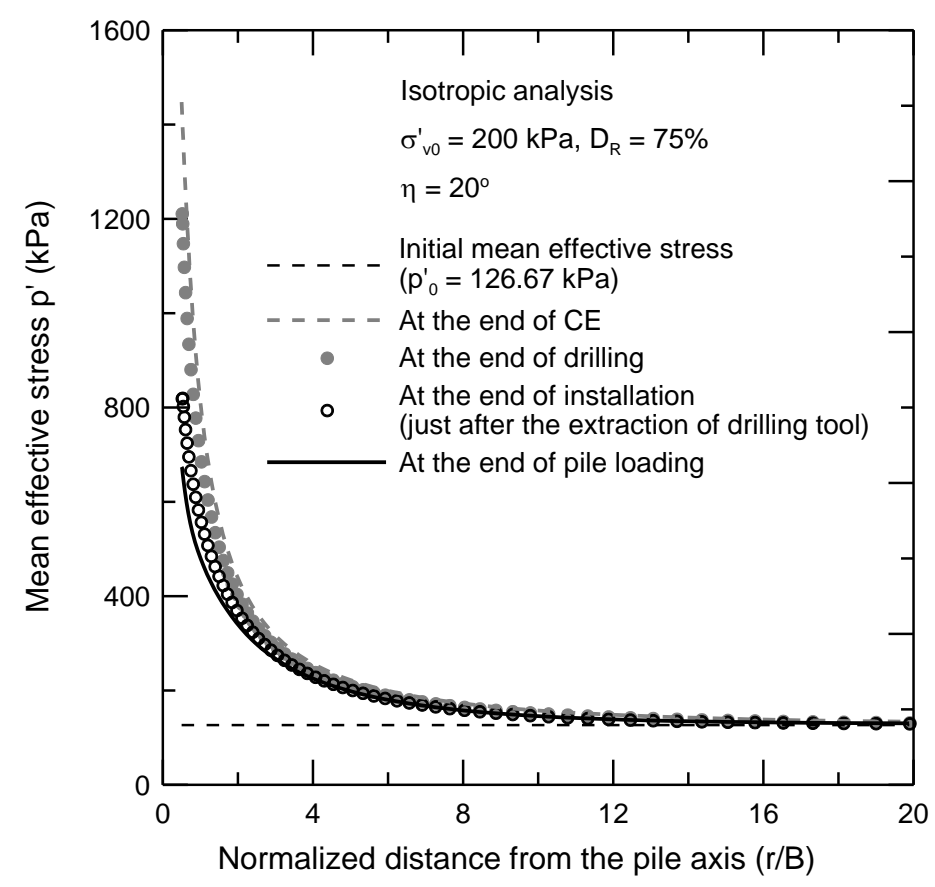

(b)

Figure 4.8 Effect of DD pile installation $\left(\eta=20^{\circ}\right)$ on the mean effective stress in the surrounding soil: (a) anisotropic analysis, and (b) isotropic analysis

Soil within a small zone (of radius equal to $1.3 B$ and $3.6 B$ from the pile axis, respectively, for anisotropic and isotropic analysis) surrounding the pile shaft dilates due to DD pile installation (Figure 4.9). A contractive zone is observed beyond this dilative zone. For an initially anisotropic sand fabric, the contractive zone is observed between radial distances of $1.3 B$ and $11 B$ from the pile axis (Figure $4.9 \mathrm{a}$ ). For an initially isotropic sand fabric this contractive zone is relatively less pronounced (Figure $4.9 \mathrm{~b}$ ). No volumetric change is observed in the zone beyond the contractive zone. 


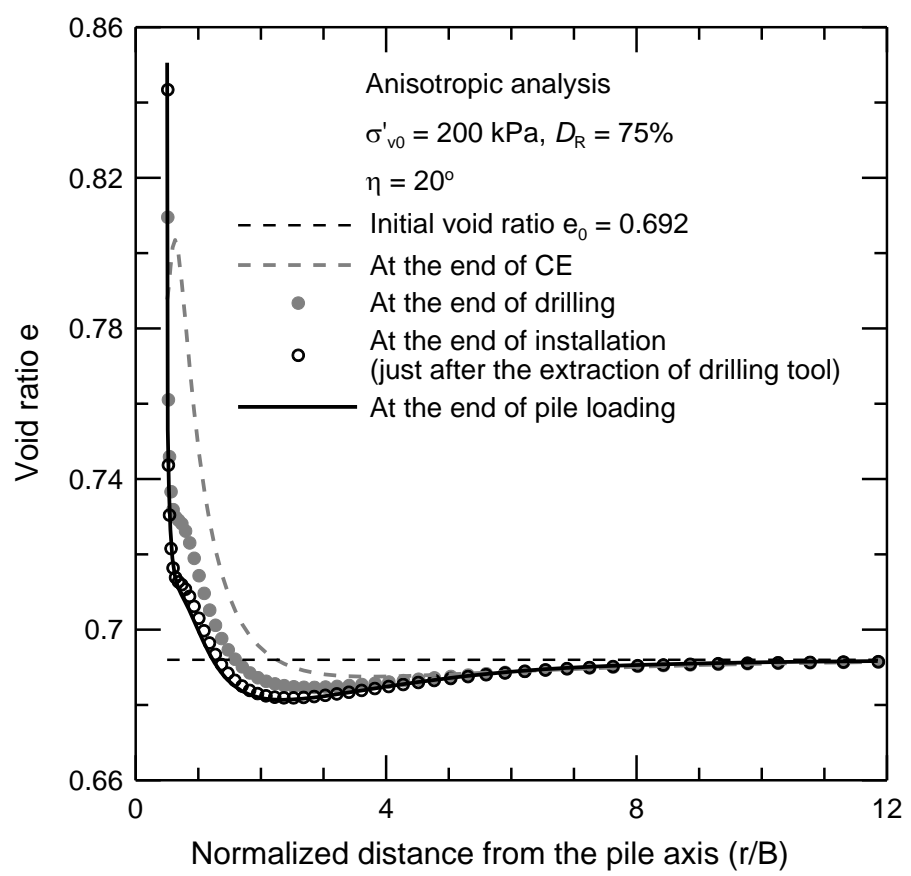

(a)

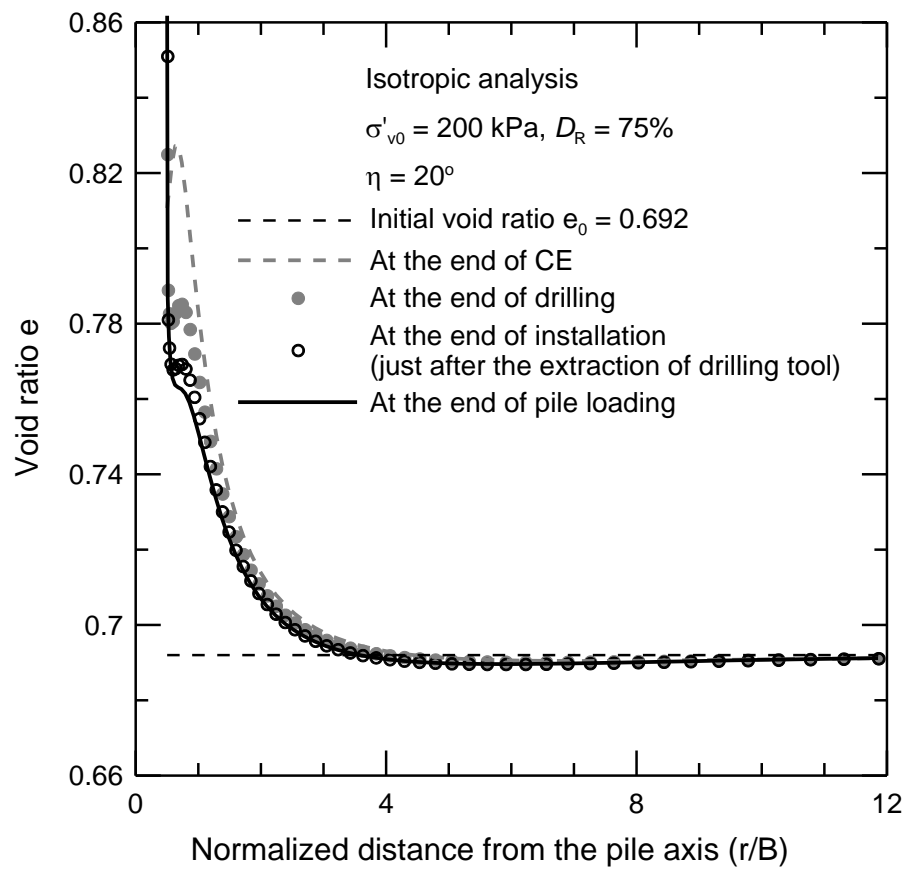

(b)

Figure 4.9 Effect of DD pile installation $\left(\eta=20^{\circ}\right)$ on the void ratio of the surrounding soil: (a) anisotropic analysis, and (b) isotropic analysis 
For different values of $\eta$, Figure 4.10 shows (for anisotropic analysis with $\sigma_{\mathrm{v} 0}^{\prime}=200 \mathrm{kPa}$, $\sigma_{\mathrm{r} 0}^{\prime}=90 \mathrm{kPa}$ and $\left.D_{\mathrm{R}}=75 \%\right)$ the profiles of normal effective stress, mean effective stress and void ratio at different radial distances from the axis of a DD pile at the end of installation. At a point just adjacent to the pile shaft, a maximum variation of $15 \%$ is observed for the normal and mean effective stresses as the value of $\eta$ changes from $0^{\circ}$ to $20^{\circ}$. The value of $\eta$ does not have any influence on the values of the normal effective stress and mean effective stress beyond radial distances of $16 B$ and $10 B$ (from the pile axis), respectively. The void ratio at any point does not practically vary (less than $1 \%$ at a point just adjacent to the pile shaft) for different values of $\eta$.

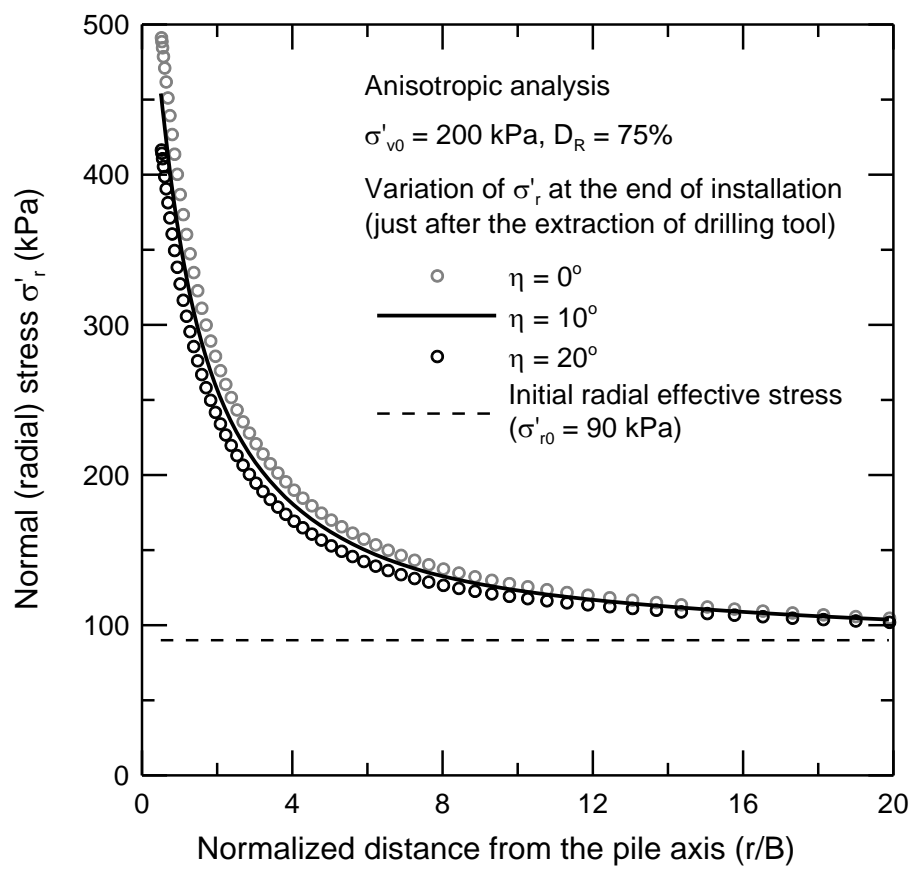

(a) 


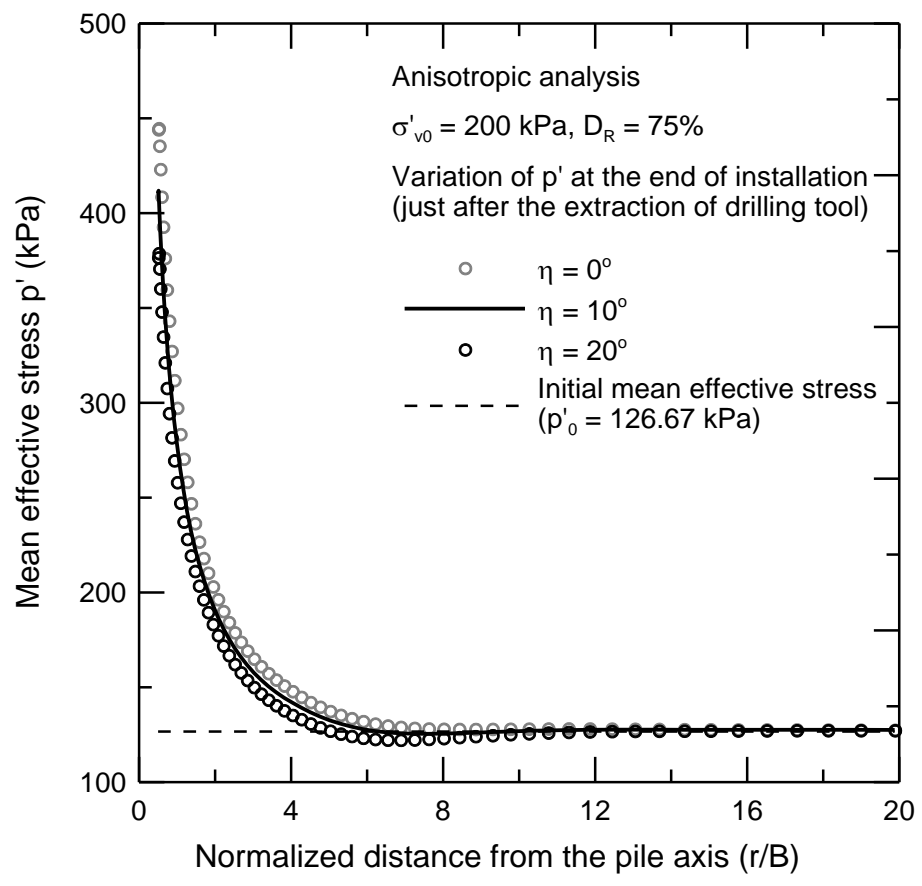

(b)

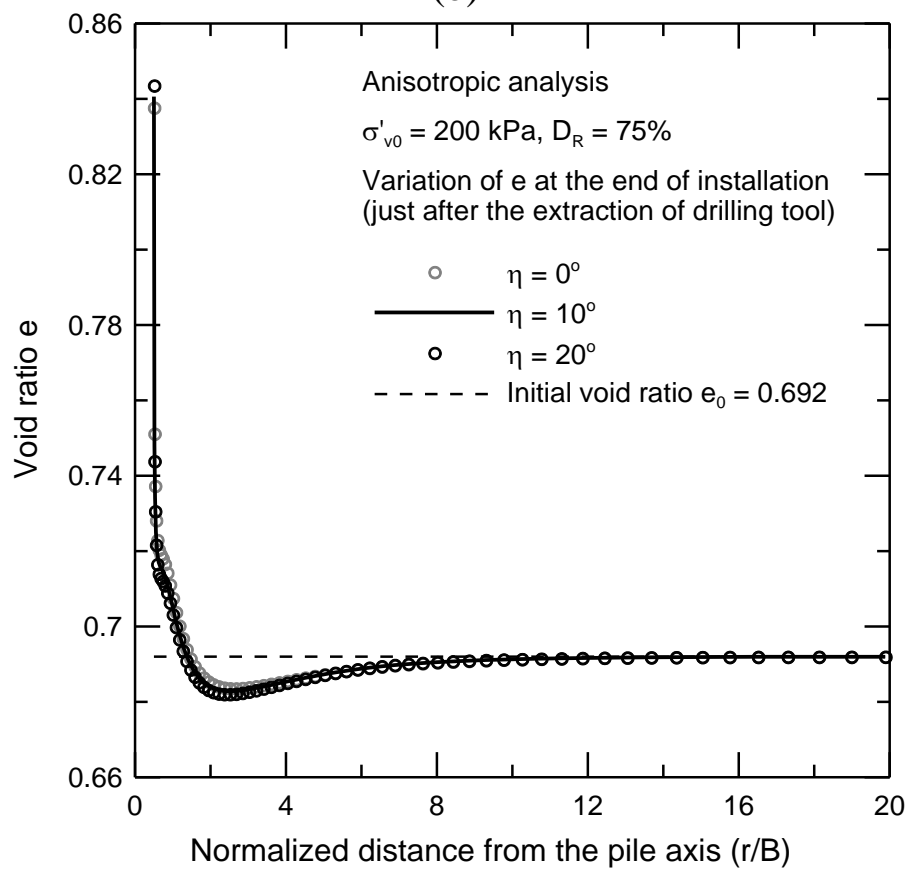

(c)

Figure 4.10 Effect of the angle $\eta$ on the stress state of the soil surrounding the pile just after the installation of a DD pile: (a) normal (radial) effective stress, (b) mean effective stress, and (c) void ratio 


\subsection{Summary of Analysis Results}

From the results of our analysis we observe that the soil surrounding a DD pile undergoes complex changes in its in situ stress state during the installation and loading of the pile. During the CE phase (associated with pile installation) the soil surrounding the pile is pushed away radially from the path of the pile. This radial displacement of soil increases the normal (radial) stress in the surrounding medium. The drilling (torsional and vertical shearing) phase associated with pile installation causes a reduction of normal (radial) stress acting adjacent to the pile shaft, however, the torsional and vertical shear stresses increases to reach limiting values at the end of this phase. Just after the extraction of the drilling tool, the torsional shear stress acting adjacent to the pile shaft becomes zero and the vertical shear stress reaches a negative limiting value. The normal (radial) stress acting on the pile shaft further decreases during the loading of the pile; the vertical shear stress acting along the pile shaft reaches a limiting value at the end of loading. The vertical shear stress acting along the pile shaft at the end of the loading stage is equal to the limit shaft resistance of the pile. In the next chapter, we present the lateral earth pressure coefficient that to be used in the calculation of limit shaft resistance of DD piles in sand. 


\section{CHAPTER 5. USE OF RESULTS IN DESIGN OF DRILLED DISPLACEMENT PILES}

\subsection{Introduction}

In this chapter, based on the FE simulation results, we propose a set of equations for the estimation of the coefficient of lateral earth pressure acting on the shaft of a DD pile. These equations can be used in the calculation of unit limit shaft resistance of a DD pile. The proposed equations demonstrate the effects of relative density and confinement on the unit limit shaft resistance of DD piles. We also demonstrate the impact of an installation parameter on the shaft capacity of DD piles.

\subsection{Proposed Equations for the Lateral Earth Pressure Coefficient}

We estimate the ratio $K / K_{0}\left(=\sigma_{\mathrm{r}}^{\prime} / \sigma_{\mathrm{r} 0}^{\prime}\right)$ from the recorded normal reaction on the pile shaft at the end of loading of the pile. The following mathematical expressions resulted from the FEA (both anisotropic and isotropic) of DD piles:

$$
\frac{K}{K_{0}}=0.33\left(\frac{\sigma_{\mathrm{v} 0}^{\prime}}{p_{\mathrm{A}}}\right)^{0.11} \exp \left[\left(\frac{D_{\mathrm{R}}}{100}\right)\left\{3.59+0.53 \ln \left(\frac{p_{\mathrm{A}}}{\sigma_{\mathrm{v} 0}^{\prime}}\right)\right\}(1-0.11 \tan \eta)\right]
$$

for anisotropic sand fabric, and

$$
\frac{K}{K_{0}}=1.30\left(\frac{\sigma_{\mathrm{v} 0}^{\prime}}{p_{\mathrm{A}}}\right)^{-0.11} \exp \left[\left(\frac{D_{\mathrm{R}}}{100}\right)\left\{2.91+0.38 \ln \left(\frac{p_{\mathrm{A}}}{\sigma_{\mathrm{v} 0}^{\prime}}\right)\right\}(1-0.12 \tan \eta)\right]
$$

for isotropic sand fabric, where $D_{\mathrm{R}}$ is expressed as a percentage (\%) between 0 and 100 and $p_{\mathrm{A}}$ is a reference stress ( $=100 \mathrm{kPa}$ or equivalent in other units). Figure 5.1 and Figure 5.2 show the variation of $K / K_{0}$ (for $\eta=10^{\circ}$ and $\eta=20^{\circ}$ ) with relative density for different initial vertical effective stress levels calculated using Equations (5.1) and (5.2) 
together with the values resulting from the FEA. $K / K_{0}$ increases with increasing relative density and decreasing initial confinement (a direct consequence of the increased soil dilatancy).

$K / K_{0}$ for the anisotropic case is always smaller than that for the isotropic case because the installation of a DD pile involves stress paths and loading modes in which the direction of the principal stress increment is closer to the horizontal plane (which the preferred orientation of the particle long axis tends to be parallel to for sands deposited under the action of gravity) than to the vertical plane. In such case, sand with an anisotropic fabric exhibits a more pronounced contractive (or less dilative) response, has less strength and is more compliant (Oda 1972; Tatsuoka et al. 1986; Tatsuoka et al. 1990; Yoshimine et al. 1998). Similar trend was also observed for $K / K_{0}$ obtained from FEA of jacked piles in sand (Basu et al. 2009a).

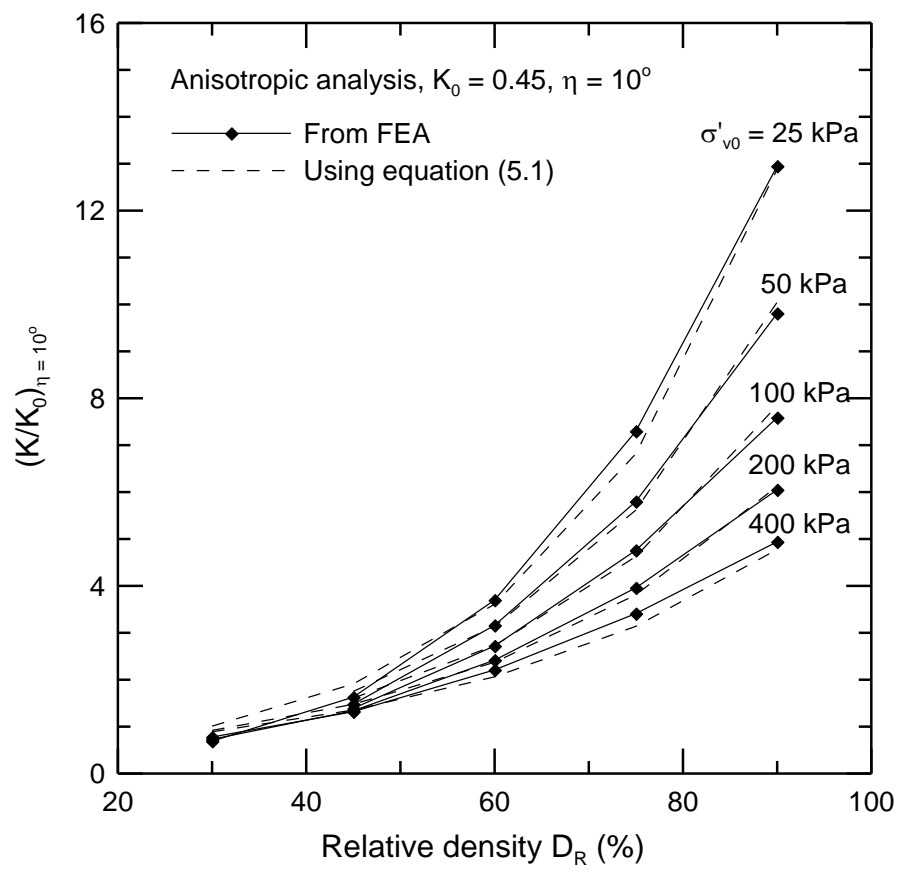

(a) 


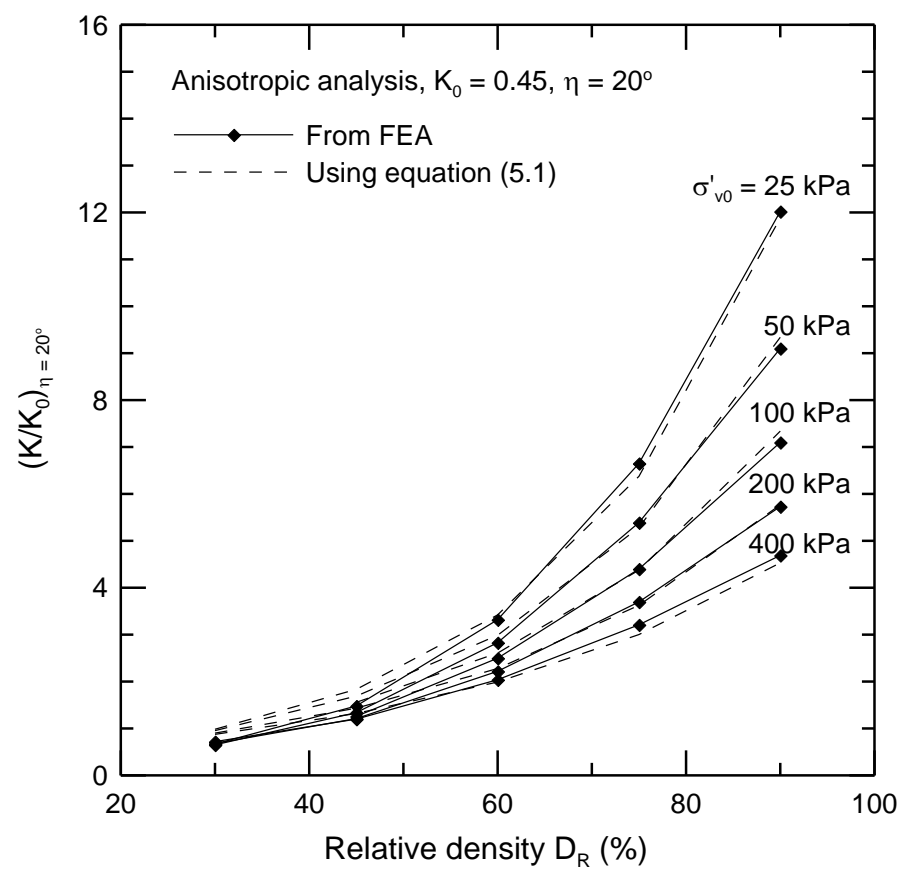

(b)

Figure $5.1 K / K_{0}$ predictions for DD piles (anisotropic analysis): (a) $\eta=10^{\circ}$, and (b) $\eta=$ $20^{\circ}$

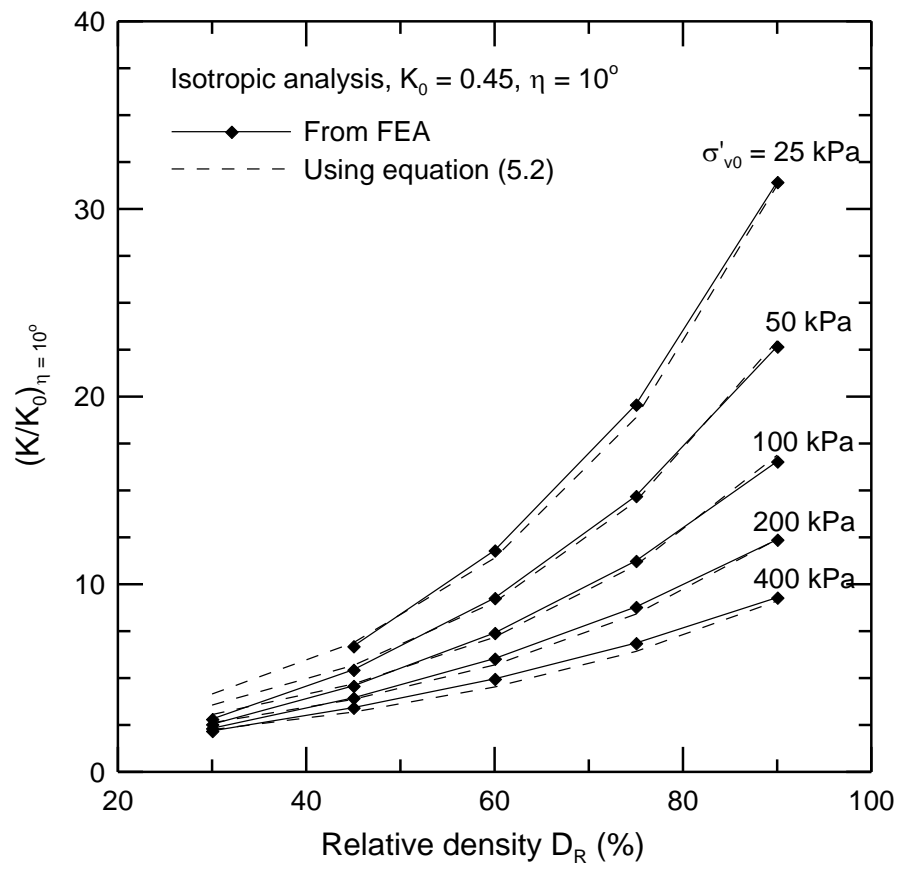

(a) 


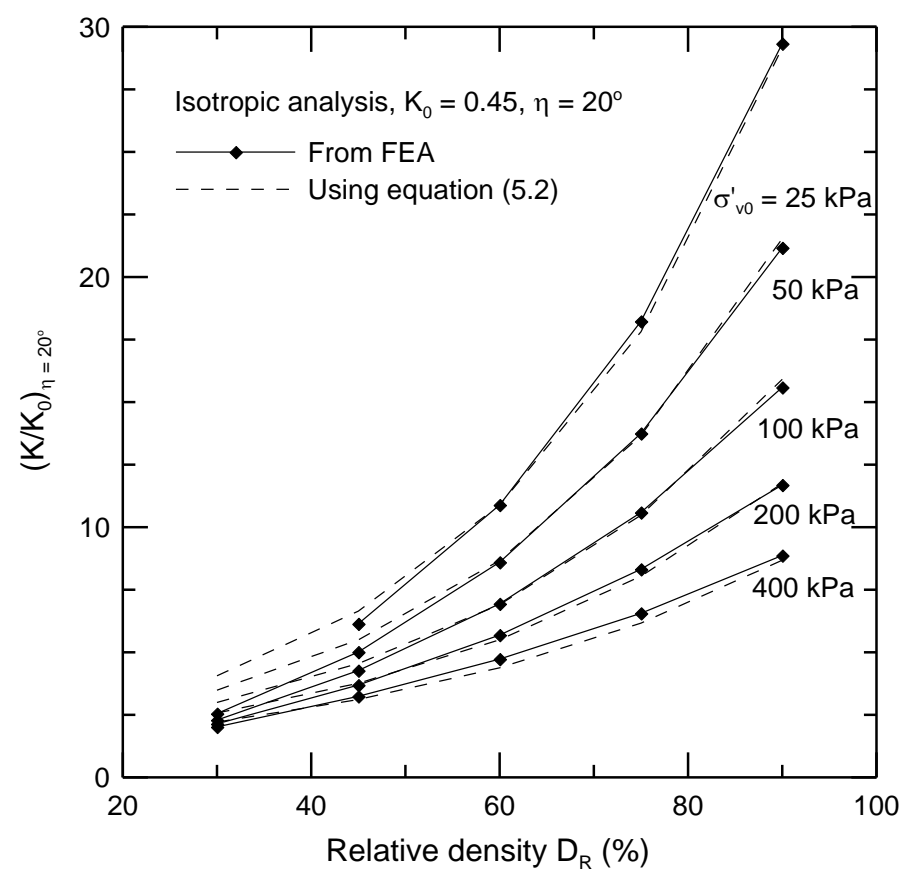

(b)

Figure $5.2 K / K_{0}$ predictions for DD piles (isotropic analysis): (a) $\eta=10^{\circ}$, and (b) $\eta=20^{\circ}$

We performed a parametric study (for $\sigma_{\mathrm{v} 0}^{\prime}=100 \mathrm{kPa}$ and $D_{\mathrm{R}}=60 \%$ ) to investigate the applicability of the proposed equations for $\eta$ values greater than $20^{\circ}$. Figure 5.3 shows $K / K_{0}$ values (for $\sigma_{\mathrm{v} 0}^{\prime}=100 \mathrm{kPa}$ and $D_{\mathrm{R}}=60 \%$ ) obtained from FEA with different values of $\eta$. Figure 5.3 also shows the prediction using equation (5.1). FEA results show that up to $\eta=45^{\circ}, K / K_{0}$ follows a decreasing trend; $K / K_{0}$ reaches an asymptotic value for $\eta \geq 45^{\circ}$. We observe that the prediction from the proposed equation matches well with the FEA results for $\eta \leq 45^{\circ}$ (with a maximum difference of $6 \%$ ). However, the proposed equation does not predict the asymptotic trend of $K / K_{0}$ for $\eta>45^{\circ}$. Therefore, equations (5.1) and (5.2) are valid for $\eta \leq 45^{\circ}$; for $\eta>45^{\circ}$ the value of $K / K_{0}$ corresponding to $\eta=45^{\circ}$ should be used. 


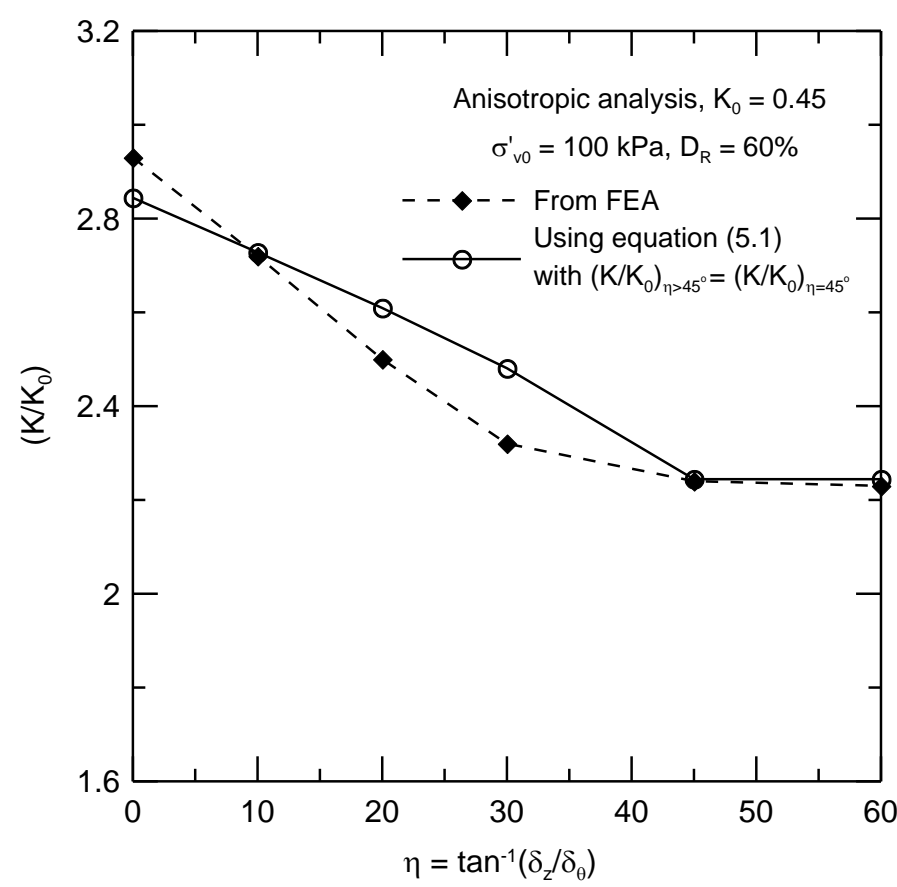

Figure 5.3 Variation of $K / K_{0}$ with different values of $\eta$ (anisotropic analysis with $\sigma_{\mathrm{v} 0}=$ $100 \mathrm{kPa}$ and $D_{\mathrm{R}}=60 \%$ )

\subsection{Effects of $K_{0} \underline{\text { and Pile Diameter } B \text { on the Earth Pressure Coefficient } K}$}

Equations 5.1 and 5.2 are based on the analyses performed for a $0.33 \mathrm{~m}$-diameter DD pile installed in normally consolidated Toyoura sand with an assumed value of $K_{0}$ equal to 0.45 . We performed a few analyses to investigate the effects of $K_{0}$ and $B$ values on the earth pressure coefficient $K$ at limit state conditions (Figure 5.4 and Figure 5.5). Figure 5.4 shows that for $K_{0}=0.6$ (an overconsolidated sand) the ratio $K / K_{0}$ differs only by $7.5 \%$ (for $\eta=10^{\circ}$ ) and $6.4 \%$ (for $\eta=20^{\circ}$ ) for installation in dense sand $\left(D_{\mathrm{R}}=90 \%\right.$ ). For medium-dense sand $\left(D_{\mathrm{R}}=45\right.$ to $\left.75 \%\right)$, the value of $K_{0}$ has minimal effect on the ratio $K / K_{0}$. Figure 5.5 shows the variation of $K / K_{0}$ at limit state conditions for two different pile diameters, $B=0.33 \mathrm{~m}$ and $0.6 \mathrm{~m}$. We observe that the ratio $K / K_{0}$ (for different $\eta$ values) does not change significantly (differing by no more than $1.6 \%$ ) as the pile diameter is changed. It should be noted that, irrespective of the pile diameter $B$, the same limit state is reached at the end of cavity expansion, and therefore, $B$ does not have a significant effect on the value of $K / K_{0}$ (at limit loading conditions) of DD piles. 


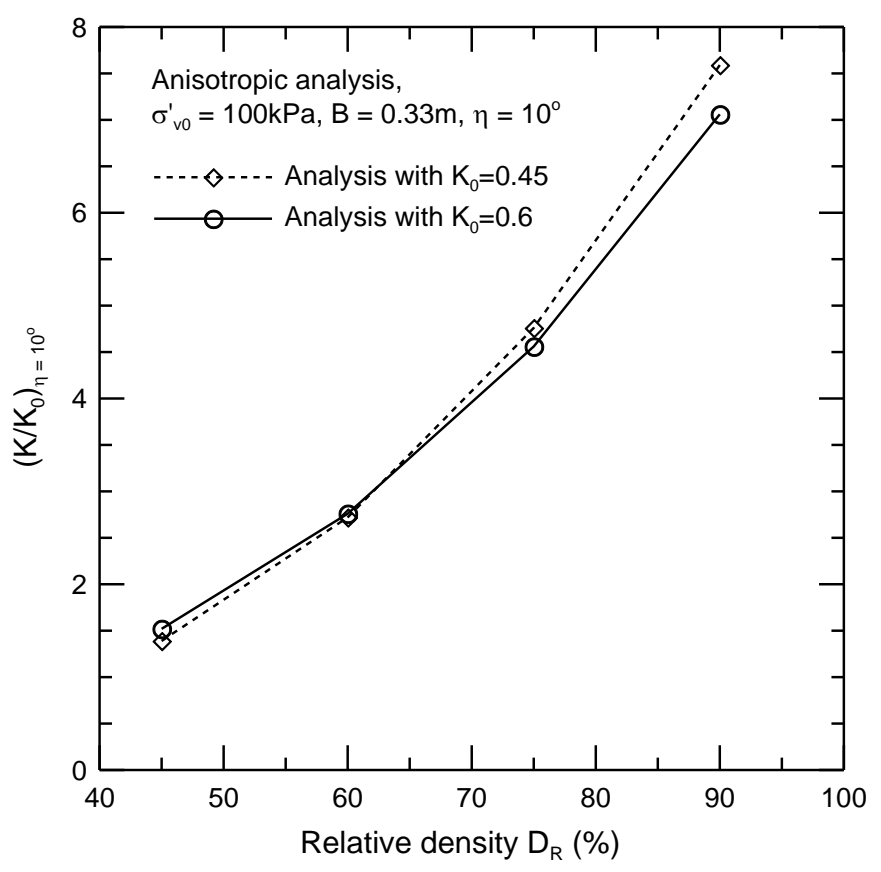

(a)

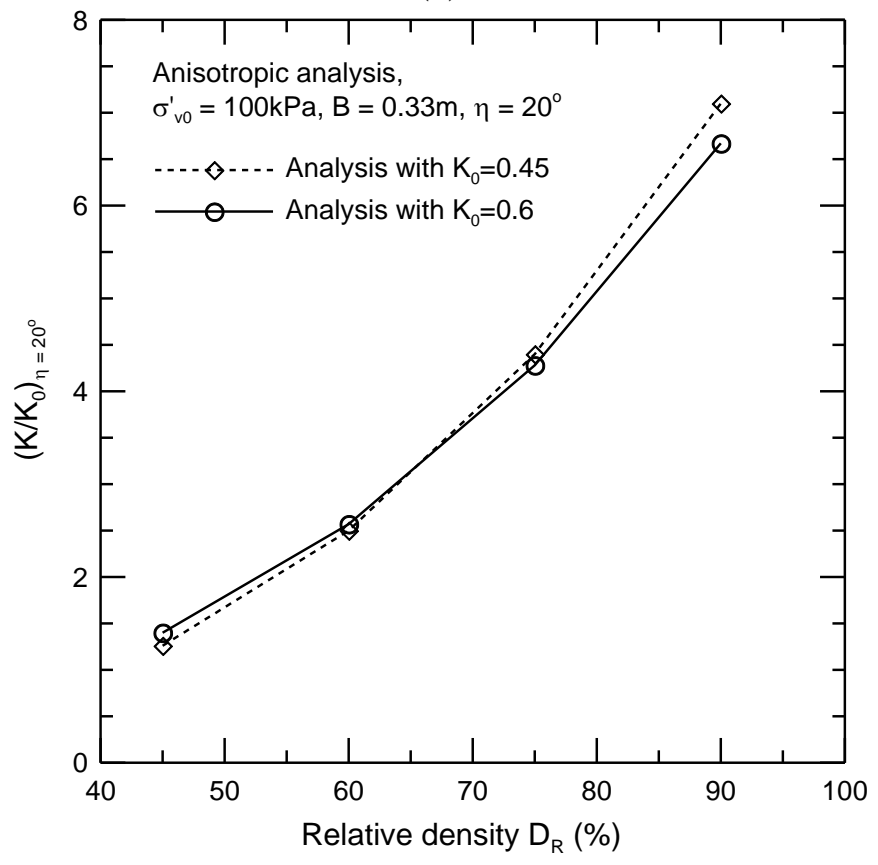

(b)

Figure 5.4 Effect of $K_{0}$ on the earth pressure coefficient $K$ at limit state conditions (anisotropic analysis with $\sigma_{\mathrm{v} 0}^{\prime}=100 \mathrm{kPa}$ ): (a) $\eta=10^{\circ}$, and (b) $\eta=20^{\circ}$ 


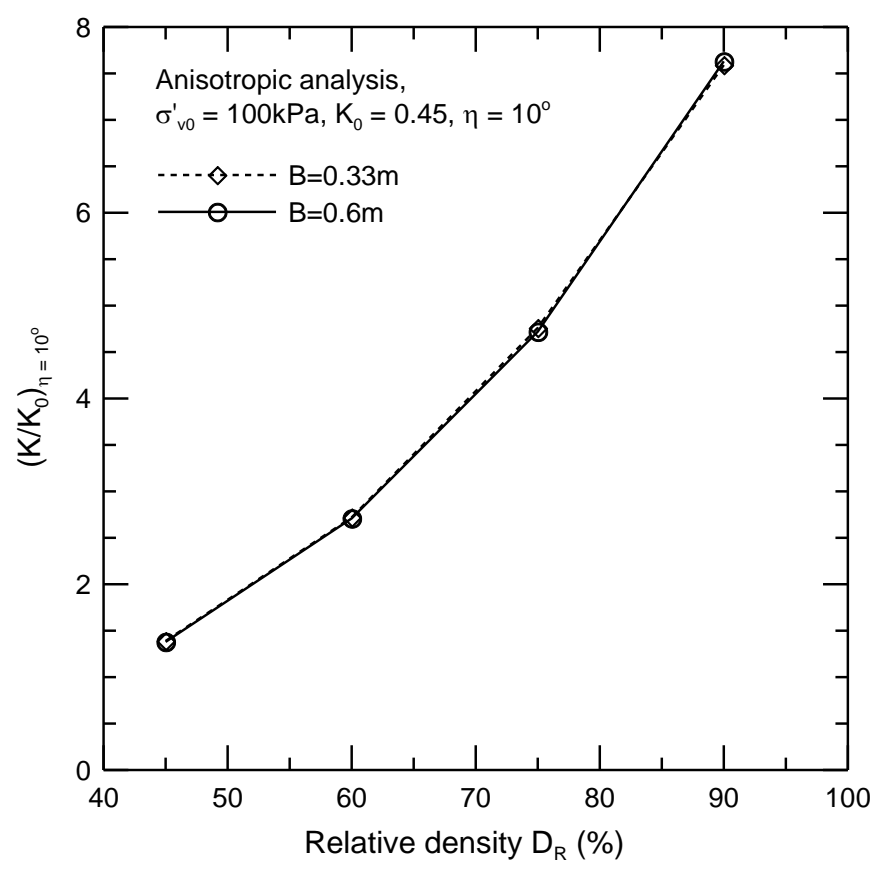

(a)

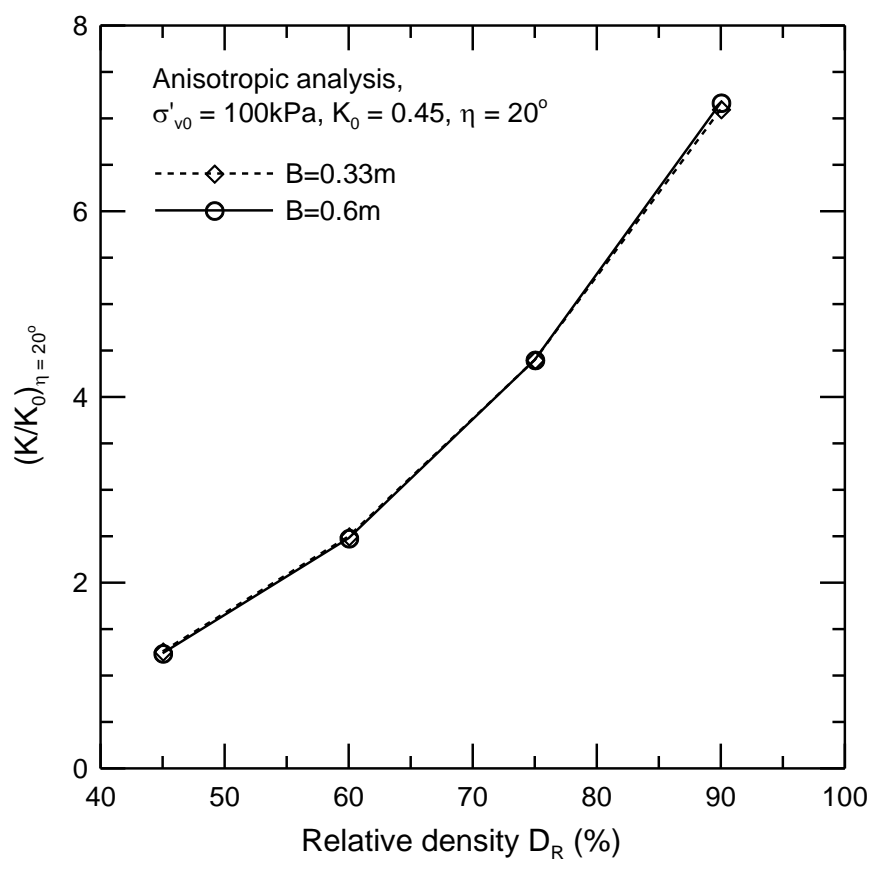

(b)

Figure 5.5 Effect of pile diameter $B$ on the ratio $K / K_{0}$ at limit state conditions (anisotropic analysis with $\sigma_{\mathrm{v} 0}^{\prime}=100 \mathrm{kPa}$ ): (a) $\eta=10^{\circ}$, and (b) $\eta=20^{\circ}$ 


\subsection{Comparison of Results from Coupled and Uncoupled Analysis}

The expressions for $K / K_{0}$, as shown in equations (5.1) and (5.2), are obtained from uncoupled analyses in which no shear displacements were applied during the CE phase of drilling (Stage 1). However, some shearing may be associated with the cavity expansion phase as well. We performed an additional set of analyses (coupled analyses) to evaluate the effect of additional shearing (both torsional and vertical) during the cavity expansion phase on the value of $K / K_{0}$. In the case of coupled analyses, we applied equal radial and torsional displacement increments (i.e., $\Delta \delta_{\mathrm{r}}=\Delta \delta_{\theta}$ ) during the cavity expansion phase. The vertical displacement increments applied during the cavity expansion phase of the coupled analyses were determined based on equation (4.2). The cavity expansion phase ended when the cavity radius became equal to the radius of the pile. Torsional and vertical shearing were continued until a limiting (critical) state that srepresented the end of drilling was reached. Figure 5.6 shows $K / K_{0}$ obtained from the coupled analyses (for $D_{\mathrm{R}}=45,60,75$, and $90 \% ; \sigma_{\mathrm{v} 0}^{\prime}=50,100,200$, and $400 \mathrm{kPa} ; \eta=10^{\circ}$ and $20^{\circ}$ ) superposed with those obtained from the uncoupled analyses. The values of $K / K_{0}$ obtained from the coupled analyses are 10 to $20 \%$ higher than those obtained from the uncoupled analyses.

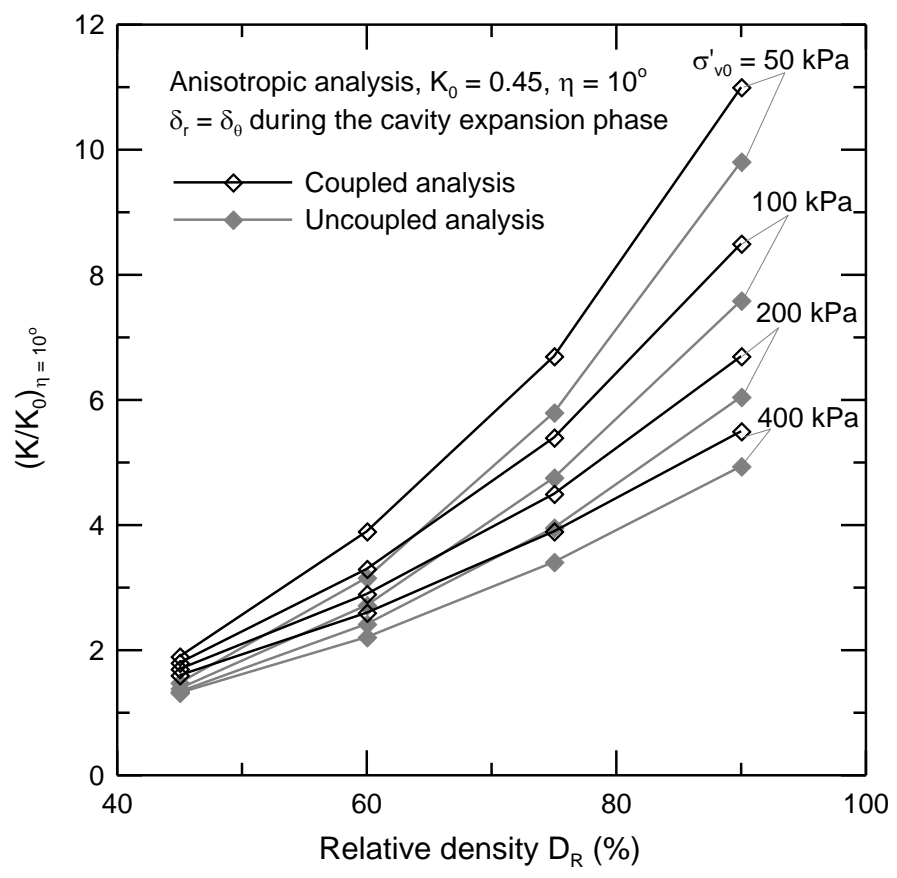

(a) 


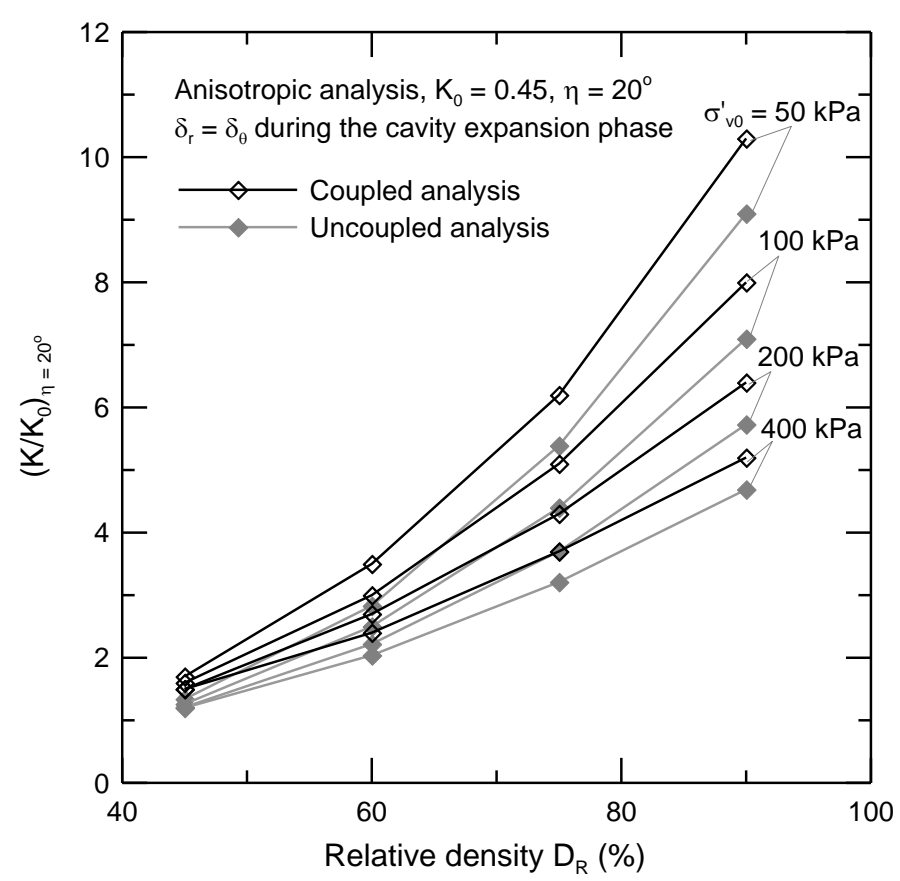

(b)

Figure 5.6 Comparison of $K / K_{0}$ obtained from coupled and uncoupled analysis: (a) $\eta=$ $10^{\circ}$, and (b) $\eta=20^{\circ}$

\subsection{Comparison of Shaft Resistances for Different Pile Types}

We compare the shaft resistance available for a DD pile with those available in cases of a nondisplacement (e.g. drilled shaft) and a full-displacement pile (installed by monotonic jacking) in sand. Loukidis and Salgado (2008), and Basu et al. (2009a) proposed FEA based equations to calculate the $K / K_{0}$ ratio for nondisplacement (drilled shaft) and fulldisplacement (jacked) piles in sand. Figure 5.7a shows that the ratio $K / K_{0}$ available for a DD pile, for different values of in situ (before pile installation) vertical effective stress, varies between 2.2 and 2.7 times (for $\sigma_{\mathrm{v} 0}^{\prime}=400 \mathrm{kPa}$ and $50 \mathrm{kPa}$, respectively) the $K / K_{0}$ for a drilled shaft installed in dense sand $\left(D_{\mathrm{R}}=75 \%\right)$. However, irrespective of the values of $\sigma_{\mathrm{v} 0}^{\prime}, K / K_{0}$ for a DD pile and that for a drilled shaft installed in medium-dense sand $\left(D_{\mathrm{R}}=\right.$ $45 \%)$ are almost the same. The difference in $K / K_{0}$ available for a monotonically jacked pile and that for a DD pile decreases as $D_{\mathrm{R}}$ increases (Figure $5.7 \mathrm{~b}$ ). $K / K_{0}$ for a monotonically jacked pile is 2.1 to 2.5 times (for $\sigma_{\mathrm{v} 0}^{\prime}=400$ and $50 \mathrm{kPa}$, respectively) the $K / K_{0}$ for a DD pile installed in medium-dense sand $\left(D_{\mathrm{R}}=45 \%\right)$. For dense sand $\left(D_{\mathrm{R}}=\right.$ 
$75 \%$ ), the monotonically jacked pile has 1.6 to 1.8 times (for $\sigma_{\mathrm{v} 0}^{\prime}=400$ and $50 \mathrm{kPa}$, respectively) higher values of $K / K_{0}$ compared to a DD pile.

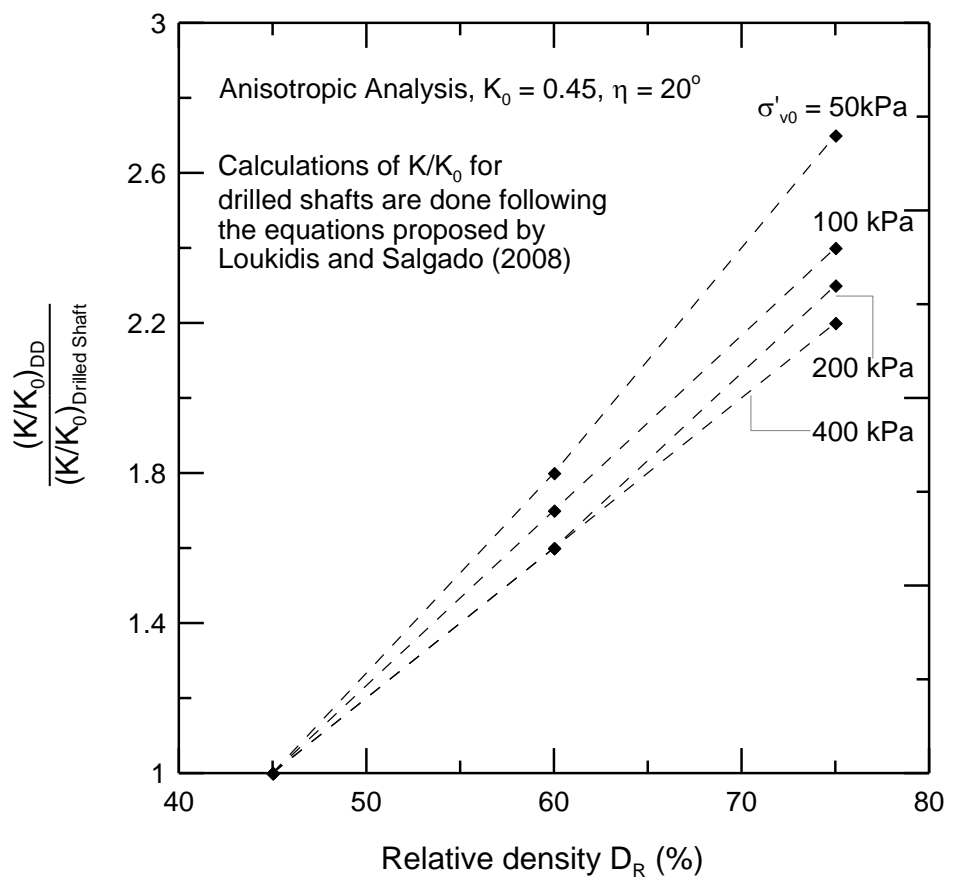

(a)

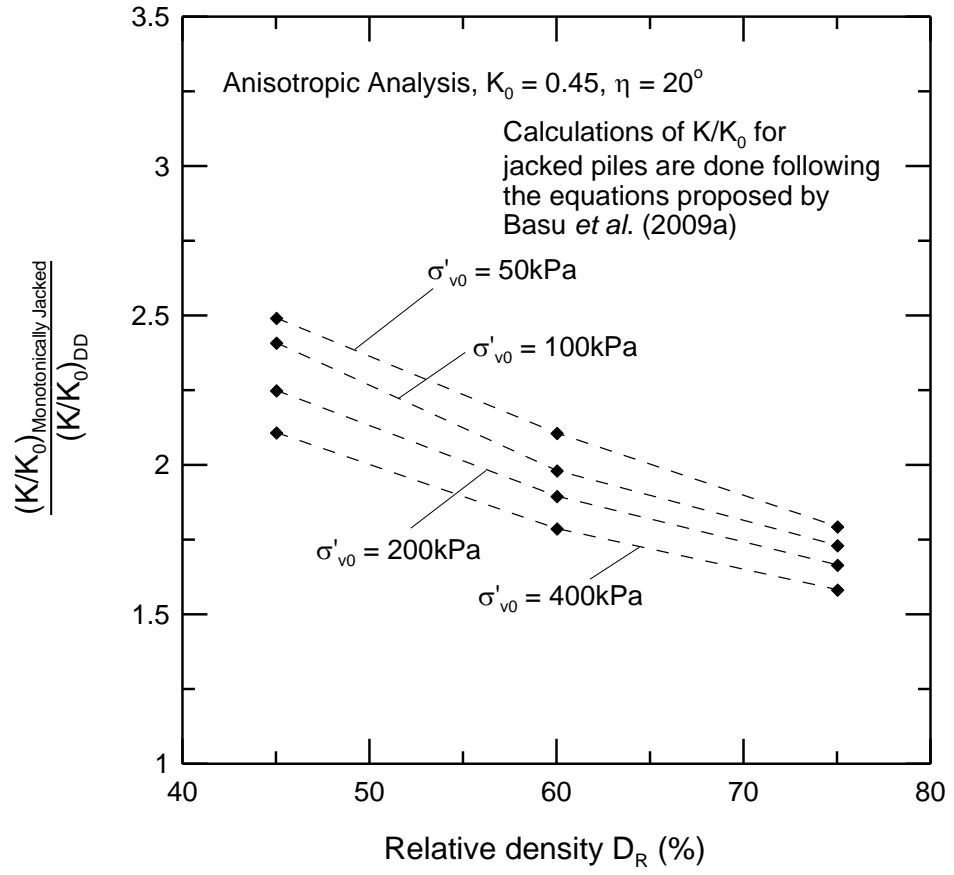

(b)

Figure 5.7 Comparison of $K / K_{0}$ for DD piles with those calculated for (a) a drilled shaft, and (b) a monotonically jacked pile 


\subsection{Design Examples}

We demonstrate the use of the proposed equations through two design examples. In the first example, we calculate the limit shaft capacity of a DD pile installed in homogeneous, medium-dense $\left(D_{\mathrm{R}}=65 \%\right)$ normally consolidated $\left(K_{0}=0.45\right)$ sand (Figure 5.8a). We compare the calculated limit shaft capacity with those obtained using different available design methods described in Chapter 2. In the second example, we evaluate the limit shaft capacity of the same DD pile installed in a multilayered (relative density varying with depth) sand deposit (Figure 5.8b). The limit shaft capacity obtained using the method proposed in this report is compared with that calculated using different empirical design methods.

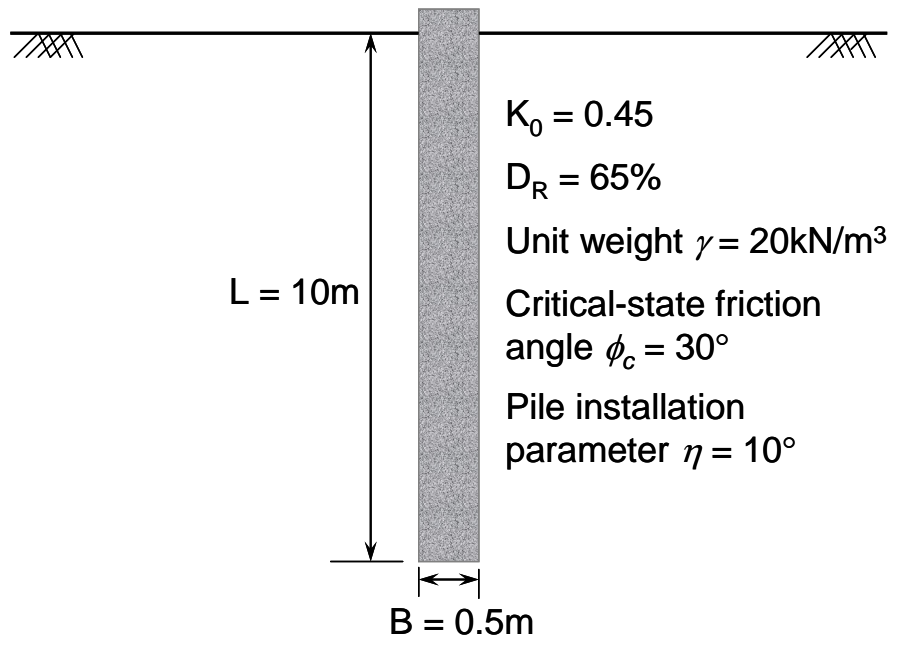

(a) 


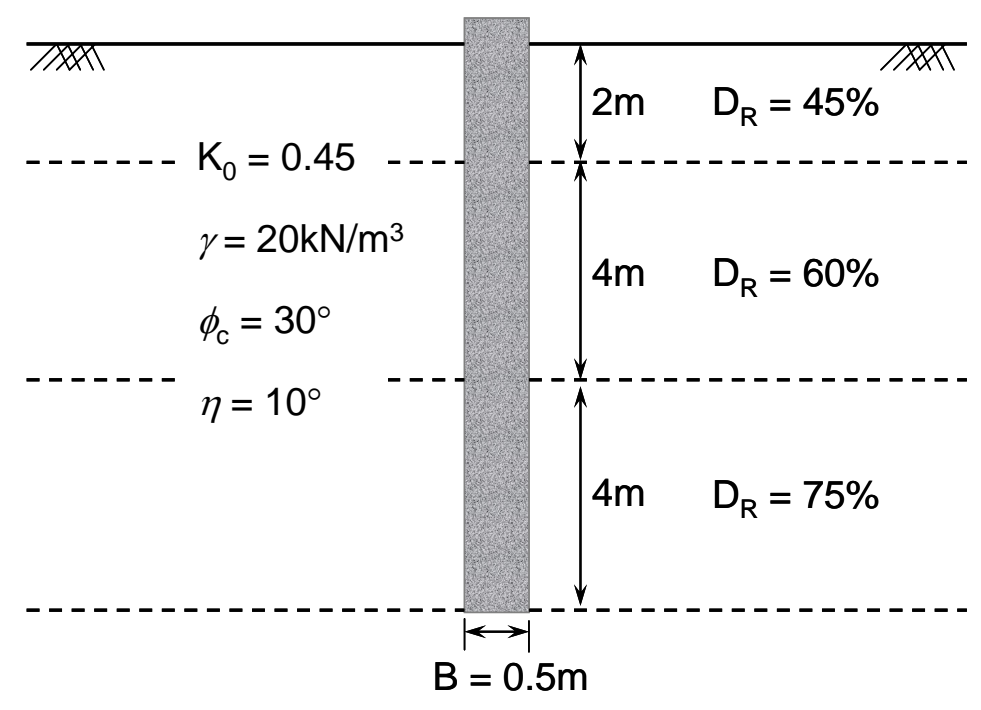

(b)

Figure 5.8 Pile and soil profile for the design examples: (a) the homogeneous sand deposit used in Example 1, and (b) the multilayered sand deposit used in Example 2

\subsubsection{DD Pile in Homogeneous Sand Deposit: Example 1}

We divide the pile in ten $1 \mathrm{~m}$-long segments to calculate the shaft capacity of the pile. We calculate the local values of limit unit shaft resistance $q_{\mathrm{sL}, \mathrm{i}}$ at the mid-depth of each segment and multiply those values with the available shaft area $\Delta A_{\mathrm{si}}(=\pi \mathrm{B} \Delta L ; \Delta L$ is the length of each segment) of each segment to obtain the shaft resistance available from each pile segment. We obtain the total shaft capacity of the pile by adding up the resistance values calculated for all the pile segments.

Sample calculations (using the proposed soil property based method) for Example 1

We present the sample calculation for a pile segment (Segment No. 6) between depths $5 \mathrm{~m}$ and $6 \mathrm{~m}$ from ground surface. The mid-depth of this segment is at $5.5 \mathrm{~m}$ from the ground surface.

At depth $5.5 \mathrm{~m}$, the in situ vertical stress $\sigma_{\mathrm{v} 0}^{\prime}=5.5 \times 20=110 \mathrm{kPa}$

Given value of relative density $D_{\mathrm{R}}=65 \%$ 
Given value of in situ later earth pressure coefficient $K_{0}=0.45$

Using Equation (5.1), for an initially anisotropic sand fabric, the value of earth pressure coefficient $K$ at limit condition is

$$
\begin{aligned}
K & =K_{0}\left[0.33\left(\frac{\sigma_{\mathrm{v} 0}^{\prime}}{p_{\mathrm{A}}}\right)^{0.11} \exp \left[\left(\frac{D_{\mathrm{R}}}{100}\right)\left\{3.59+0.53 \ln \left(\frac{p_{\mathrm{A}}}{\sigma_{\mathrm{v} 0}^{\prime}}\right)\right\}(1-0.11 \tan \eta)\right]\right] \\
& =0.45 \times 0.33\left(\frac{110}{100}\right)^{0.11} \exp \left[\left(\frac{65}{100}\right)\left\{3.59+0.53 \ln \left(\frac{100}{110}\right)\right\}\left(1-0.11 \tan 10^{\circ}\right)\right] \\
& =1.4
\end{aligned}
$$

As discussed earlier in this report, the interface friction angle $\delta$ can be calculated from the critical-state friction angle $\phi_{\mathrm{c}}$ of the soil. In the present example, for a DD pile (i.e. for a rough pile-soil interface), $\delta$ is calculated as:

$$
\delta=0.95 \phi_{\mathrm{c}}=0.95 \times 30^{\circ}=28.5^{\circ}
$$

Now, the limit shaft resistance available at a depth $5.5 \mathrm{~m}$ is

$$
\begin{aligned}
\left.q_{\mathrm{sLi}}\right|_{\text {at } 5.5 \mathrm{~m} \mathrm{depth}} & =\sigma_{\mathrm{v} 0}^{\prime}(K \tan \delta) \\
& =110\left(1.4 \tan 28.5^{\circ}\right) \\
& =85.6 \mathrm{kPa}
\end{aligned}
$$

The available shaft area $\Delta A_{\text {si }}$ for this pile segment (Segment No. 6):

$$
\Delta A_{\mathrm{si}}=\pi B \Delta L=\pi \times 0.5 \times 1=1.6 \mathrm{~m}^{2}
$$

Thus, the available shaft resistance $\Delta Q_{\text {sLi }}$ from this pile segment (Segment No. 6) will be:

$$
\begin{aligned}
\Delta Q_{\mathrm{sLi}} & =q_{\mathrm{sLi}} \Delta A_{\mathrm{si}} \\
& =85.6 \times 1.6 \\
& =134.4 \mathrm{kPa}
\end{aligned}
$$


Similarly, $\Delta Q_{\mathrm{sLi}}$ for all other pile segments are calculated and added up to obtain the limit shaft capacity $Q_{\mathrm{sL}}$ of the pile.

$$
\begin{aligned}
Q_{s L} & =\sum_{\mathrm{i}=1}^{10} \Delta Q_{\mathrm{sLi}} \\
& =1204.4 \approx 1204 \mathrm{kN}
\end{aligned}
$$

Table 5.1 summarizes the calculation results for Example 1. Table 5.1also shows the results obtained by using the empirical design methods described in Chapter 2. To use the empirical design methods, we need to obtain a CPT resistance profile from the soil properties specified in Example 1 (see Figure 5.8a). Based on the results of cavity expansion analysis in sand, Salgado and Prezzi (2007) proposed the following expression to calculate $q_{\mathrm{c}}$ as a function of $D_{\mathrm{R}}$ (expressed in $\left.\%\right), \sigma_{\mathrm{h} 0}$, and $\phi_{\mathrm{c}}$

$$
\frac{q_{c}}{p_{A}}=1.64 \exp \left[0.1041 \phi_{c}+\left(0.0264-0.0002 \phi_{c}\right) D_{\mathrm{R}}\right]\left(\frac{\sigma_{\mathrm{h}}^{\prime}}{p_{\mathrm{A}}}\right)^{0.841-0.0047 D_{R}}
$$

where $D_{\mathrm{R}}$ is in $\%$. We used Equation (5.3) to calculate the values of cone resistance $q_{\mathrm{c}}$ at different depths along the pile. Figure 5.9 shows the $q_{\mathrm{c}}$ profile (calculated using Equation 5.3) used in the calculation of shaft resistance using the empirical design methods (i.e. Methods A, B, and C). 


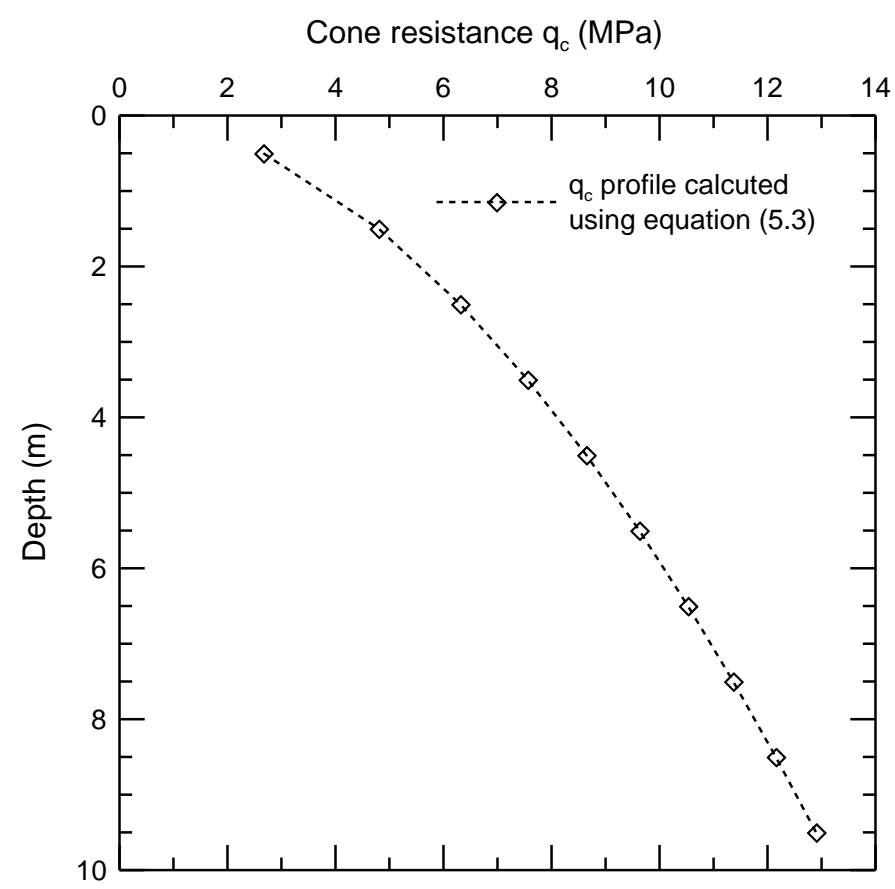

Figure 5.9 Cone resistance $q_{\mathrm{c}}$ profile for Example 1

Example 1 shows that the empirical design methods predict higher limit shaft capacity for a DD pile installed in a homogeneous, medium-dense sand deposit. The limit shaft capacity calculated using the method proposed in this report (developed from the results of anisotropic analysis) compares reasonably well with that predicted by the design methods B and C (with differences equal to 11.4 and $15.9 \%$, respectively). The design method A predicts $27 \%$ higher limit shaft capacity than that calculated using the design method proposed in this report.

\subsubsection{DD Pile in a Multilayered Sand Deposit: Example 2}

We follow the same steps, as described in Example 1, to calculate the shaft resistance of the DD pile installed in a multilayered sand deposit (with relative density varying with depth). Figure 5.10 shows the $q_{\mathrm{c}}$ profile (calculated using Equation 5.3) used in the calculation of shaft resistance using the empirical design methods (i.e. Methods A, B, and C). Calculation results are summarized in Table 5.2. The limit shaft capacity of DD pile 
calculated using the equation (developed from the results of anisotropic analysis) proposed in this report matches well with that predicted by the design methods $\mathrm{B}$ and $\mathrm{C}$ (with differences equal to 3.8 and $0.1 \%$, respectively). As we observed in Example 1, in this case also, the design method A predicts higher limit shaft capacity compared to the other design methods.

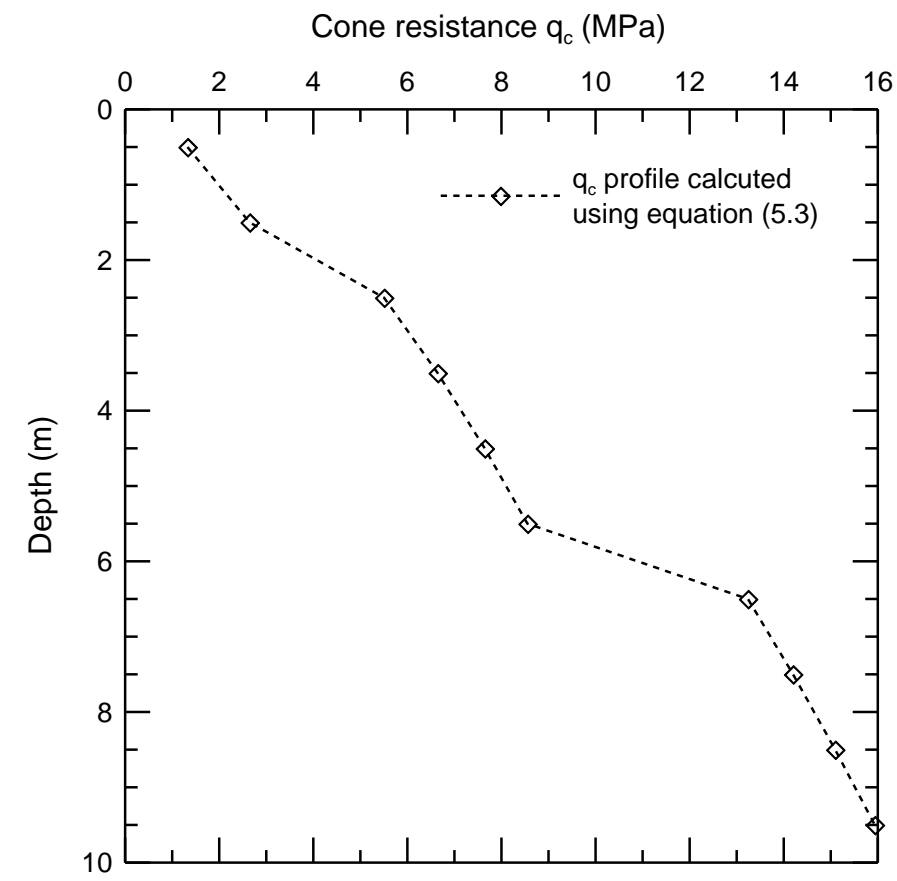

Figure 5.10 Cone resistance $q_{\mathrm{c}}$ profile for Example 2 
Table 5.1 Calculation of limit shaft resistance (for Example 1) using different design methods

\begin{tabular}{|c|c|c|c|c|c|c|c|c|c|c|c|c|c|}
\hline \multirow[b]{2}{*}{$\begin{array}{c}\text { Pile } \\
\text { segment }\end{array}$} & \multirow[b]{2}{*}{$\begin{array}{c}\text { Mid- } \\
\text { depth } \\
(\mathbf{m})\end{array}$} & \multicolumn{4}{|c|}{ Proposed Method } & \multicolumn{4}{|c|}{ Method A } & \multicolumn{2}{|c|}{ Method B } & \multicolumn{2}{|c|}{ Method C } \\
\hline & & $\left(\begin{array}{c}\sigma_{\mathrm{v0}}^{\prime} \\
(\mathrm{kPa})\end{array}\right.$ & $K / K_{0}$ & $\mid \begin{array}{c}\boldsymbol{q}_{\mathrm{sLi}} \\
(\mathbf{k P a})\end{array}$ & $\underset{(\mathbf{k N})}{\Delta Q_{\text {sLi }}}$ & $\begin{array}{c}\text { Cone } \\
\text { resistance } \boldsymbol{q}_{\mathrm{c}} \\
\text { (MPa) }\end{array}$ & 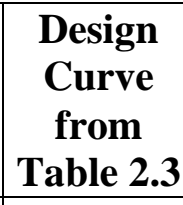 & \begin{tabular}{|c}
$q_{\mathrm{sLi}}$ from \\
Figure \\
$2.11(\mathrm{kPa})$
\end{tabular} & $\underset{(\mathbf{k N})}{\Delta Q_{\text {sLi }}}$ & $\begin{array}{c}q_{\mathrm{sLi}} \text { from } \\
\text { Equation } \\
(2.10)(\mathrm{kPa})\end{array}$ & $\underset{(\mathbf{k N})}{\Delta Q_{\text {sLi }}}$ & $\begin{array}{c}q_{\mathrm{sLi}} \text { from } \\
\text { Equation } \\
(2.18)(\mathrm{kPa})\end{array}$ & $\underset{(\mathbf{k N})}{\Delta Q_{\text {sLi }}}$ \\
\hline 1 & 0.5 & 10 & 5.5 & 13.4 & 21.1 & 2.7 & Q3 & 41.9 & 65.8 & 26.7 & 41.9 & 29.6 & 46.5 \\
\hline 2 & 1.5 & 30 & 4.3 & 31.4 & 49.3 & 4.8 & Q4 & 77.7 & 122.1 & 48.0 & 75.4 & 53.3 & 83.7 \\
\hline 3 & 2.5 & 50 & 3.8 & 46.5 & 73.1 & 6.3 & $\mathrm{Q} 4$ & 90.6 & 142.3 & 63.1 & 99.1 & 70.1 & 110.0 \\
\hline 4 & 3.5 & 70 & 3.5 & 60.3 & 94.8 & 7.6 & Q4 & 100.5 & 157.9 & 75.6 & 118.7 & 83.9 & 131.8 \\
\hline 5 & 4.5 & 90 & 3.3 & 73.3 & 115.1 & 8.6 & Q5 & 108.6 & 170.6 & 86.5 & 135.8 & 96.0 & 150.7 \\
\hline 6 & 5.5 & 110 & 3.2 & 85.6 & 134.4 & 9.6 & Q5 & 115.5 & 181.4 & 96.3 & 151.2 & 106.9 & 167.9 \\
\hline 7 & 6.5 & 130 & 3.1 & 97.3 & 152.9 & 10.5 & Q5 & 121.5 & 190.9 & 105.3 & 165.4 & 116.9 & 183.6 \\
\hline 8 & 7.5 & 150 & 3.0 & 108.7 & 170.7 & 11.4 & Q5 & 126.8 & 199.2 & 113.7 & 178.5 & 115.5 & 181.4 \\
\hline 9 & 8.5 & 170 & 2.9 & 119.7 & 188.1 & 12.2 & Q5 & 131.6 & 206.7 & 121.5 & 190.9 & 118.6 & 186.3 \\
\hline 10 & 9.5 & 190 & 2.8 & 130.5 & 204.9 & 12.9 & Q5 & 136 & 213.6 & 129.0 & 202.6 & 121.6 & 191.0 \\
\hline \multicolumn{5}{|c|}{$Q_{\mathrm{sL}}(\mathrm{kN})$} & 1204.4 & & & & 1650.4 & & 1359.6 & & 1432.8 \\
\hline
\end{tabular}


Table 5.2 Calculation of limit shaft resistance (for Example 2) using different design methods

\begin{tabular}{|c|c|c|c|c|c|c|c|c|c|c|c|c|c|c|}
\hline \multirow[b]{2}{*}{$\begin{array}{c}\text { Pile } \\
\text { segment }\end{array}$} & \multirow[b]{2}{*}{$\begin{array}{c}\text { Mid- } \\
\text { depth } \\
(\mathbf{m})\end{array}$} & \multirow[b]{2}{*}{$\begin{array}{c}\text { Relative } \\
\text { density } \\
(\%)\end{array}$} & \multicolumn{4}{|c|}{ Proposed Method } & \multicolumn{4}{|c|}{ Method A } & \multicolumn{2}{|c|}{ Method B } & \multicolumn{2}{|c|}{ Method C } \\
\hline & & & 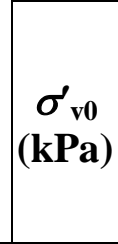 & $K / K_{0}$ & $\left(\begin{array}{c}q_{\mathrm{sLi}} \\
(\mathbf{k P a})\end{array}\right.$ & $\begin{array}{c}\Delta Q_{\text {sLi }} \\
(\mathbf{k N})\end{array}$ & $\begin{array}{c}\text { Cone } \\
\text { resistance } \\
q_{\mathrm{c}}(\mathrm{MPa})\end{array}$ & $\begin{array}{c}\text { Design } \\
\text { Curve } \\
\text { from } \\
\text { Table } \\
2.3 \\
\end{array}$ & $\begin{array}{c}q_{\mathrm{sLi}} \\
\text { from } \\
\text { Figure } \\
2.11 \\
(\mathrm{kPa})\end{array}$ & $\underset{(\mathbf{k N})}{\Delta Q_{\text {sLi }}}$ & $\begin{array}{c}\boldsymbol{q}_{\mathrm{sLi}} \text { from } \\
\text { Equation } \\
(2.10) \\
(\mathbf{k P a})\end{array}$ & $\underset{(\mathbf{k N})}{\Delta Q_{\mathrm{sLi}}}$ & $\begin{array}{c}\boldsymbol{q}_{\mathrm{sLi}} \text { from } \\
\text { Equation } \\
(\mathbf{2 . 1 8}) \\
(\mathbf{k P a})\end{array}$ & $\underset{(\mathbf{k N})}{\Delta Q_{\text {sLi }}}$ \\
\hline 1 & 0.5 & 45 & 10 & 2.1 & 5.2 & 8.2 & 1.3 & Q3 & 29.4 & 46.2 & 13.2 & 20.8 & 14.7 & 23.1 \\
\hline 2 & 1.5 & 45 & 30 & 1.9 & 13.7 & 21.5 & 2.6 & Q3 & 41.7 & 65.5 & 26.4 & 41.5 & 29.4 & 46.1 \\
\hline 3 & 2.5 & 60 & 50 & 3.1 & 38.3 & 60.2 & 5.5 & Q4 & 83.9 & 131.8 & 55.0 & 86.4 & 61.1 & 95.9 \\
\hline 4 & 3.5 & 60 & 70 & 2.9 & 50.1 & 78.8 & 6.6 & Q4 & 93.3 & 146.6 & 66.4 & 104.3 & 73.7 & 115.8 \\
\hline 5 & 4.5 & 60 & 90 & 2.8 & 61.3 & 96.3 & 7.6 & $\mathrm{Q} 4$ & 101.2 & 159.0 & 76.4 & 120.1 & 84.8 & 133.3 \\
\hline 6 & 5.5 & 60 & 110 & 2.7 & 71.9 & 113.0 & 8.6 & Q5 & 123.3 & 193.7 & 85.5 & 134.3 & 94.9 & 149.1 \\
\hline 7 & 6.5 & 75 & 130 & 4.3 & 136.5 & 214.5 & 13.2 & Q5 & 153.0 & 240.3 & 132.4 & 208.0 & 123.0 & 193.1 \\
\hline 8 & 7.5 & 75 & 150 & 4.1 & 151.3 & 237.7 & 14.2 & Q5 & 158.0 & 248.2 & 142.0 & 223.0 & 126.8 & 199.2 \\
\hline 9 & 8.5 & 75 & 170 & 4.0 & 165.6 & 260.2 & 15.1 & Q5 & 162.3 & 254.9 & 150.9 & 237.1 & 130.4 & 204.8 \\
\hline 10 & 9.5 & 75 & 190 & 3.9 & 179.4 & 281.9 & 15.9 & Q5 & 166.1 & 260.9 & 159.4 & 250.3 & 133.7 & 210.1 \\
\hline & & $Q_{\mathrm{sL}}(\mathrm{kN}$ & & & & 1372.3 & & & & 1747.1 & & 1425.8 & & 1370.5 \\
\hline
\end{tabular}




\section{CHAPTER 6. SUMMARY AND CONCLUSIONS}

\subsection{Summary}

Drilled displacement (DD) piles are being increasingly used as foundation elements for structures, particularly in projects requiring accelerated construction or involving the rehabilitation of foundations of existing, overstressed structures. Different types of DD piles are available in practice; each type is classified according to the design of the drilling tool and associated installation method. This report consolidates the information available on DD piling technology, reviews and compares the empirical design methods typically used for these piles, and presents a numerical approach to model shaft resistance of DD piles in sand.

Installation of DD piles produces greater radial displacement of soil than that produced by nondisplacement piles (e.g., drilled shafts), particularly in the case of sandy soils which gain additional strength through densification. The radial displacement of soil around the pile shaft contributes to the high capacity obtained for DD piles. Accordingly, our focus has been on analyzing the shaft resistance of DD piles in sand and proposing a design procedure based on the results of the analyses. The analyses were done using the finite element (FE) method and an advanced constitutive model for sand. The constitutive model captures all the key features required for these analyses, and the FE analyses are 1D analyses of shaft resistance that can handle the large deformations and displacements involved in pile installation.

The substantial changes in the state of the soil surrounding the DD pile result from the complex loading imposed (during installation of these piles) on the soil by expansion of a cylindrical cavity to make room for the specially designed drilling tool, by torsional and vertical shearing as the drilling tool gradually moves down into the ground, and by the reversed vertical shearing caused by extraction of the drilling tool from the ground. During the cavity expansion phase (associated with pile installation) the soil surrounding the pile is pushed away radially from the path of the pile. This radial 
displacement of soil increases the normal (radial) stress in the surrounding medium. The drilling (torsional and vertical shearing) phase associated with pile installation causes a reduction of normal (radial) stress acting adjacent to the pile shaft. Just after the extraction of the drilling tool, the torsional shear stress acting adjacent to the pile shaft becomes zero and the vertical shear stress reaches a negative limiting value. The normal (radial) stress acting on the pile shaft further decreases during the loading of the pile; the vertical shear stress acting along the pile shaft reaches a limiting value (equal to the limit shaft resistance) at the end of loading. Design equations are proposed that can be used to calculate the lateral earth pressure coefficient acting on the pile at limit condition.

Development of a database containing in situ test results (performed before and after pile installation) and pile load test results can help improve the prediction capability and consistency of the proposed design method for DD piles. These load tests should be extended to large pile settlements (certainly in excess of $10 \%$ of the pile diameter), the piles should preferably be instrumented (so that, at a minimum, base and shaft resistances may be separated) and the test sites must be well characterized. Results from pile installation modeling, as described in this report, in conjunction with well designed field load tests and systematic monitoring of pile installation will lead to meaningful advances in the design and practice of DD piles.

\subsection{Conclusions}

Based on findings of the present study, we can draw the following conclusions:

1. The changes in the soil caused by the installation and loading of DD pile are very complex and cannot be modeled with any reliability in a simplistic way.

2. The DD pile installation process is not simply a cavity expansion process, as many have believed. Torsional and vertical shearing has a large impact in that they reduce approximately $50 \%$ of the normal stress on the pile shaft from the very large stresses that would be predicted by cavity expansion alone. 
3. At the end of installation and loading of a DD pile, the soil adjacent to the pile shaft reaches a critical state that is similar to the one corresponding to a simple shear loading condition.

4. Soil within a small zone (of radius equal to $1.3 B$ and $3.6 B$ from the pile axis, respectively, for anisotropic and isotropic analysis with $\sigma_{\mathrm{v} 0}^{\prime}=100 \mathrm{kPa}$ and $D_{\mathrm{R}}=90 \%$ ) surrounding the pile shaft dilates due to DD pile installation. A contractive zone is observed beyond this dilative zone. No volumetric change is observed in the zone beyond a radius of approximately equal to $12 B$ from the pile axis.

5. The installation parameter $\eta$ does not have a significant effect on the stress state (e.g., the mean effective stress $p^{\prime}$ and void ratio $e$ ) of the soil surrounding the pile. However, as $\eta$ increases from 0 to $45^{\circ}$, the limit shaft resistance decreases by as much as $35 \%$ to reach an asymptotic value at $\eta \geq 45^{\circ}$.

6. The lateral earth pressure coefficient $K$ acting on the pile shaft at the limit condition increases with increasing relative density and decreasing initial confinement. The value of $K / K_{0}$ for an initially anisotropic sand fabric is always smaller than that for an initially isotropic sand fabric.

7. The pile diameter $B$ and the in situ lateral earth pressure coefficient $K_{0}$ do not affect significantly the value of $K / K_{0}$ at the limit condition. For a very dense, overconsolidated sand $\left(D_{\mathrm{R}}=90 \%, K_{0}=0.6\right)$ under moderate vertical confinement $\left(\sigma_{\mathrm{v} 0}^{\prime}=100 \mathrm{kPa}\right)$, the $K / K_{0}$ ratio varies only up to $7.5 \%$ when compared to that obtained for a normally consolidated sand $\left(K_{0}=0.45\right)$ under similar conditions.

8. The ratio $K / K_{0}$ available for a DD pile, for different values of in situ (before pile installation) vertical effective stress, varies between 2.2 and 2.7 times (for $\sigma_{\mathrm{v} 0}=400 \mathrm{kPa}$ and $50 \mathrm{kPa}$, respectively) the $K / K_{0}$ for a drilled shaft installed in dense sand $\left(D_{\mathrm{R}}=75 \%\right)$. 
However, irrespective of the values of $\sigma_{\mathrm{v} 0}, K / K_{0}$ for a DD pile and that for a drilled shaft installed in medium-dense sand $\left(D_{\mathrm{R}}=45 \%\right)$ are almost the same.

9. $K / K_{0}$ for a monotonically jacked pile is 2.1 to 2.5 times (for $\sigma_{\mathrm{v} 0}^{\prime}=400$ and $50 \mathrm{kPa}$, respectively) the $K / K_{0}$ for a DD pile installed in medium-dense sand $\left(D_{\mathrm{R}}=45 \%\right)$. For dense sand $\left(D_{\mathrm{R}}=75 \%\right)$, the $K / K_{0}$ for monotonically jacked pile is 1.6 to 1.8 times (for $\sigma_{\mathrm{v} 0}=400$ and $50 \mathrm{kPa}$, respectively) that for a DD pile. 


\section{LIST OF REFERENCES}

Abbo, A. J. and Sloan, S. W. (2000). Solid nonlinear analysis code (SNAC), User manual version 2.0, Department of Civil, Surveying and Environmental Engineering, University of Newcastle, Australia.

American Pile Driving, Inc. <americanpiledriving.com > as seen on March 2, 2007.

Aoki, N., and Velloso, D. A. (1975). An Approximate Method to Estimate the Bearing Capacity of Piles. Proceedings of the 5th Pan-American Conference of Soil Mechanics and Foundation Engineering, Buenos Aires, Vol. 1, pp. 367-376.

Application de l'Eurocode 7 en Belgique (2008). Directives pour le dimensionnement en ELU de pieux sous charge axiale en compression, Version de mars 2008.

Bardet, J. P. (1986). Bounding surface plasticity model for sands. Journal of Engineering Mechanics, Vol. 112, No. 11, pp. 1198-1217.

Basu, P., Loukidis, D., Prezzi, M., and Salgado, R. (2009a). Analysis of shaft resistance of jacked piles in sands. Accepted for publication in the International Journal for Analytical and Numerical Methods in Geomechanics.

Basu, P., Salgado, R., Prezzi, M., and Chakraborty, T. (2009b). A method for accounting for pile setup and relaxation in pile design and quality assurance. JTRP draft report submitted to INDOT for project no. SPR2930.

Bauduin, C. (2001). Design procedure according to Eurocode 7 and analysis of the test results. Screw Piles - Installation and Design in Stiff Clay, Holeyman (ed.), Swets and Zeitlinger, Lisse, pp. 275 - 303.

Bottiau, M. (2006). Recent evolutions in deep foundation technologies. Proceedings of the DFI/EFFC 10th International Conference on Piling and Deep Foundations, Amsterdam, The Netherlands.

Brettmann, T. and NeSmith, W. (2005). Advances in auger pressure grouted piles: design, construction and testing. Advances in Designing and Testing Deep Foundations. Geotechnical Special Publication No. 129, ASCE, pp. 262-274.

Brettmann, T., (2003). Constructibility of augured cast-in-place piles. Geo-Strata, $8-11$. 
Brown, D. A. (2005). Practical considerations in the selection and use of continuous flight auger and drilled displacement piles. Advances in auger pressure grouted piles: design, construction and testing. Advances in Designing and Testing Deep Foundations. Geotechnical Special Publication No. 129, ASCE, pp. 251-261.

Brown, D. and Drew, C. (2000). Axial capacity of augured displacement piles at Auburn University, New Technological and Design Developments in Deep Foundations, Proceedings of sessions of Geo- Denver 2000, Geotechnical Special Publication No. 100, ASCE, pp. 397-403.

Bustamante, M. and Gianeselli, L., (1993). Design of auger displacement piles from insitu tests. Deep Foundations on Bored and Auger Piles, BAP II, Balkema, Rotterdam, pp. 21-34.

Bustamante, M. and Gianeselli, L., (1998). Installation parameters and capacity of screwed piles. Deep Foundations on Bored and Auger Piles, BAP III, Balkema, Rotterdam, pp. 95-108.

Chakraborty, T. (2009). Development of a clay constitutive model and its application to pile boundary value problems. Ph. D. Thesis. Purdue University, U.S.A.

Chin, F. V. (1970). Estimation of ultimate load of piles not carried to failure. Proc. $2^{\text {nd }}$ Southeast Asian Conference on Soil Engineering, 81-90.

Collins, I.F., Pender, M.J. and Yan, W. (1992). Cavity expansion in sands under drained loading conditions. International Journal of Numerical and Analytical Methods in Geomechanics, Vol. 16, No. 1, pp. 3-23.

Colombi, A. (2005). Physical modeling of an isolated pile in coarse grained soil. Ph.D. Thesis. University of Ferrara.

Dafalias, Y. F. and Hermann, L. R. (1982). Bounding surface formulation of soil plasticity. Soil Mechanics - Transient and Cyclic Loads, (eds. Pande and Zienkiewicz), Whiley, New York, pp. 253-282.

Dafalias, Y. F., Papadimitriou, A. G. and Li, X. S. (2004). "Sand Plasticity Model Accounting for Inherent Fabric Anisotropy." Journal of Engineering Mechanics, ASCE, Vol. 130, No. 11, pp.1319-1333.

Dafalias, Y., F., and Hermann, L. R. (1986). Bounding surface plasticity II: Application to isotropic cohesive soils. Journal of Engineering Mechanics, Vol. 112, No. 12, pp. 1263-1291.

De Beer, E. (1971, 1972). Méthodes de déduction de la capacité portante d'un pieu à partir des résultats des essais de pénétration. Bruxelles, Journal des Travaux publics de Belgique, Vol. 72, No. 4 (pp. 191-268), No. 5 (pp. 321-353), and No. 6 (pp. 351-405). 
De Cock, F. and Imbo, R., (1994). Atlas screw pile: a vibration-free, full displacement, cast-in-place pile. Transportation Research Record 1447, pp 49-62.

De Vos, M., Bauduin, C. and Maertens, J. (2003). The current draft of the application rules of Eurocode 7 in Belgium for the design of pile foundations. Belgian Screw Pile Technology - Design and Developments, Maertens and HuyBrechts (eds.), Swets and Zeitlinger, Lisse, pp. $303-325$.

FHWA Technical Report No. 41-30-2175. (1993). Axial load-displacement behavior of drilled shaft foundations in piedmont residuum.

Fioravante, V. (2002). On the shaft friction modeling of non-displacement piles in sand. Soils and Foundations, Vol. 42, No. 2, pp. 23-33.

Fleming, W. G. K. and Thorburn, S., (1983). Recent piling advances, state of the art report. Proceedings of the International Conference on Advances in Piling and Ground Treatment for Foundations, ICE, London, pp 1-16.

Franke, E. (1989). Co-report to discussion, session 13: large-diameter piles. $12^{\text {th }}$ International Conference on Soil Mechanics and Foundation Engineering, Rio de Janeiro.

Gens, A. and Potts, D. M. (1984). Formulation of quasi-axisymmetric boundary value problems for finite element analysis. Engineering Computations - International journal for computer-aided engineering and software, Vol. 1, pp. 144-150.

Geoforum (2008). <http://www.geoforum.com/info/pileinfo/class_list.asp?Method=4> as seen on November 25, 2008.

Holeyman, A. E. (2001). Screw piles - installation and design in stiff clay. Proceedings of the Symposium on Screw Piles, Brussels, Belgium. Swets and Zeitlinger B. V., Lisse, The Netherlands.

Holeyman, A., Bauduin, C., Bottiau, M., Debacker, P., De Cock, F. A., Dupont, E., Hilde, J. L., Legrand, C., Huybrechts, N., Mengé, P., Miller, J. P., and Simon., G. (2001). Design of axially loaded piles - 1997 Belgian practice. Screw Piles Installation and Design in Stiff Clay, Holeyman (ed.), Swets and Zeitlinger, Lisse, pp. $63-88$.

Hu, Y. and Randolph, M.F. (1998) A practical numerical approach for large deformation problems in soil. International Journal of Numerical and Analytical Methods in Geomechanics, Vol. 22, No. 5, pp. 327-350.

HuyBrechts, N. and Whenham, V. (2003). Pile testing campaign on the Limelette test site and installation techniques of screw piles. Belgian Screw Pile Technology - Design and Developments, Maertens and HuyBrechts (eds.), Swets and Zeitlinger, Lisse, pp. 71 130. 
Jardine, R., Chow, F. C. (1998). Research into the Behaviour of Displacement Piles for Offshore Foundations. Health and Safety Executive, OTO 98833.

Lehane, B. M., Jardine, R. J., Bond, A. J., Frank, R. (1993). Mechanisms of Shaft Friction in Sand from Instrumented Pile Tests. Journal of Geotechnical Engineering, ASCE, Vol. 119, No. 1, pp. 19-35.

Li, X. S. and Dafalias, Y. F. (2000). Dilatancy of cohesionless soils. Géotechnique, Vol. 50, No. 4, pp. 449-460.

Lings, M. L., and Dietz, M. S. (2005). The peak strength of sand-steel interfaces and the role of dilations. Soils and Foundations, Vol. 45, No. 6, pp. 1-14.

Lopes, F. R., and Laprovitera, H. (1988). On the Prediction of the Bearing Capacity of Bored Piles from Dynamic Penetration Tests. Deep Foundations on Bored and Auger Piles, W. Van Impe (ed.), Balkema, Rotterdam, pp. 537-540.

Loukidis D. and Salgado R. (2008). Analysis of the shaft resistance of non-displacement piles in sand. Géotechnique, Vol. 58, No. 4, 283-296.

Loukidis, D. (2006). Advanced constitutive modeling of sands and applications to foundation engineering. Ph. D. Thesis, Purdue University, U.S.A.

Loukidis, D. and Salgado, R. (2009). Modeling sand response using two-surface plasticity. Computers and Geotechnics, Vol. 36, No. 1-2, pp. 166-186.

Maertens, J. and Huybrechts, N., (2003a). Results of the static pile load tests at the Limelette test site. Belgian Screw Pile Technology - Design and Developments, Maertens and HuyBrechts (eds.), Swets and Zeitlinger, Lisse, pp. 167 - 214.

Maertens, J., and Huybrechts, N. (2003b). Belgian screw pile technology design and recent developments. Proceedings of the $2^{\text {nd }}$ Symposium on Screw Piles, Brussels, Belgium. Swets and Zeitlinger B. V., Lisse, The Netherlands.

Mandolini, A., Ramodini, M., Russo, G. and Viggiani, C. (2002). Full scale loading tests on instrumented CFA piles. Proceedings of the International Deep Foundations Congress 2002, Geotechnical Special Publication No. 116, Vol. 2, ASCE, pp. 10881097.

Manzari, M. T. and Dafalias, Y. F. (1997). A critical state two-surface plasticity model for sands. Géotechnique, Vol. 47, No. 2, pp. 255-272.

NeSmith, W. M., (2002). Static capacity analysis of augured, pressure-injected displacement piles. Proceedings of the International Deep Foundations Congress 2002, Geotechnical Special Publication No. 116, Vol. 2, ASCE, pp. 1174-1186. 
Oda, M. (1972). Initial fabrics and their relations to mechanical properties of granular material. Soils and Foundations, Vol. 12, No. 1, pp. 17-36.

Papadimitriou, A. G. and Bouckovalas, G. D. (2002). Plasticity model for sand under small and large cyclic strains: a multiaxial formulation. Soil Dynamics and Earthquake Engineering, Vol. 22, No. 3, pp.191-204.

Papadimitriou, A. G., Bouckovalas, G. D. and Dafalias, Y. F. (2001). Plasticity model for sand under small and large cyclic strains. Journal of Geotechnical and Geonvironmental Engineering, ASCE, Vol. 127, No. 11, pp. 973-983.

Porcino, D., Fioravante, V., Ghionna, V. N., and Pedroni, S. (2003). Interface Behavior of Sands from Constant Stiffness Direct Shear Tests. Geotechnical Testing Journal, Vol. 26, No. 3, pp. 1-13.

Potts, D. M. and Martins, J. P. (1982). The shaft resistance of axially loaded piles in clay. Géotechnique, Vol. 32, No. 4, pp. 369-386.

Prezzi, M. and Basu, P. (2005). Overview of construction and design of auger cast-inplace and drilled displacement piles. Proceedings of DFI's $30^{\text {th }}$ annual conference on deep foundations, Chicago, U.S.A., pp. $497-512$.

Randolph, M.F. and Wroth, C.P. (1978). Analysis of deformation of vertically loaded piles. Journal of Geotechnical Engineering, ASCE, Vol. 104, GT12, pp. 1-17.

Salgado, R. (2008). Engineering of Foundations. Mc Graw-Hill, New York, U.S.A.

Salgado, R. and Prezzi, M. (2007). Computation of cavity expansion pressure and penetration resistance in sands. International Journal of Geomechanics, ASCE, Vol. 7, No. 4, pp. 251-265.

Salgado, R. and Randolph, M.F. (2001) Analysis of cavity expansion in sand. International Journal of Geomechanics. Vol. 1, No. 2, pp. 175-192.

Schmertmann, J. H. (1978). Guidelines for Cone Penetration Test, Performance and Design. U.S. Department of Transportation, FHWA-TS-78-209.

Subba Rao, K. S., Allam, M. M., and Robinson, R. G. (1998). Interfacial Friction between Sands and Solid Surfaces. Proc. ICE, Geotechnical Engineering, Vol. 131, pp. 75-82.

Tatsuoka, F., Nakamura, S., Huang, C. C., and Tani, K. (1990). Strength anisotropy and shear band direction in plain strain tests of sand. Soils and Foundations, Vol. 30, No. 1, pp. 35-54. 
Tatsuoka, F., Sakamoto, M., Kawamura, T., and Fukushima, S. (1986). Strength and deformation characteristics of sand in plane strain compression at extremely low pressures. Soils and Foundations, Vol. 26, No. 1, pp. 65-84.

Uesugi, M., and Kishida, H. (1986). Influential factors of friction between steel and dry sands. Soils and Foundations, Vol. 26, No. 2, pp. 33-46.

Uesugi, M., Kishida, H., and Uchikawa, Y. (1990). Friction between Dry Sand and Concrete under Monotonic and Repeated Loading. Soils and Foundations, Vol. 30, No. 1, pp. 115-128.

Van Alboom, G. and Whenham, V. (2003). Soil investigation campaign at Limelette (Belgium): results, Belgian Screw Pile Technology - Design and Recent Developments, Maertens and HuyBrechts (eds.), Swets and Zeitlinger, Lisse, pp. 21 70.

Van Impe, W. F. (1986). Evaluation of deformation and bearing capacity parameters of foundations, from static CPT-results. Proceedings of the Fourth International Geotechnical Seminar: Field Instrumentation and In Situ Measurements, NTI, Singapore, pp 51-70.

Van Impe, W. F. (1988). Considerations in the auger pile design. Proceedings of the $1^{\text {st }}$ International Geotechnical Seminar on Deep Foundations on Bored and Auger Piles, BAP I, Balkema, Rotterdam, pp. 193-217.

Van Impe, W. F. (2004). Two decades of full scale research on screw piles : An overview. Published by The Laboratory of Soil Mechanics, Ghent University, Belgium.

Van Impe, W. F., De Beer, E., and Lousberg, E. (1988). Prediction of the single pile bearing capacity in granular soils out of CPT results. Proceedings of the International Symposium on Penetration Testing (ISOPT I), Speciality Session, Orlando, pp 1-34.

Wang, Z.-L., Dafalias, Y. F., and Shen, C.-K. (1990). Bounding surface hypoplasticity model for sand. Journal of Engineering Mechanics, Vol. 116, No. 5, pp. 983-1001.

Yoshimine, M., Isihara, K., and Vargas, W. (1998). Effects of principal stress direction and intermediate principal stress on undrained shear behavior of sand. Soils and Foundations, Vol. 38, No. 3, pp. 179-188.

Yu, H.S. and Houlsby, G.T. (1991) Finite cavity expansion in dilatants soils: loading analysis. Géotechnique, Vol. 41, No. 2, pp. 173-183. 